El método SROI

en la evaluación económica de intervenciones sanitarias 



\section{El método SROI \\ en la evaluación \\ económica de \\ intervenciones \\ sanitarias}

Editores:

María Merino

Álvaro Hidalgo

Con el patrocinio de:

(1) NOVARTIS
Realizado por:

Weber 


\section{Edita:}

(c) Fundación Weber

C/ Moreto, 17 - $5^{\circ}$ Dcha.

28014 Madrid

Coordinación editorial: iris.sanpedro@weber.org.es

ISBN: 978-84-949427-5-4

D.L.: M-18206-2019

Impreso en Madrid, mayo 2019

Ejemplar gratuito. Prohibida su venta. 


\section{CAPÍTULOS}

Capítulo María Merino / Yoana Ivanova / Álvaro Hidalgo

1 INTRODUCCIÓN

Capítulo Yolanda Rueda

2 SROI, ¿QUÉ ES, PARA QUÉ SIRVE?

Capítulo Marta Trapero-Bertran

3 DEFINIENDO LOS LÍMITES E IDENTIFICANDO LOS STAKEHOLDERS PARA REALIZAR UN BUEN SROI

Capítulo José María Abellán

4 ASPECTOS METODOLÓGICOS DE UN ANÁLISIS SROI

Capítulo Jaime Espín

5 LAS PREFERENCIAS DEL PACIENTE: VALOR AÑADIDO DEL SROI

Capítulo Beatriz González López-Valcarcel

6 APLICACIONES PRÁCTICAS DEL MÉTODO SROI

Capítulo Cristina Ibarrola

7 SROI EN LA TOMA DE DECISIONES: LA VISIÓN DEL GESTOR

Capítulo Santiago Alfonso / Maite San Saturnino

8 SROI: LA UTILIDAD PARA LOS PACIENTES

Capítulo María Merino / Yoana Ivanova / Álvaro Hidalgo

9 CONCLUSIONES FINALES 



\section{ÍNDICE}

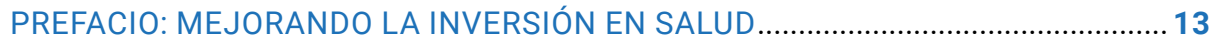

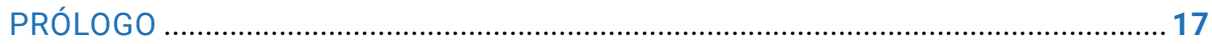

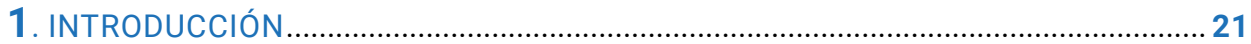

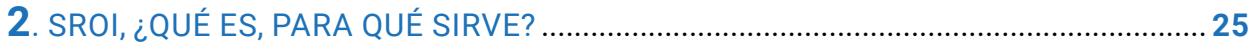

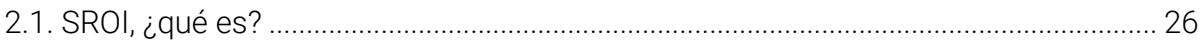

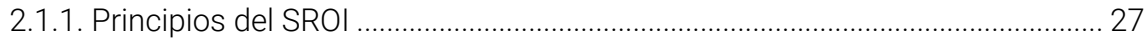

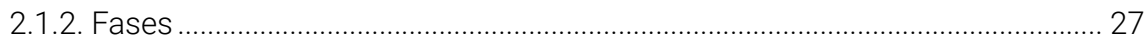

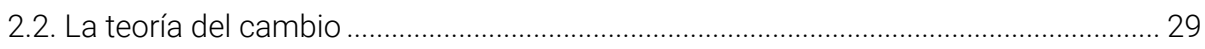

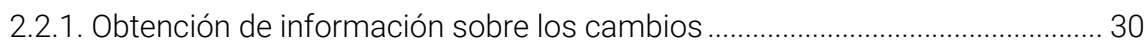

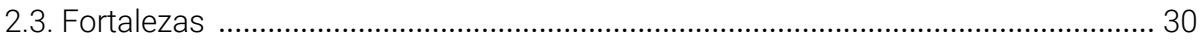

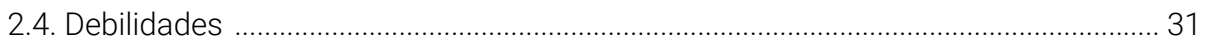

2.5. Perspectivas de futuro en el sistema sanitario ................................................................. 32

3. DEFINIENDO LOS LÍMITES E IDENTIFICANDO LOS STAKEHOLDERS

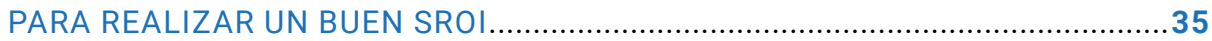

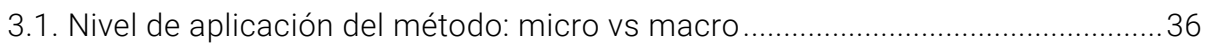

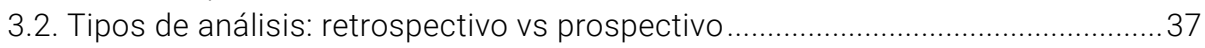

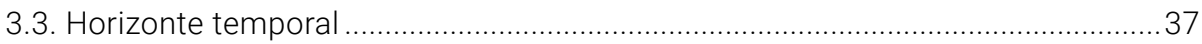

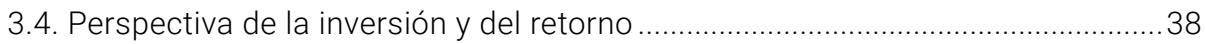

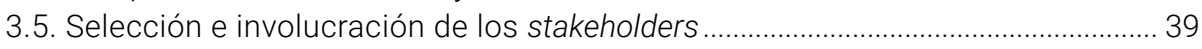

4. ASPECTOS METODOLÓGICOS DE UN ANÁLISIS SROI .................................................. 45

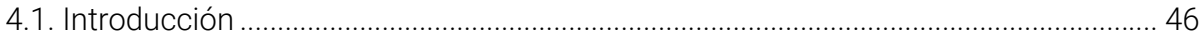

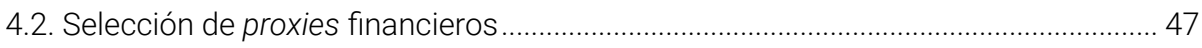

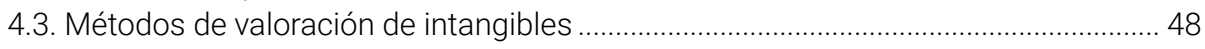

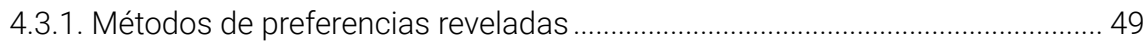

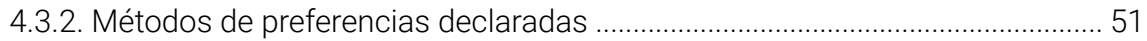

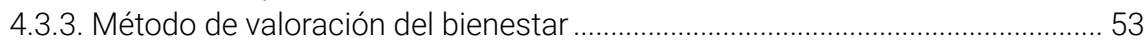

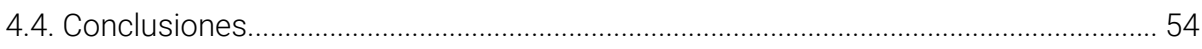

5. LAS PREFERENCIAS DEL PACIENTE: VALOR AÑADIDO DEL SROI...........................59

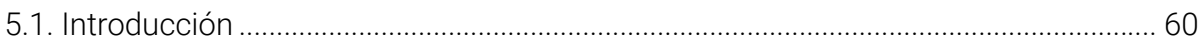

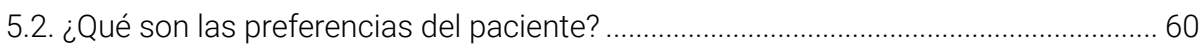

5.3. ¿De qué métodos disponemos para conocer las preferencias
del paciente?

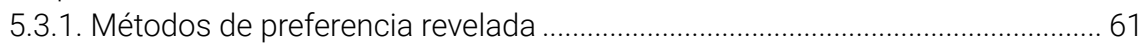

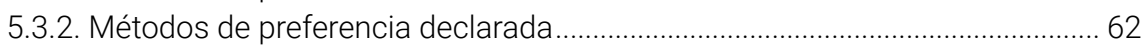

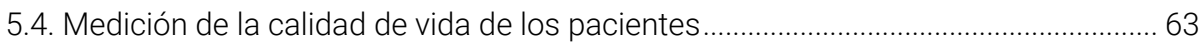

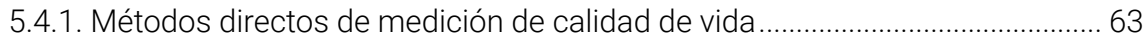

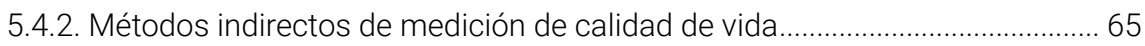




\section{ÍNDICE}

5.5. Cómo se incorporan en el SROI: empoderamiento del paciente 66

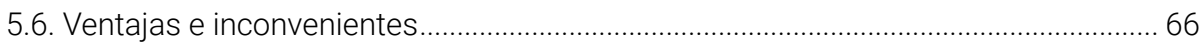

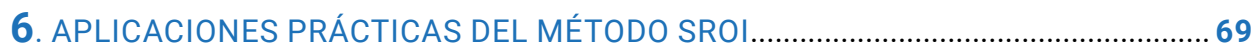

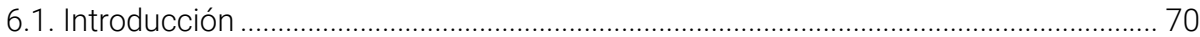

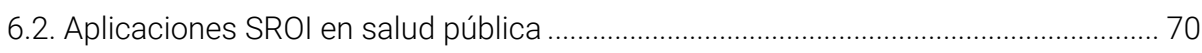

6.2.1. Aplicaciones extramurales 2015-2018 ...................................................... 73

6.2.2. Aplicaciones intramurales en sanidad: medicina clínica y organización ........ 76

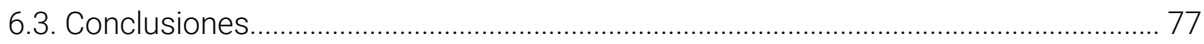

7. SROI EN LA TOMA DE DECISIONES: LA VISIÓN DEL GESTOR ..................................83

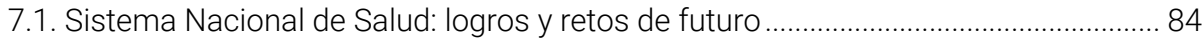

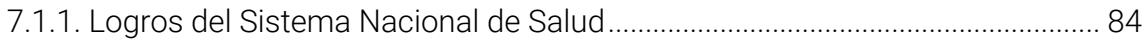

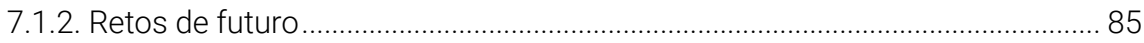

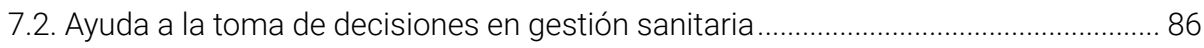

7.3. Método SROI en el abordaje ideal de la insuficiencia cardiaca ................................ 88

7.4. Fortalezas y debilidades de SROI como herramienta en la toma de decisiones

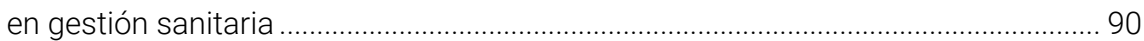

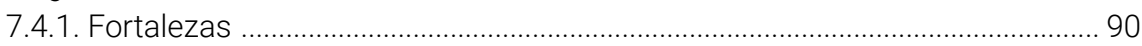

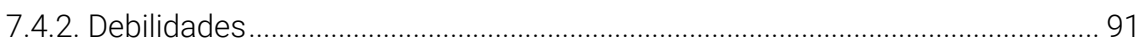

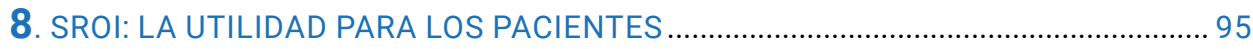

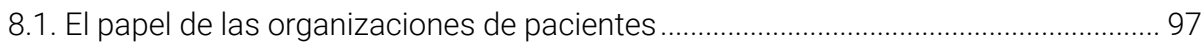

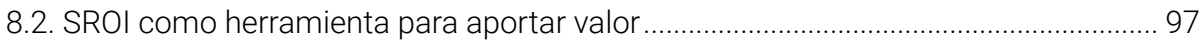

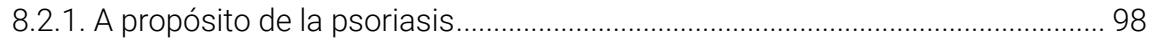

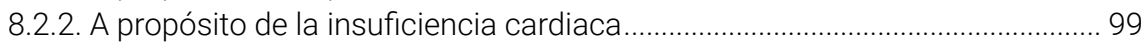

8.3. La perspectiva de los pacientes ante el método SROI .............................................. 99

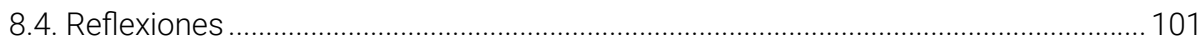

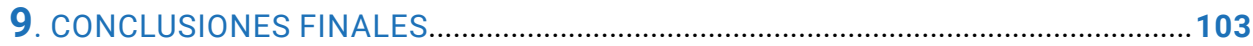

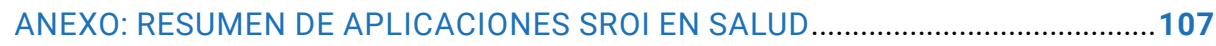

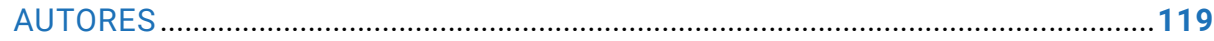




\section{ÍNDICE DE TABLAS}

TABLA 3.1. MÉTODOS PARA INVOLUCRAR A LOS STAKEHOLDERS

TABLA 3.2. COMPONENTES PRAGMÁTICOS DE INVOLUCRACIÓN DE LOS STAKEHOLDERS

TABLA 4.1. MÉTODOS DE VALORACIÓN DE INTANGIBLES Y PROXIES FINANCIEROS QUE ESTIMAN

TABLA 4.2. VALOR DE LOS CUIDADOS INFORMALES SEGÚN LOS MÉTODOS DEL COSTE DE OPORTUNIDAD Y DEL COSTE DE REEMPLAZO (EN €) $\mathbf{5 0}$

TABLA 4.3. ESTIMACIONES DE LA PRIMA SALARIAL Y DEL VALOR DE UNA VIDA ESTADÍSTICA

TABLA 4.4. RELACIÓN ENTRE VARIACIÓN COMPENSADA, VARIACIÓN EQUIVALENTE, DISPOSICIÓN A PAGAR Y DISPOSICIÓN A ACEPTAR 51

TABLA 4.5. DAP Y DAA POR PRESTAR O RECIBIR UNA HORA ADICIONAL DE CUIDADOS INFORMALES (EN €) Y P-VALUES DE LA DIFERENCIA DAP-DAA 52

TABLA 4.6. COMPENSACIÓN MONETARIA DE LOS CUIDADORES INFORMALES 53

TABLA 4.7. COMPENSACIÓN NECESARIA PARA ALCANZAR LA SATISFACCIÓN DE UNA PERSONA QUE NO TIENE EL PROBLEMA DE SALUD (EN €) 54

TABLA 5.1. ATRIBUTOS Y NIVELES POSIBLES EN UN DISCRETE CHOICE EXPERIMENT

\section{ÍNDICE DE FIGURAS}

FIGURA 2.1. FASES DEL SROI

FIGURA 2.2. CADENA DE CREACIÓN DE IMPACTOS

FIGURA 5.1. TAXONOMÍA DE LA CALIDAD DE VIDA RELACIONADA CON LA SALUD 61

FIGURA 5.2. ESCALA VISUAL ANALÓGICA

FIGURA 5.3. EJEMPLO DE LOTERÍA ESTÁNDAR (3 SECUENCIAS)

FIGURA 5.4. ESQUEMA DE LA COMPENSACIÓN TEMPORAL 64

FIGURA 5.5. CUESTIONARIO DE CALIDAD DE VIDA EUROQOL-5D 65

FIGURA 7.1. GASTO SANITARIO PÚBLICO EN ESPAÑA (EN €). PERIODO 2002-2017 


\section{ABREVIATURAS}

DAA Disposición A Aceptar

DAP Disposición A Pagar

DCE Discrete Choice Experiment

IC Insuficiencia Cardiaca

OCDE Organización para la Cooperación y el Desarrollo Económicos

OMS Organización Mundial de la Salud

ROI Return on Investment

SNS Sistema Nacional de Salud

SROI Social Return on Investment

VVE Valor de una Vida Estadística 


\section{PREFACIO}

MEJORANDO LA INVERSIÓN EN SALUD

Carles Blanch 
E n pleno siglo XXI, es indiscutible que los sistemas sanitarios -especialmente los que tienen un fuerte componente público, como el Sistema Nacional de Salud español- deben ser fruto de la colaboración de todos los actores implicados en la salud. De esta manera, los profesionales, la industria, la investigación, los gestores, los planificadores, los reguladores, tienen un rol importante y deben funcionar como un engranaje que les permita poner el foco en el paciente, conseguir que el sistema funcione de la mejor manera posible y que, además, sea sostenible y perdurable en el tiempo.

Se está observando un interés creciente en la medición de los resultados en salud como objetivo último de este engranaje, dado que estos resultados representan la mejora del proceso de enfermedad de los pacientes y también de los propios servicios sanitarios. Los medicamentos han sido uno de los elementos de los servicios sanitarios que más ha sistematizado la medición de resultados, empezando ya en las fases de investigación y llegando a la medida de resultados en la utilización clínica de los fármacos.

Por otro lado, se habla mucho de los costes de la asistencia sanitaria y en especial de los costes de los fármacos y de su impacto final en los presupuestos de sanidad de todos los países. Los costes de los medicamentos han sido históricamente una fuente de análisis en todos los sistemas sanitarios, ya sea por la facilidad de conocer la dosis e intensidad de la intervención, la relación causa-efecto demostrada en los ensayos clínicos, el coste económico, etc.

De hecho, hay una multitud de metodologías para medir los costes de los tratamientos y sus resultados, como los estudios de coste-efectividad, los estudios de coste-beneficio o los estudios de minimización de costes, entre otros. La filosofía subyacente en estas metodologías utilizadas tradicionalmente es entender que el medicamento es una inversión en salud, más allá que sólo un coste. Ahora bien, pocas veces se ha visto la producción de fármacos como una inversión general del país o de la sociedad, sino que, generalmente, se ha considerado como un beneficio industrial para las compañías farmacéuticas.

El reciente informe sobre el valor del medicamento desde una perspectiva sociali, establece y cuantifica el valor social de la innovación farmacológica medido no sólo como eficacia o seguridad de los medicamentos sino en resultados en salud, calidad de vida en los pacientes, así como el impacto general que tiene la industria farmacéutica en la economía del país como un sector productivo relevante. El medicamento aporta un beneficio que va más allá del ámbito meramente sanitario. La eficacia de los medicamentos en el alivio de procesos de morbi-mortalidad trasciende lo puramente clínico y abarca el campo económico, pero también el social. En el plano económico los medicamentos pueden aportar un valor en ahorros potenciales en los costes totales de la enfermedad, posibilitando que se liberen recursos del sistema de salud, para destinarlos a otros usos. Así, los nuevos medicamentos pueden tener un impacto en la reducción de la frecuentación del sistema de salud (menos hospitalizaciones, menos visitas médicas, menos visitas a urgencias) y también en la reducción de las pérdidas laborales al reducirse el absentismo y el presentismo laboral.

i Weber. El valor del medicamento desde una perspectiva social. Madrid: Fundación Weber; 2018. Disponible en:

http://weber.org.es/publicacion/elvalordelmedicamentodesdeunaperspectivasocial/ 
Hay que pensar que estos ahorros no son sólo debidos a la posibilidad de disponer de mejores fármacos y más innovadores, ya que también tienen un impacto importante las mejoras en los procesos asistenciales, en las técnicas quirúrgicas, los dispositivos médicos, la prevención y mejoras en el diagnóstico y seguimiento.

El papel de la industria farmacéutica ha estado desde el principio ligado a la innovación. Sobre todo, la capacidad de transformar la investigación básica en productos útiles para los pacientes. Más y más a menudo, acciones y metodologías utilizadas por la industria se adoptan como modelos innovadores, aunque también es cierto que la propia industria, dada su capacidad adaptativa y su flexibilidad, es capaz de adoptar tecnologías y metodologías innovadoras.

La innovación farmacéutica ha logrado grandes avances en resultados de salud, con la curación de enfermedades, alargando la supervivencia y la esperanza de vida, reduciendo la progresión de la enfermedad y mejorando la calidad de vida de las personas. Ahora bien, esta innovación no sólo va ligada a procesos productivos de los fármacos sino también a la innovación en gestión, adaptación a nuevos sistemas de evaluación y recientemente a modelos de compra innovadora de productos y servicios.

En el caso que nos ocupa, la utilización del método SROI (Social Return On Investment), fundamentado en medir el impacto social, es claramente la adopción de una innovación metodológica para la medida del impacto de la actividad sanitaria, de la cual la utilización del fármaco es un aspecto más. Se trata de poner en el centro de la actividad al paciente y los resultados para valorar cómo interactúan con cada uno de los factores que intervienen en el proceso asistencial. De esta manera se puede buscar el mayor impacto y rendimiento social de los tratamientos, conjuntamente con las otras actuaciones de protección, prevención y cuidado de la salud, y pensar que los costes derivados de todas estas acciones no son unos costes prescindibles, sino que son parte de una inversión necesaria e irrenunciable en la búsqueda del mejor estado de salud posible para los ciudadanos.

En este sentido, la industria tiene que apostar claramente por este tipo de evaluaciones donde el medicamento sea un elemento más de todo el sistema asistencial y así sea considerado por todos los implicados. Esto permitirá saber cuáles son las ventajas de disponer de los mejores tratamientos, dónde se obtienen mayores beneficios y medir exactamente cuál es ese impacto en el sentido del valor social que aportan al abordaje de la patología.

Haber sido pioneros en nuestro país en la utilización del método SROI para el abordaje de la psoriasis y de la insuficiencia cardiaca, nos ha permitido obtener una visión de 360 grados acerca de ambas patologías y es un reflejo de nuestro interés en continuar desarrollando fármacos que dentro de un engranaje estructural y organizativo continúen mejorando la salud de los pacientes y facilitando la mejora de la salud de nuestra población. 


\section{PRÓLOGO}

Hugo Narrillos Roux

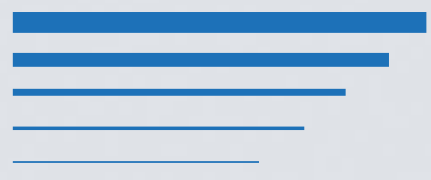


no de los grandes avances que ha experimentado la economía en los últimos 10 años ha sido la consideración de que el valor que crean los proyectos empresariales no es solamente económico-financiero, sino que dichos proyectos también crean, o destruyen, valor medioambiental y valor social. Así, se ha incorporado a nuestro léxico el término "inversiones de impacto" cuyo amplio significado incluye entre otros conceptos, el conjunto de inversiones que aúnan las características mencionadas anteriormente.

Por valor sociali se entiende la cuantificación de la importancia relativa que las personas dan a los cambios que experimentan en sus vidas. Y como no todo este valor es capturado por los precios de mercado, poder medirlo cobra su importancia.

Varias iniciativas abogan por aflorar el valor social como, por ejemplo, el hecho de que un 25\% del patrimonio de los fondos de inversión en el mundo está en activos llamados ESG (medioambientales, sociales y de gobernanza)ii; o como que el Ayuntamiento de Madrid ha convocado un generoso concurso público para invertir en este tipo de proyectosiii; o que la mayoría de las empresas de cierto tamaño intentan cumplir los llamados Objetivos de Desarrollo Sostenible de $2030^{\circ}$.

Las consecuencias para nuestra sociedad son muy importantes, porque estas consideraciones evidencian algo que, deliberadamente o no, permanecía oculto (la creación o destrucción de valor social o medioambiental). Muy atrás en el tiempo quedan, afortunadamente, argumentos totalmente obsoletos como que la responsabilidad social de las empresas es sólo retribuir al accionista, obviando la responsabilidad que tienen las mismas en la creación o destrucción de valores adicionales al económico-financiero.

Un aspecto primordial de esta forma de proceder es la obligatoriedad de rendir cuentas por parte de aquellos que crean valor. Responsabilizarse sobre lo que se hace, ayuda a visibilizarlo y a que ese algo exista. De hecho, si todos los agentes económicos introdujeran estos cambios en la forma que tenemos de contabilizar el valor, muy probablemente lograríamos un mundo más equitativo y sostenible.

Por otra parte, tener acceso a la descripción total del valor empresarial es tremendamente útil tanto para los gestores como para los llamados grupos de Interés ${ }^{\vee}$ (en inglés, stakeholders) de un proyecto empresarial, pues de esta manera pueden tomarse decisiones sobre si un proyecto crea valor en su conjunto o no, o en qué parcelas deberíamos incidir para crear más valor.

Esta obra es un excelente compendio de la aplicación en el campo de la gestión sanitaria del método de medición de impacto social llamado Retorno Social de la Inversión, o más conoci-

\footnotetext{
Definición de valor social: http://www.socialvalueuk.org/what-is-social-value/. Consultada el 27 de marzo de 2019.

ii Infografía sobre ESG. La inversión sostenible y de impacto social en el mundo: https://www.andbank.es/observatoriodelinversor/ esg-la-inversion-sostenible-impacto-mundo-infografia/. Consultada el 21 de marzo de 2019.

iii Noticia EP concurso público: https://www.europapress.es/madrid/noticia-abierto-plazo-concurso-publico-ayuntamiento-madrid-invertir-iniciativas-impacto-social-20190223171336.html. Consultada el 27 de marzo de 2019.

iv https://sustainabledevelopment.un.org/?menu=1300. Consultada el 21 de marzo de 2019.

v Se denomina grupos de interés al conjunto de partes interesadas y/o afectadas por la actividad de una organización. https:// www.eoi.es/wiki/index.php/Grupos_de_inter\%C3\%A9s_en_Responsabilidad_Social_y_Sostenibilidad_Empresarial. Consultada el 21 de Marzo de 2019
} 
do por su acrónimo anglosajón SROI (Social Return On Investment). En el libro han colaborado varios autores con amplia experiencia en la aplicación de dicha metodología en el sector de la salud. El aporte de todos ellos ha sido básico para conformar este importante estudio.

Tal y como se menciona a lo largo del libro, una de las grandes virtudes del método SROI es involucrar a todos los grupos de interés, no sólo a los financiadores del proyecto. Este aspecto le confiere un enfoque global, pues intenta analizar cómo afecta el proyecto a los distintos colectivos con los que interactúa, y lo que es aún mas importante, pone la vida de las personas en el epicentro de la gestión.

El terreno de la salud es uno de los campos en que el SROI encuentra una mayor acogida por parte de los gestores de proyectos. Además de evaluar los proyectos en términos de retorno económico-financiero, se van a tener en cuenta los beneficios que tienen no sólo en los pacientes que reciben un tratamiento, sino en otros Grupos de Interés tales como familiares, cuidadores, y diversas áreas de la Administración como los sistemas sanitarios o tributarios, y esto sitúa al sector en una corriente actual e innovadora.

SROI no es el único método que existe para medir el impacto social, pero, como se suele decir entre sus usuarios, es una forma de trabajo adicional a otras formas de hacer empleadas en el ámbito sanitario.

Este libro se presenta como un valioso aporte al terreno de la toma de decisiones en la gestión sanitaria. El uso del SROI está convirtiendo a dicho sector en un puntal de la aplicación de esta metodología que ayuda a dar una visión mucho más completa de una intervención.

Valencia, 28 de marzo de 2019

\section{Dr. Hugo Narrillos Roux}

Accredited SROI Practitioner, Social Value International

Consultor y Formador en SROI 


\section{CAPÍTULO}

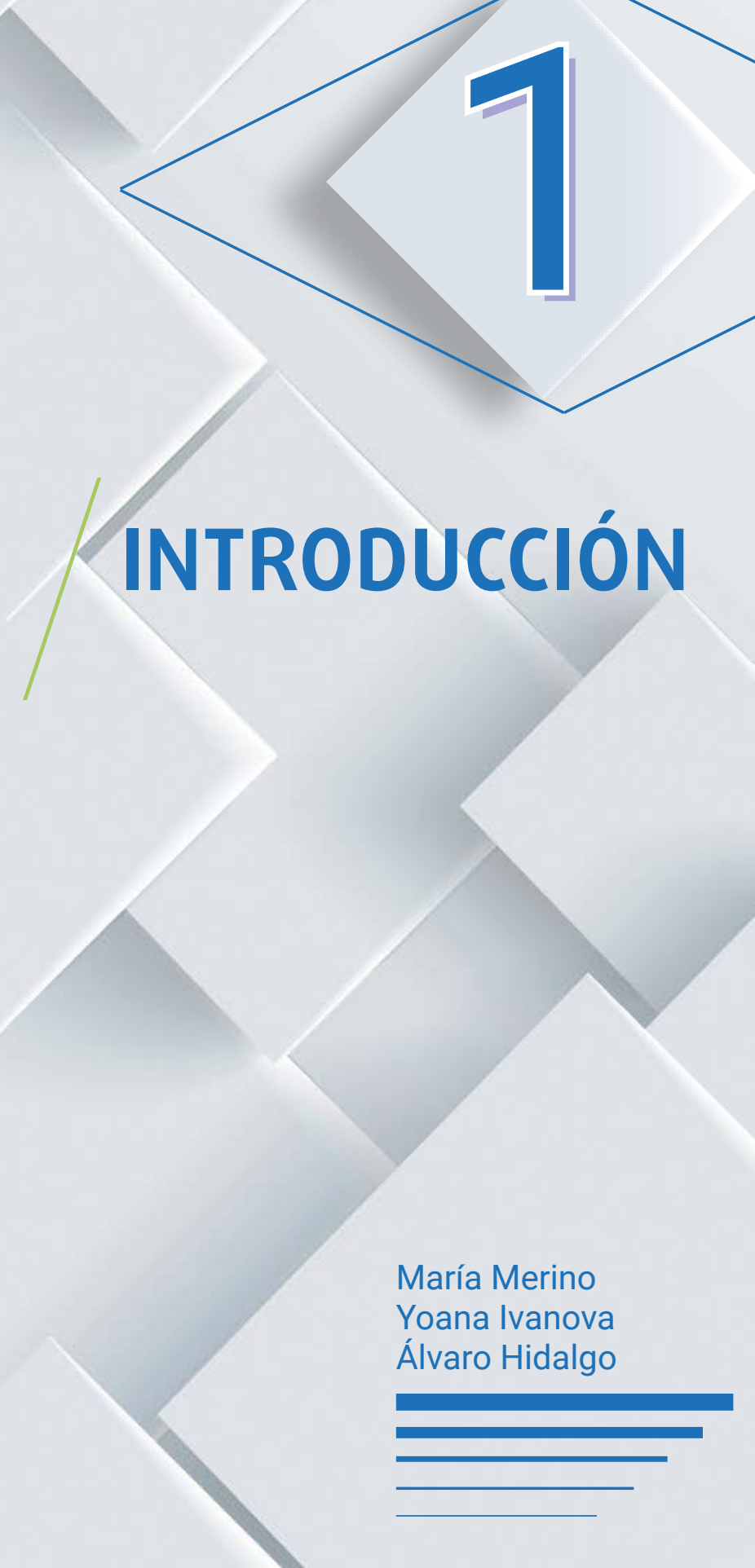


a economía de la salud sigue los principios básicos de la economía general, principalmente en relación a la cantidad de recursos disponibles, que son limitados y siempre van ligados a un coste de oportunidad por el que elegir una opción implica rechazar otra. Por ello, la gestión sanitaria se enfrenta desde siempre al reto de tomar decisiones sobre aquellas alternativas que ofrecen mejores resultados con los menores recursos posibles. EI SNS (Sistema Nacional de Salud) es responsable además no solo de ofrecer a los pacientes los recursos necesarios sino de hacerlo en condiciones de equidad.

Por otro lado, en las últimas décadas la economía de la salud lleva brindando al SNS diferentes métodos de evaluación económica de intervenciones sanitarias para que pueda llevar a cabo esta labor como, por ejemplo, los análisis coste-efectividad, coste-utilidad o coste-beneficio.

En la actualidad, el método del Retorno Social de la Inversión (denominado SROI por sus siglas en inglés, Social Return On Investment) ${ }^{[1]}$, con relativamente poco tiempo de recorrido, se presenta como una herramienta incipiente para ayudar a la toma de decisiones. Con gran similitud respecto al análisis coste-beneficio, este método muestra características adicionales que podrían ser de relevancia y utilidad en la evaluación de intervenciones sanitarias.

La primera de ellas es que contempla los beneficios sanitarios y no sanitarios derivados de una intervención, desde tres puntos de vista (económico, social y medioambiental), teniendo en cuenta tanto los cambios positivos como los negativos derivados de la intervención.

La segunda es la búsqueda de la participación activa de los grupos de interés de mayor relevancia en la intervención. Entre ellos, se encuentran los pacientes. Se les da voz en aspectos directamente relacionados con la patología. Reflexionan y evalúan la intervención en marcha, mostrando los impactos más subjetivos e intangibles, que son aquellos que viven en primera persona.

La cuantificación de estos aspectos intangibles es difícil puesto que no llevan asignado un precio de mercado, pero sí tienen un valor que no se debe obviar. De hecho, en muchas ocasiones los impactos negativos se vuelven invisibles ante la sociedad por el mero hecho de que no se puedan cuantificar monetariamente, pero es de justicia social hacer el esfuerzo de intentar valorarlos y tenerlos en cuenta en la implementación de las intervenciones sanitarias.

La tercera y última cualidad que nos parece interesante destacar es que todo el trabajo de análisis de la intervención va guiado por lo que se denomina "la teoría del cambio", a través de la cual se explica cómo una determinada acción puede generar un determinado retorno. La explicación y documentación de los cambios confieren al análisis un carácter más racional.

En un contexto de envejecimiento poblacional gracias al incremento de la esperanza de vida, que genera a la vez un mayor nivel de dependencia, nos obliga a buscar las mejores alternativas y a ser capaces de llegar a una gestión óptima, basada en la excelencia. El objetivo no es recortar la inversión sin más, sino alcanzar la sostenibilidad. De hecho, la Organización Mundial de la Salud publicó en 2017 un documento de posicionamiento con el objetivo de "resaltar la relevancia de SROI para orientar las inversiones en salud y bienestar en el contexto de la implementación de la Agenda 2030 para el desarrollo sostenible en general, y en el marco de la política europea de salud 2020 en particular"[2]. 
Por todo lo expuesto, el objetivo de este libro es dar a conocer en el ámbito sanitario un método complementario para evaluar las intervenciones sanitarias, que tiene en cuenta aspectos intangibles de las intervenciones y la involucración de los principales grupos de interés. Se pretende que los lectores entiendan cada uno de los elementos que configuran el método SROI y su aplicación práctica al ámbito sanitario.

A continuación, presentamos cómo se estructura este libro. En el capítulo 2, Yolanda Rueda realiza una introducción al método SROI, explicando de forma pormenorizada todos los elementos que lo componen y su utilidad de cara a la gestión de recursos sanitarios: los siete principios en los que se basa; las seis fases que se deben seguir, desde la definición del alcance y la involucración de los grupos de interés, hasta la comunicación de los resultados; la teoría del cambio, por la que, a partir de los recursos disponibles, se llega a alcanzar el objetivo buscado; los diferentes métodos para obtener información útil para el análisis; y finalmente, las fortalezas del método y sus debilidades.

En el capítulo 3 Marta Trapero-Bertran aporta luz a aspectos metodológicos concretos a tener en cuenta en el desarrollo de un análisis SROI: el nivel de aplicación (micro versus macro), el tipo de análisis (retrospectivo versus prospectivo), el horizonte temporal, la perspectiva de la inversión y del retorno, y la selección e involucración de los stakeholders. Explica cómo la elección entre unas y otras alternativas metodológicas influirá en el resultado final.

A continuación, el capítulo 4 hace un repaso por los métodos disponibles para la valoración de los intangibles, pieza fundamental en el análisis SROI. José María Abellán nos explica su fundamentación y mecánica, así como sus pros y sus contras.

Seguidamente, en el capítulo 5, Jaime Espín Balbino nos habla de las preferencias del paciente, aspecto frecuentemente olvidado en el uso de la evaluación económica como instrumento para la toma de decisiones, principalmente por la dificultad de su incorporación al análisis. Este capítulo resalta la importancia de tener en cuenta a todos los grupos de interés a la hora de realizar una evaluación económica.

El capítulo 6, elaborado por Beatriz González López-Valcárcel, presenta una revisión de las aplicaciones prácticas del SROI en salud pública, distinguiendo entre las experiencias extramurales y las intramurales. A su vez, diferencia el tratamiento de la salud como outcome principal o como secundario. Reflexiona además sobre los cauces por los que el método ha ido evolucionando y el reto pendiente de avanzar en su legitimación.

En el capítulo 7, Cristina Ibarrola nos muestra el punto de vista de la gestión sanitaria en relación al método SROI. Presenta una perspectiva global del sistema sanitario en su relación con la sociedad actual, cuyos elementos y características se interrelacionan entre sí.

Finalmente, el capítulo 8, llevado a cabo por Santiago Alfonso y Maite San Saturnino, representantes de las principales asociaciones de pacientes con psoriasis e insuficiencia cardiaca, respectivamente, cierran este libro dando voz a los pacientes, y poniendo de manifiesto la necesidad de aumentar la participación y la democratización de la salud.

Esperamos que este texto sirva como manual de consulta para todos aquellos interesados en la aplicación del método SROI en la evaluación económica en el ámbito sanitario. 


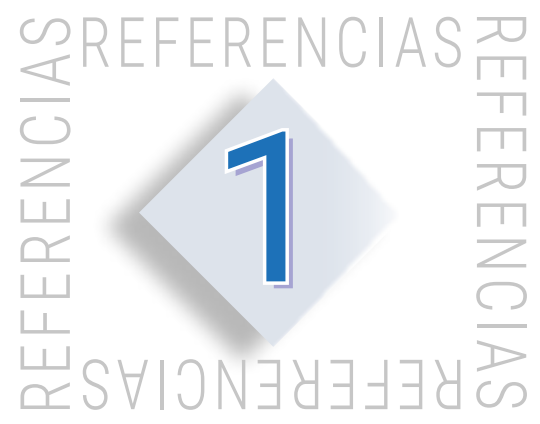

1. Nicholls J, Lawlor E, Neitzert E, Goodspeed T. A guide to Social Return on Investment. UK: The SROI Network. Accounting for Value; 2012. Disponible en: http://www.socialvalueuk.org/app/ uploads/2016/03/The\%20Guide\%20to\%20Social\%20Return\%20on\%20Investment\%202015.pdf

2. Hamelmann C, Turatto F, Then V, Dyakova M. Social return on investment: accounting for value in the context of implementing Health 2020 and the 2030 Agenda for Sustainable Development. Copenhagen: WHO Regional Office for Europe; 2017. Disponible en: http://www.euro.who.int/_data/assets/ pdf_file/0009/347976/20170828-h0930-SROI-report-final-web.pdf?ua=1 


\section{CAPÍTULO}

\section{SROI, ¿QUÉ ES, PARA QUÉ SIRVE?}

Yolanda Rueda 


\subsection{SROI, ¿QUÉ ES?}

El método SROI (del inglés, Social Return on Investment), facilita conocer, cuantificar y comunicar el retorno social de una inversión. Como toda metodología, tiene beneficios y limitaciones, pero en paralelo a que en los últimos años ha crecido el interés por la gestión y medición del impacto social, ha crecido el interés por este método que, entre otras, nos aporta información de valor, cualitativa y cuantitativa, para la toma de decisiones.

El SROI puede ser utilizado para diferentes fines, desde la planificación estratégica, en tanto que ayuda a dirigir los recursos a las actividades que generan un mayor impacto social, a la comunicación del valor social que se genera o para atraer o tomar decisiones de inversión.

Tradicionalmente el SROI se ha utilizado tanto por inversores como por el tercer sector (organizaciones no lucrativas), con objetivos distintos, mientras los primeros tratan de garantizar y maximizar su inversión, los segundos tratan de atraer inversores y comunicar el valor social de su intervención. En los últimos años ha crecido el interés y el uso de SROI por tanto del sector público como por parte de las empresas privadas.

Podemos encontrar muchas razones para evaluar el impacto social, razones que pueden dar respuesta, entre otras, a las siguientes preguntas:

- ¿Estamos alcanzando los objetivos que habíamos fijado?

- ¿Podemos ser más eficientes en la planificación, ejecución y evaluación de iniciativas?

- ¿Conocen nuestros públicos internos y externos el resultado e impacto de nuestra actividad?

- ¿Incorporamos resultados sociales y medioambientales en la rendición de cuentas?

SROI es útil tanto para predecir el impacto social que se generaría (análisis prospectivo) como para evaluar una intervención ya realizada (análisis retrospectivo), aunque es mucho más frecuente su uso para la evaluación.

El método se desarrolla a partir de un análisis tradicional de coste-beneficio y se concreta en un coeficiente (o una ratio) medido en euros que se obtiene al comparar el valor generado por una iniciativa y la inversión necesaria para realizarla. Por ejemplo, un SROI de 3,2 euros significa que por cada euro que se invierte se generan 3,2 euros de impacto social. Y hablamos de "lo social" como un concepto amplio, en el que se engloba el impacto económico, el social y el medioambiental.

Uno de los valores diferenciales de este método es que tiene en cuenta los cambios que se generan en todos los agentes de interés (stakeholders) involucrados y los hace partícipes a lo largo de todo el proceso de análisis.

La base de la metodología está en la identificación de los cambios para poder llegar a cuantificar los impactos que se pueden atribuir de manera directa a la iniciativa que se pretende evaluar. En este sentido, SROI no debe ser visto solo como una herramienta que nos aporta un dato cuantitativo (el coeficiente SROI) sino un marco en el que adentrarse a explorar y analizar los cambios que se generan, a través de la construcción de la teoría del cambio. Así, el SROI combina metodología cualitativa y cuantitativa. 


\subsubsection{Principios del SROI}

En 2009, con la publicación del manual de uso del SROI ${ }^{[1]}$, se concretaron los 7 principios del método SROI:

1. Involucrar a los stakeholders: Seguramente sea uno de los principios diferenciadores respecto a otras metodologías. Pero, ¿a qué llamamos stakeholder? A todo aquél que participa aportando recursos (contribuye a que el impacto sea posible) y/o aquél que resulta beneficiado por la iniciativa (recibe el impacto). Los stakeholders participan en la evaluación siempre que sean lo suficientemente relevantes. Por ejemplo, si un stakeholder aporta un 1\% de los recursos, cabe valorar si es imprescindible su incorporación, ya que quizá su motivación para participar sea menor y el coste de obtener información por su parte será muy elevado. Los que participen lo harán en todo el proceso de evaluación de forma activa y se incorporarán en lo que el método llama "mapa de impactos".

2. Entender lo que cambia: el valor social se crea para cada uno de los stakeholders, para los que se recogen los cambios, positivos y/o negativos, que la actividad produce para cada uno de ellos. Se detalla también cómo se producen estos cambios y la relación entre ellos.

3. Valorar lo que cambia: para cada uno de los cambios identificados se proponen indicadores llamados proxies para aproximarse al valor económico del cambio. Este punto crea controversia en la metodología, dado que se trata de una elección subjetiva por parte de los participantes, y, por tanto, su elección influye en el resultado final. Realizar un análisis de sensibilidad ayuda a disminuir este posible sesgo.

4. Incluir solo lo esencial: es importante evidenciar los cambios identificados incluyendo solo aquellos que aporten información suficiente y de valor, para que los stakeholders puedan sacar conclusiones acerca del impacto alcanzado.

5. No excederse en reivindicaciones: cabe preguntarse si todo el cambio que se genera es gracias a la organización. Se incorpora solo el cambio que las organizaciones son responsables de crear. Para ello el método introduce una serie de correctores que ayudan a discriminar el cambio del que son responsables otros o aquel que puede darse incluso sin intervención.

6. Ser transparente: toda la información, decisiones y resultados se consensúan con los stakeholders, incluso las decisiones que se tomarán una vez conocido el resultado.

7. Verificar el resultado: una revisión independiente ayuda a reducir la posible subjetividad aplicada al análisis y verificar el resultado obtenido.

\subsubsection{Fases}

El método SROI se desarrolla en seis fases consecutivas:

Fase 1 Definición del alcance de la evaluación e identificación de agentes de interés (stakeholders). El proceso se inicia concretando qué alcance se le dará a la evaluación: periodo de análisis, actividad/proyecto, etc. A continuación, se realiza la identificación de los agentes de interés que se ven implicados de alguna manera por el desarrollo del programa o proyecto. 
Fase 2 Elaboración del mapa de cambios: consiste en concretar, para cada uno de los stakeholders, la inversión (inputs), es decir los recursos que aportan, los resultados (outputs) obtenidos y los cambios (outcomes). En este punto se describen los cambios que experimentan los stakeholders, logrados por la ejecución de las actividades y acciones de los programas.

Fase 3 Cuantificación de los cambios. Una vez descritos los cambios, se aplican indicadores para medir el impacto alcanzado, estos indicadores son los denominados financial proxies, llamados así ya que nos permiten aproximarnos al valor económico del cambio. Además, se cuantifican las unidades de cambio conseguidas (cuántos agentes de interés alcanzan un cambio concreto), y su duración en el tiempo.

Fase 4 Medida del impacto social. Los impactos resultan de corregir el valor calculado, la parte de la consecución de los cambios que no se puede atribuir a la intervención. Para ello se utilizan unos correctores:

- Deadweight (Peso muerto): refleja los cambios que se hubiesen producido, aunque el programa no hubiera existido.

- Attribution (Atribución): es la proporción de los resultados que no pueden atribuirse de manera directa a las acciones del programa, ya que existen otros agentes en el contexto que participan en su consecución.

- Drop off (Deterioro): es la depreciación de los cambios en el tiempo. Sólo aplica a los cambios que duran más de un año.

- Displacement (Desplazamiento): es la proporción de los cambios que desplaza la realización de otros cambios. Por ejemplo, una intervención en un grupo de pacientes que requiera disminuir la intervención en otro grupo de pacientes y que se prevea alcanzar menos cambios en este grupo, debe ser considerado como un desplazamiento y corregirse.

Fase 5 Cálculo del SROI. En un análisis retrospectivo, es el coeficiente entre la suma del total de impactos y la suma de la inversión.

$$
\text { SROI = } \frac{\text { Suma de los impactos } €}{\text { Suma de la inversión } €}
$$

Si se trata de un análisis prospectivo, se deben actualizar los impactos con el valor actual neto. Entonces,

$$
\text { SROI }=\frac{\text { Valor Actual Neto impactos } €}{\text { Valor Actual Neto inversión } €}
$$

Fase 6 Comunicación, uso y certificación. El proceso metodológico no está completo si no se reporta a los stakeholders que han intervenido, se define el uso del resultado y se garantiza, mediante una persona independiente de la organización, que el proceso se ha seguido correctamente, es decir, que cumple con los principios que define la metodología. 
FIGURA 2.1. FASES DEL SROI

\begin{tabular}{|c|c|c|c|c|c|}
\hline FASE 1 & FASE 2 & FASE 3 & FASE 4 & FASE 5 & FASE 6 \\
\hline $\begin{array}{l}\text { Definir el } \\
\text { alcance e } \\
\text { identificar } \\
\text { stakeholders }\end{array}$ & $\begin{array}{c}\text { Elaboración } \\
\text { del mapa de } \\
\text { cambios }\end{array}$ & $\begin{array}{c}\text { Cuantificación } \\
\text { de los } \\
\text { cambios }\end{array}$ & $\begin{array}{l}\text { Medida } \\
\text { del impacto } \\
\text { social }\end{array}$ & $\begin{array}{l}\text { Cálculo } \\
\text { del SROI }\end{array}$ & $\begin{array}{l}\text { Comunicación, } \\
\text { uso y } \\
\text { certificación }\end{array}$ \\
\hline
\end{tabular}

Fuente: elaboración propia.

\subsection{LA TEORÍA DEL CAMBIO}

Cuando se realiza una intervención es porque se espera que algo cambie. Pero, ¿se tiene la certeza de lo que ha cambiado y cuánto? ¿En qué medida la organización es protagonista de este cambio? ¿Existen otros factores que han influido en el cambio?

En un plan estratégico se plasman los deseos de cambios y se define la visión como el deseo de adónde queremos llegar en un periodo temporal concreto.

La teoría del cambio marca la hoja de ruta para alcanzar los cambios que se propone la organización. Es un viaje con paradas a corto, medio y largo plazo que se puede dibujar en un mapa consensuado por todos los que participan en el viaje. Y aquí entran los stakeholders, o agentes de interés, porque no solo cambia lo que está en manos de la organización, sino que se promueve un cambio más allá del objetivo directo y estos stakeholders también colaboran en alcanzar el cambio de la organización. Ordenar qué cambia, quién contribuye a los cambios y cuándo se producen es parte del proceso de construcción de la teoría del cambio.

En este punto es necesario introducir la diferencia entre cambio e impacto. Realmente con SROI se evalúa el impacto de un cambio. A la cuantificación del impacto se llega quitándole al valor de los cambios aquellos factores que, bien podrían haberse producido sin intervenir o bien no hemos contribuido en exclusiva a que se produzcan (los correctores que comentaba con anterioridad). La siguiente figura explica cómo se generan los impactos.

FIGURA 2.2. CADENA DE CREACIÓN DE IMPACTOS

\begin{tabular}{|c|c|c|c|c|}
\hline $\begin{array}{l}\text { INSUMOS } \\
\text { (inputs) }\end{array}$ & ACTIVIDADES & $\begin{array}{l}\text { RESULTADOS } \\
\text { (outputs) }\end{array}$ & $\begin{array}{l}\text { CAMBIOS } \\
\text { (outcomes) }\end{array}$ & $\begin{array}{c}\text { AJUSTE DEL } \\
\text { OBJETIVO }\end{array}$ \\
\hline $\begin{array}{l}\text { Recursos } \\
\text { aportados a la } \\
\text { iniciativa }\end{array}$ & $\begin{array}{l}\text { Actividades } \\
\text { que se realizan } \\
\text { gracias a la } \\
\text { inversión }\end{array}$ & $\begin{array}{l}\text { Resultados } \\
\text { medibles de la } \\
\text { actividad }\end{array}$ & $\begin{array}{l}\text { Cambios que se } \\
\text { alcanzan } \\
- \\
\text { Correctores de } \\
\text { los cambios que } \\
\text { no se pueden } \\
\text { atribuir a la enti- } \\
\text { dad /iniciativa } \\
= \\
\text { IMPACTOS }\end{array}$ & $\begin{array}{c}\text { Modificar el } \\
\text { objetivo para } \\
\text { alcanzar el } \\
\text { impacto deseado }\end{array}$ \\
\hline
\end{tabular}

Fuente: elaboración propia a partir de Olsen et al. ${ }^{[2]}$ 


\subsubsection{Obtención de información sobre los cambios}

Obtener información sobre qué cambia y cuánto cambia (unidades de cambio) es la base de la concreción de la teoría de cambio. Dado que en una evaluación normalmente se tendrán en cuenta diferentes stakeholders del proyecto, para cada uno de ellos se debe decidir la mejor forma de recolectar la información para evidenciar los cambios. Aquí, las metodologías son variadas, desde entrevistas en profundidad a grupos nominales para stakeholders con un número pequeño de componentes a encuestas para un grupo elevado, como puede ser, por ejemplo, un grupo de pacientes con una patología determinada o a sus cuidadores/ familiares.

Los recursos disponibles para la realización de la evaluación también pueden determinar la metodología a utilizar.

En el caso de poder llevar a cabo una encuesta, puede realizarse con una muestra y debe garantizarse que esta sea representativa estadísticamente del conjunto de la población a analizar.

El cuestionario es clave y la selección de variables a incluir e incluso el tipo y redacción de las preguntas se recomienda que esté consensuado con los stakeholders, especialmente con los más cercanos al grupo a encuestar.

En el caso de pacientes, por ejemplo, profesionales sanitarios, profesionales sociales y un grupo de pacientes/cuidadores reducido pueden ayudar a enfocar de forma más eficiente el cuestionario proponiendo un conjunto de hipótesis de los cambios que se alcanzarían y que, gracias al cuestionario, se validarían o descartarían.

Por experiencia personal, como mínimo, la información debe recoger:

- La frecuencia de uso de los pacientes de los diferentes servicios incluidos en la iniciativa a evaluar.

- Los cambios, positivos o negativos, que han experimentado (en caso de evaluación retrospectiva) o consideran que experimentarán (evaluación prospectiva) con la iniciativa.

- Resulta interesante, además, que valoren en qué medida este cambio es importante para ellos, pues ayuda a priorizar los cambios y descartar del análisis cambios irrelevantes.

- Además, en qué medida estos cambios creen que son fruto de la iniciativa concreta (por ejemplo, con una escala de valoración cualitativa o cuantitativa) o fruto de otras intervenciones ajenas. Por ejemplo, el paciente puede recibir atención por parte del sistema sanitario, por parte de una asociación de pacientes, puede tener una ayuda a domicilio de una empresa privada, etc. $Y$ todos estos agentes pueden estar contribuyendo a la mejora de la calidad de vida del paciente.

\subsection{FORTALEZAS}

Toda herramienta de evaluación tiene fortalezas y debilidades, comparada con otras cuyos fines sean parecidos. En el caso de SROI se identifican las siguientes: 
- Fortalece la relación con los stakeholders. Así como otras metodologías solo tienen en cuenta la evaluación desde la perspectiva del "beneficiario directo", SROI incorpora una perspectiva global del análisis y evalúa el impacto para el conjunto de agentes que intervienen, directa o indirectamente. Esto permite involucrarlos en todo el proceso y que sean conocedores de la ejecución y resultados de la actividad y del funcionamiento de la organización.

- Es útil en su totalidad o en partes de la metodología. SROI es útil para diversos objetivos, desde la planificación estratégica, a profundizar en los cambios, comunicar el impacto o calcular la mejor inversión. Por ejemplo, una organización que no tenga una clara teoría del cambio podría utilizar solo las primeras fases de SROI para profundizar internamente en los cambios que produce y los que pretende alcanzar.

- Monetiza el impacto social. Mientras que puede ser difícil valorar y consensuar la parte cualitativa de los resultados (qué cambios se producen), el hecho de disponer de la cuantificación del valor y del coeficiente SROI en términos económicos (euros), facilita la compresión por parte de todos.

- Favorece la comunicación interna. En estos proyectos de evaluación normalmente están implicadas varias personas/departamentos dentro de la organización, lo que favorece la mejora de la comunicación.

- Recopila información de valor. En organizaciones que no dispongan de un cuadro de mando sobre su actividad, con SROI es posible iniciar este proceso, ya que requiere la recopilación de actividad y resultados a la que, además, se podrán incorporar indicadores de cambio.

\subsection{DEBILIDADES}

En la utilización de SROI como herramienta para la gestión y medición del impacto social deben tenerse en cuenta las debilidades para gestionar las expectativas.

- No disponer de suficiente información: iniciar una evaluación de impacto social cuando no se dispone de información suficiente, necesaria para generar una buena matriz de impactos sería un error, aunque en este caso, SROI puede utilizarse para ir construyendo la información necesaria (fortaleza). En este caso, la obtención de resultados se dilataría más en el tiempo, hasta la obtención de la información necesaria.

- La subjetividad del proceso: la implicación de diferentes stakeholders decisores sobre el proceso, así como la selección de los llamados financial proxies confieren subjetividad al proyecto de evaluación. El análisis de sensibilidad sobre los resultados, puede contribuir, en parte, a reducirla.

- Cuantificar los intangibles: los cambios que se producen pueden ser tangibles (por ejemplo, poder trabajar 5 horas más a la semana es fácilmente cuantificable) o intangibles, como mejorar la calidad de vida, el bienestar emocional o las relaciones sociales. ¿En qué medida cuantificamos estos intangibles? Existe cierta subjetividad que puede influir en el resultado final.

- La elección de stakeholders relevantes: no seleccionar bien los stakeholders relevantes o que uno de ellos no quiera o pueda participar del proyecto de evaluación tiene implicaciones sobre el resultado que se obtendrá. 
- No es posible comparar resultados: al tratarse de una evaluación profunda realizada ad-hoc para un proyecto o iniciativa, que parte de una teoría del cambio concreta, los resultados del coeficiente SROI no pueden compararse con otros similares. No existe un SROI mejor que otro: un SROI es bueno en la medida que su resultado es superior a 1, a partir de cuando se empieza a generar más impacto que inversión realizada y en la medida que se ajusta a los objetivos, cuantitativos o cualitativos, marcados.

- No tener capacidad para cambiar las cosas: ser eficientes significa que, una vez evaluado un proceso, somos capaces de identificar qué debemos cambiar para ser más eficientes. Si finalizada la evaluación con SROI la organización o personas concretas no son capaces de realizar los cambios necesarios identificados, SROI pierde parte de su utilidad principal.

\subsection{PERSPECTIVAS DE FUTURO EN EL SISTEMA SANITARIO}

En España, del 2010 al 2016 hemos visto cómo de forma progresiva se ha ido reduciendo el gasto público en salud per cápita (de $1.566 €$ a $1.538 €$ ) y es en 2017 cuando se ha vuelto a situar al nivel de 2009 (1.565 €/cápita)'. Las políticas de restricciones económicas, sin duda, afectaron a la sanidad.

La salud es responsabilidad, en mayor o menor medida, de todos los agentes que intervienen en la prevención de enfermedades, en la investigación de nuevos fármacos y dispositivos, en la asistencia sanitaria, etc., en definitiva, de la Administración pública, empresas de salud, institutos o centros de investigación, organizaciones de pacientes y de los propios pacientes o ciudadanos con necesidades de salud.

¿Podemos ser más eficientes gastando menos o invirtiendo mejor? Ahora que se debate sobre el "dejar de hacer" ${ }^{\text {ii }}$ como una de las claves para optimizar el SNS (Sistema Nacional de Salud), resulta imprescindible medir para concretar qué podemos "dejar de hacer" para ser más eficientes, siempre con la vista puesta en la mejora de la salud de la ciudadanía y bajo la premisa de la sostenibilidad del sistema.

Identificar el valor social que generamos es parar a reflexionar sobre qué queremos cambiar, si tenemos que seguir haciendo lo mismo o debemos adaptarnos a los cambios que están a nuestro alrededor. Y si sabemos qué queremos cambiar, tenemos que planificar cómo hacerlo, "dejando de hacer" y poniendo los recursos solo en lo que realmente importa.

La Organización Mundial de la Salud (OMS) publicó un documento de posicionamiento con el objetivo de "resaltar la relevancia de SROI para orientar las inversiones en salud y bienestar en el contexto de la implementación de la Agenda 2030 para el Desarrollo Sostenible en general, y en el marco de la política europea de salud 2020 de la OMS, en particular"[3].

Sin duda, el método SROI se ofrece como una herramienta útil en el sistema sanitario, necesitado de cambios profundos para adaptarse a la realidad de la ciudadanía a la que debe procurar la mejor atención.

https://datosmacro.expansion.com/estado/gasto/salud/espana [acceso: 16 de diciembre de 2018]

ii https://www.diariofarma.com/2018/11/30/colaboracion-profesionalizacion-de-la-gestion-uso-de-datos-y-dejar-de-hacer-claves-para-optimizar-el-sns [acceso: 18 de diciembre de 2018] 


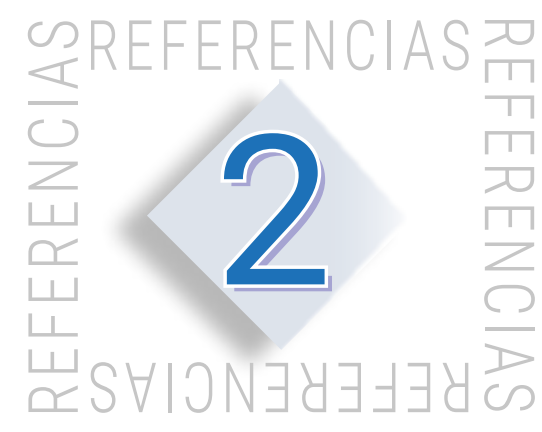

1. Nicholls J, Lawlor E, Neitzert E, Goodspeed T. A guide to Social Return on Investment. UK: The SROI Network. Accounting for Value; 2012. Disponible en: http://www.socialvalueuk.org/app/ uploads/2016/03/The\%20Guide\%20to\%20Social\%20Return\%20on\%20Investment\%202015.pdf

2. Olsen S, Galimidi B. Impact measurement approaches: recommendations to impact investors. The Rockefeller Foundation; 2008. Disponible en: http://wmfn.org.uk/wp-content/uploads/2017/09/RIIC_ Report_Final.pdf

3. Hamelmann $C$, Turatto F, Then $V$, Dyakova M. Social return on investment: accounting for value in the context of implementing Health 2020 and the 2030 Agenda for Sustainable Development. Copenhagen: WHO Regional Office for Europe; 2017. (Investment for Health and Development Discussion Paper). Disponible en: http://www.euro.who.int/_data/assets/pdf_file/0009/347976/20170828h0930-SROI-report-final-web.pdf?ua=1 


\section{CAPÍTULO}

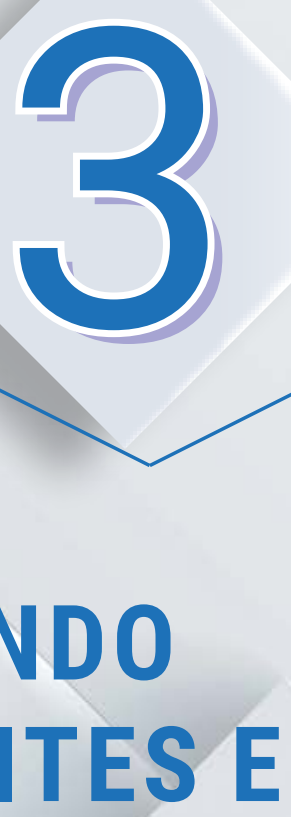

IDENTIFICANDO LOS

STAKEHOLDERS PARA

REALIZAR UN BUEN SROI

Marta Trapero-Bertran 
E ste tercer capítulo trata de ahondar en los elementos básicos de un análisis del retorno social de la inversión haciendo énfasis en los diferentes niveles en los que este tipo de análisis se puede aplicar, los diferentes tipos de análisis y perspectivas, la importancia del horizonte temporal y, por último, la involucración de los diferentes stakeholders en el análisis. La selección de éstos y el compromiso de la aplicación de este tipo de análisis de manera más pragmática en el día a día de los diferentes stakeholders es muy relevante para el éxito de un buen SROI (Social Return On Investment).

El escenario ideal sería poder tener unas guías de buenas prácticas a nivel nacional o internacional que orientaran cuáles son las asunciones o requisitos básicos para realizar un buen SROI, pero estas no están consensuadas aún en la disciplina sanitaria. Podemos encontrar algunas guías a nivel internacional que pueden dar consejos, pero no podemos decir que sean guías consensuadas entre los diferentes países ${ }^{[1]}$.

\subsection{NIVEL DE APLICACIÓN DEL MÉTODO: MICRO VS MACRO}

El análisis SROI puede utilizarse tanto a nivel micro como macro, mostrando el valor de las intervenciones para el ciudadano individual, para el municipio en cuestión o para la sociedad en general. Esta interconexión entre los diferentes niveles, micro y macro, es una de las características que hace al análisis SROI más atractivo para los stakeholders, ya que se pueden analizar tanto los resultados para los individuos como para la sociedad. De hecho, se puede hacer el mismo análisis con datos individuales, a nivel micro, y datos agregados, a nivel macro, y ver si el retorno de la inversión sería diferente para diferentes niveles de aplicación.

Un buen ejemplo de esta interrelación es el Proyecto New Start de Rebild Municipality, tal y como explica Lindgaard en su informe de 2015 para Deloitte ${ }^{[2]}$. Este proyecto se estableció para garantizar una intervención en las familias vulnerables del municipio que, hasta entonces, habían estado en contacto con los departamentos administrativos de dicho municipio, pero a menudo sin ningún impacto o éxito. Estas familias se caracterizaban por tener problemas sociales complejos, por ejemplo, un gran número de padres con problemas de salud mental, o que habían estado sin trabajo durante mucho tiempo y que al mismo tiempo habían estado o estaban sujetos a varias intervenciones sociales diferentes. Los niños de estas familias heredaron los problemas de los padres y, por lo tanto, tuvieron un menor rendimiento en la escuela que sus compañeros de clase con antecedentes menos complicados. Muchos de los niños también sufrían de baja autoestima y problemas de salud mental, y generalmente se los dejaba a su suerte. En lugar de abordar diversos síntomas, se ofreció a las familias sujetas al Proyecto New Start una intervención cohesiva, priorizada y sólida, en todas las áreas profesionales del municipio. Esto incluyó esfuerzos para crear relaciones de confianza entre el personal de los servicios municipales y las familias, de modo que juntos pudieran trabajar hacia soluciones realistas para los problemas que afrontaban estas familias. El proyecto contribuyó a mejorar el bienestar de las familias de forma individual, pero también con un enfoque en el apoyo a la escolarización de los niños y la participación de los padres en el mercado laboral o el sistema educativo. El Proyecto New Start fue un éxito a nivel micro, para las familias vulnerables, y también a nivel macro, con efectos económicos beneficiosos, incluso a corto plazo, para ese municipio o sociedad. Los padres recibieron ayuda a nivel micro para enfrentar sus problemas, aumentando su motivación para tomar el control de sus propias vidas y estas mejoras tuvieron un impacto extremadamente positivo para muchos de los niños: vínculos más fuertes con sus escuelas, mayor autoestima, etc. 
Además, lograr que más padres encuentren trabajo o mejoren su nivel educativo dio lugar a ganancias económicas en forma de ingresos de transferencia reducidos. A más largo plazo, los ahorros económicos pueden resultar considerablemente mayores, especialmente si se rompe el estancamiento de la herencia social, de modo que los niños vulnerables no se conviertan en adultos vulnerables. El SROI permite evaluar el impacto de la inversión de recursos a nivel micro, y a ambos niveles al mismo tiempo, y sus conclusiones pueden dar respuestas a decisiones pendientes de los stakeholders en diferentes niveles de aplicación.

\subsection{TIPOS DE ANÁLISIS: RETROSPECTIVO VS PROSPECTIVO}

Tal y como se explica en Nicholls et al. ${ }^{\left[{ }^{1]}\right.}$ hay dos tipos de análisis de SROI: el análisis retrospectivo, que se basa en resultados reales que ya se han producido y en datos que anteriormente se han recogido, y el prospectivo, que predice cuánto valor social se creará si las intervenciones cumplen los resultados esperados.

Los SROI prospectivos son especialmente útiles en las primeras etapas de planificación de una actividad. Este tipo de SROI puede ayudar a mostrar cómo la inversión puede llegar a maximizar su impacto y también puede ser útil para identificar qué es lo que se debe medir una vez iniciada la intervención. Un SROI retrospectivo siempre tiene el desafío de ver si los datos ya recogidos podrán cumplir las necesidades del análisis. En este análisis puede ser difícil obtener los datos del impacto de una intervención después de que haya sucedido el evento. Además, a veces con los datos existentes no podemos dar respuesta a las preguntas que nos planteamos en el análisis, y, por lo tanto, si este es el caso, es importante establecer los mecanismos de recogida de datos necesarios para poder llevar a cabo un análisis en el futuro que dé respuesta a las preguntas que se plantean ${ }^{[1]}$. Este tipo de análisis siempre necesitará datos sobre resultados, sin embargo, un SROI prospectivo lo que hará es proporcionar la base para construir un marco de medición para capturar los resultados.

A menudo, es preferible comenzar a utilizar un SROI prospectivo del valor social, en lugar de hacer un análisis retrospectivo, ya que esto garantiza que los sistemas de recogida de datos sean los correctos para poder realizar un análisis completo en el futuro. En cualquier caso, cualquiera que sea la decisión sobre el tipo de análisis SROI, retrospectivo o prospectivo, es importante que el análisis tenga una perspectiva multidisciplinar mediante la participación de diferentes stakeholders del sistema que pertenezcan a diferentes niveles de decisión, tanto de nivel micro como macro ${ }^{[3]}$.

\subsection{HORIZONTE TEMPORAL}

En un SROI es importante definir por adelantado el tiempo total de estimación de los resultados del análisis, al igual que en otro tipo de análisis como la evaluación económica. En el SROI está claro que hay una preferencia clara por el corto plazo, ya que al invertir en intervenciones siempre existe un gran interés por estimar cuál es el tiempo mínimo para recuperar la inversión. Sin embargo, si el horizonte temporal utilizado es a más de un año siempre se aplica directamente el concepto de preferencia temporal, que comúnmente también se incorpora en evaluación económica, a través del proceso de descuento de costes y beneficios futuros al valor presente.

Muchas intervenciones de salud pública no producen beneficios inmediatos, pero pueden suponer un impacto significativo a lo largo de la vida de una persona. Por lo tanto, en esos 
casos debería utilizarse un horizonte temporal igual al tiempo de vida de los pacientes. Sin embargo, puede haber impactos donde el retorno de la inversión se dé también a corto plazo, aunque a menudo son menores los beneficios observados en estos casos que en análisis con horizontes temporales a largo plazo. El horizonte temporal tiene una gran influencia en el SROI estimado, ya que el impacto en los resultados estará muy influenciado por el período de tiempo del análisis. Por ejemplo, en un análisis de SROI realizado por Finkelstein et al. en el que se examinaron programas dirigidos a la obesidad infantil en los Estados Unidos ${ }^{[4]}$, se seleccionó un horizonte temporal de cinco años. El resultado mostró una baja probabilidad de retorno de la inversión positivo para mantener los programas analizados. Sin embargo, los autores señalaron que muchos niños obesos se convierten en adultos obesos y, en consecuencia, la aplicación de un horizonte temporal más largo podría haber mostrado resultados diferentes. Otro ejemplo que ilustra la importancia del horizonte de tiempo es el analizado por la herramienta NICE ROI, diseñada por Pokhrel et al ${ }^{[5]}$, que es un análisis de SROI para intervenciones para dejar de fumar, la cual se diseñó para calcular los beneficios a corto y largo plazo que supone el dejar de fumar y en la que se contemplaron varios horizontes temporales, desde el corto plazo hasta el final de la vida de los pacientes.

Por lo tanto, plantear un SROI con diferentes horizontes temporales permite evaluar los costes a lo largo del tiempo y también estimar en qué momento del tiempo se recuperarán los costes de inversión. Lo que llamaríamos en economía el "breakeven", que es la situación en la que la inversión está en un punto muerto, es decir, cuando se ha recuperado justo la inversión que se ha hecho. Sin embargo, hay que tener en cuenta que la disponibilidad de datos o información es muy importante a la hora de plantear qué horizonte temporal puedes utilizar para el análisis. Si la disponibilidad de datos es escasa, quizás sea recomendable empezar por un horizonte temporal a corto plazo y luego, en función de la disponibilidad de evidencia y datos, realizar un análisis aumentando el período de tiempo.

\subsection{PERSPECTIVA DE LA INVERSIÓN Y DEL RETORNO}

Otro elemento fundamental del SROI es la perspectiva que se adopta para el análisis. Para los stakeholders es muy importante que el SROI sea capaz de producir resultados tanto desde una perspectiva del sistema de salud como desde una perspectiva social más amplia.

Evidentemente el análisis SROI se puede realizar desde múltiples perspectivas, siendo las más comunes la perspectiva del sistema sanitario o la perspectiva social. Si se toma como referencia la perspectiva del sistema sanitario, solo se incluirán los costes en los que incurre el financiador sanitario de salud y el impacto se limitaría a la salud de las personas. En cambio, si el trabajo se plantea desde una perspectiva social, se habrán de tener en cuenta todos los costes directos sanitarios asociados al financiador, pero también, los de los pacientes y los cuidadores/familiares/amigos/personas en general y las pérdidas de productividad laboral, que deberían también incluirse. Es decir, desde esta perspectiva también se valorarían los beneficios producidos en la salud del individuo, y también aquellos beneficios producidos en la salud de los cuidadores/familiares/amigos/personas, además de otros beneficios extendidos. Si bien la adopción de una perspectiva social puede resultar más atractiva, se debe tener en cuenta que la suposición implícita, aunque se adopte esta perspectiva, es que quien toma las decisiones está dispuesto a renunciar a los beneficios en salud por otros resultados, como la mejora de la productividad laboral. Por lo tanto, es importante tener en cuenta, que la elección de la perspectiva debe relacionarse con los objetivos fundamentales de la organiza- 
ción para la cual se encarga la herramienta de SROI. También es importante tener en cuenta que puede ser muy difícil incorporar todos los costes de las intervenciones de salud pública y todos los beneficios sociales de las mismas, y esto debe valorarse a la hora de tomar la decisión sobre la elección de la perspectiva.

\subsection{SELECCIÓN E INVOLUCRACIÓN DE LOS STAKEHOLDERS}

Representar las necesidades e intereses de los stakeholders a lo largo del proceso es fundamental para una buena evaluación del programa. Se debe alentar a los investigadores a identificar e involucrar activamente a los stakeholders relevantes en la investigación para poder así articular una comprensión clara del contexto, identificar correctamente las necesidades de los usuarios y que la investigación propuesta satisfaga estas necesidades o tenga un impacto en la comprensión de estas necesidades. Para lograrlo es imprescindible preservar la transparencia de los métodos y de los datos que respaldan la herramienta de SROI final. A nivel general podríamos recomendar, tal y como lo hacen Nicholls et al. ${ }^{[1]}$, que para identificar e involucrar a los stakeholders se elabore una lista de todos aquellos stakeholders que podrían afectar o ser afectados por las actividades que se van a evaluar, ya sea el cambio o el resultado positivo o negativo, intencional o no intencional, es decir, incluir todos aquellos stakeholders que pueden experimentar cambios sustanciales como resultado de la actividad. Estos cambios deberían estar relacionados con la actividad en todo su alcance. Un error común es incluir stakeholders que son relevantes para la organización, pero no para las actividades establecidas en el alcance. Por ejemplo, si se está realizando un análisis SROI de un proyecto, hay que tener cuidado de no incluir a los stakeholders por el mero hecho de ser un stakeholder, y que no puedan beneficiarse ni él ni la institución a la que representa de su participación en el proyecto del SROI.

El segundo paso sería encontrar diferentes métodos para involucrar a los stakeholders. Algunos de estos posibles métodos están descritos en la tabla 3.1.

\section{TABLA 3.1. MÉTODOS PARA INVOLUCRAR A LOS STAKEHOLDERS}

- Reunir a los stakeholders en un solo lugar y preguntarles directamente;

- Realizar una actividad en formato de taller, con discusiones informales y un rotafolio para registrar las respuestas;

- Completar un formulario durante una reunión programada regularmente, por ejemplo, una reunión general anual de una organización u otra reunión de conjunto;

- Llamar a los representantes de los grupos de los stakeholders clave y preguntarles;

- Enviar por correo electrónico un breve formulario a los representantes de los grupos de los stakeholders clave;

- Organizar un evento social para que los diferentes stakeholders, en un ambiente informal, intercambien opiniones y experiencias;

- Realizar entrevistas individuales

Fuente: Nicholls et al. ${ }^{[1]}$

Idealmente, se debería recopilar información directamente de los stakeholders. Sin embargo, la falta de tiempo o recursos puede significar que parte de la información deba provenir de la investigación existente con los stakeholders. Siempre que sea posible, la fuente de información debería basarse en preguntar directamente a los grupos de interés. Puede haber 
stakeholders que no puedan participar, por ejemplo, las generaciones futuras. En este caso, se debe identificar personas que los representen y que puedan hablar en su nombre.

Es particularmente importante ser sensible a la cantidad de tiempo y recursos que los stakeholders pueden aportar a este proceso, ya sea personal, o como participantes. Antes de las reuniones, hay que pensar en las aportaciones, productos y resultados de cada stakeholder para garantizar que el tiempo se utilice de la manera más eficiente posible. Si es probable que tenga que hablar con ellos nuevamente para recopilar más datos para su análisis, asegúrese de decirles esto para que sepan qué esperar. Es importante también pensar en las formas en que las personas ya se reúnen, por ejemplo, reuniones públicas o sesiones de capacitación, y ver si puede hacer uso de alguna de ellas. Además, cuando le está pidiendo a la gente que dedique una cantidad significativa de tiempo al proceso sin un beneficio obvio para ellos, hay que considerar la posibilidad de ofrecer incentivos como almuerzo, gastos de viaje o cupones para fomentar la asistencia.

No hay que preocuparse por obtener una muestra grande que sea estadísticamente representativa. Se pueden dejar de hacer nuevas investigaciones cuando ya no se obtiene información o ideas nuevas, lo que se llama llegar "al punto de saturación y, por lo tanto, se puede esperar razonablemente haber escuchado las ideas principales. Este enfoque se usa comúnmente en la investigación social.

Algunos de los consejos que dan Lindgaard et al. ${ }^{[2]}$ son que la mayoría de los recursos deben dedicarse a los stakeholders que son vitales para realizar un análisis exhaustivo. Si no se establecen prioridades, existe el riesgo de gastar demasiado tiempo en stakeholders menos importantes. Para ello, puede ser una buena idea agrupar a los stakeholders. Puede ser útil designar representantes de los grupos de stakeholders relevantes, para lograr una utilización óptima de los recursos. Naturalmente, hay ventajas si se logra involucrar al mayor número de stakeholders posible, pero en vista del tiempo y los recursos disponibles, en ocasiones es necesario contar con una selección de stakeholders que represente al grupo objetivo. Es importante ser inclusivo a la hora de identificar los stakeholders que puedan ayudar a evaluar el impacto social de la intervención, y buscar opiniones lo más diversas posibles.

Al involucrar a los stakeholders, puede ser una ventaja listarlos en un orden específico. Esto asegurará una visión general y también puede ser útil al presentar las opciones metodológicas elegidas y descartadas. Este proceso puede parecer una tarea simple, pero la planificación y priorización pueden ahorrar tiempo tanto para uno mismo como para ellos.

Los stakeholders pueden involucrarse de diferentes maneras como, por ejemplo, realizando grupos focales, encuestas con cuestionarios, talleres, llamadas telefónicas con representantes de los stakeholders o a través de las redes sociales. La forma en que participan los stakeholders depende de la cantidad de tiempo del que disponen y del grupo de stakeholders.

Además de servir como fuentes importantes de conocimiento para algunos análisis, la participación de los stakeholders puede presentar otras ventajas. La participación activa y las oportunidades para compartir ideas y críticas constructivas pueden convertir a los participantes en miembros motivados del equipo, lo que aumenta su compromiso y responsabilidad con la intervención. Si los stakeholders están involucrados durante el proceso, por ejemplo, no solo serán un elemento que ayude a recopilar conocimientos para el proyecto, 
sino que también tendrán la oportunidad de reflexionar sobre su trabajo, lo que en sí mismo, puede fortalecer la intervención.

Uno de los ejemplos que podemos seguir y analizar es el que se utilizó para el proyecto europeo del EQUIPT que construyó un análisis de SROI para intervenciones que ayudaran a dejar de fumar ${ }^{[5,6]}$. El estudio EQUIPT definió a los stakeholders en cinco categorías: aquellos que participan en la elaboración de políticas sanitarias, compradores de servicios / productos de farmacoterapia (incluidas autoridades financieras), proveedores de servicios profesionales (incluidos clínicos y especialistas en control del tabaco), generadores de evidencia (académicos e investigadores), y defensores de la promoción de la salud. Los stakeholders se identificaron al inicio del estudio y proporcionaron información clave en todas las etapas de la investigación a medida que evolucionaba, incluyendo la fase de identificación de necesidades, la fase piloto y de prueba (de los conceptos y herramientas de SROI en el entorno local) y la fase de difusión (haciendo recomendaciones de salud pública, evaluando los supuestos de transferencia y creando un plan de difusión efectivo).

El método de participación de los stakeholders fue impulsado por el pragmatismo, en lugar de cualquier teoría específica existente en torno a la participación. Los tres componentes de este enfoque pragmático se resumen en la tabla 3.2.

\section{TABLA 3.2. COMPONENTES PRAGMÁTICOS DE INVOLUCRACIÓN DE LOS STAKEHOLDERS}

\begin{tabular}{|c|c|}
\hline $\begin{array}{l}\text { OBJETIVOS DEL MÉTODO } \\
\text { DE PARTICIPACIÓN }\end{array}$ & ACCIONES A EMPRENDER \\
\hline $\begin{array}{l}\text { Identificar las necesidades de los grupos } \\
\text { de interés }\end{array}$ & $\begin{array}{l}\text { - Consultas informales y formales } \\
\text { - Encuestas } \\
\text { - Talleres con encuestas pre y post evento } \\
\text { - Talleres con encuestas pre y post evento y trabajo grupal } \\
\text { - Discusiones grabadas } \\
\text { - Pruebas de usabilidad y evaluaciones heurísticas }\end{array}$ \\
\hline Involucrar a los interesados en todo & $\begin{array}{l}\text { - Informar y estar informado (proceso iterativo) } \\
\text { - Desde el diseño hasta el pilotaje/pruebas hasta la difusión } \\
\text { - Estableciendo un proceso de relaciones personales que se acaban } \\
\text { traduciendo en una colaboración más estrecha }\end{array}$ \\
\hline Mantener la integridad científica & $\begin{array}{l}\text { - Transparencia en el uso de los mejores datos disponibles en el } \\
\text { modelado } \\
\text { - Juicio (consenso de expertos) donde la evidencia no es sólida } \\
\text { - Análisis de sensibilidad } \\
\text { - Comunicación accesible }\end{array}$ \\
\hline
\end{tabular}

Fuente: elaboración propia a partir de Pokhrel et al. ${ }^{[7]}$

Se emplearon varios métodos de recopilación de datos para obtener entrevistas que describieron las necesidades de los interesados (es decir, para conocer las necesidades locales y cómo las herramientas de SROI podrían ayudar a abordarlas), como por ejemplo, talleres de consenso (para discutir y acordar sobre los hallazgos e idear un conjunto de recomenda- 
ciones), una herramienta pragmática construida en un software fácil de manejar y de uso extendido (para probar los supuestos subyacentes de la herramienta), talleres exploratorios (para comprender el uso de herramientas similares existentes y su transferibilidad a otros contextos) y evaluaciones de usabilidad (para probar la funcionalidad de la herramienta de ROI). Esto se complementó con un sitio web actualizado para este proyecto desde donde los stakeholders podían descargar todos los materiales relevantes.

Una parte importante de este compromiso fueron las encuestas (cara a cara y en línea) en las que se preguntó a los stakeholders sobre una serie de cuestiones relacionadas con los contextos de decisión: (a) sus percepciones sobre el uso de evidencia en la formulación de políticas; (b) sus opiniones sobre sus propias necesidades locales; (c) la importancia que le darían a varias intervenciones de control del tabaco basadas en la evidencia; (d) y su intención de utilizar una herramienta de retorno de la inversión si estuviera disponible. Han salido varias publicaciones sobre esta encuesta, y en España hay un artículo publicado por Muñoz et al. ${ }^{[6]}$. Del mismo modo, se realizó un trabajo importante para comprender cuán útiles fueron los conceptos, herramientas y evidencia de retorno de la inversión para los actores locales y cómo se podría garantizar la transferencia de la herramienta más allá de los países de estudio. Por lo tanto, el proceso de selección e involucración de los stakeholders son dos acciones clave para el éxito del diseño y aplicabilidad de un SROI. 


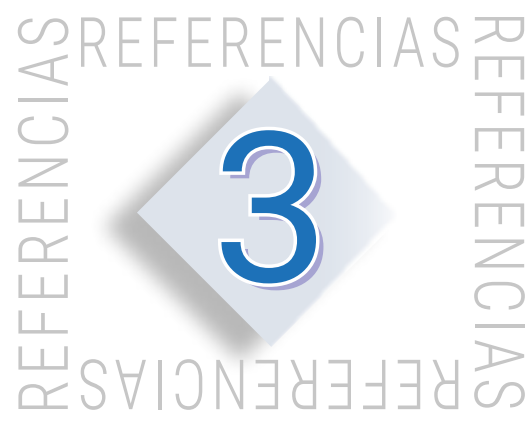

1. Nicholls J, Lawlor E, Neitzert E, Goodspeed T. A guide to Social Return on Investment. UK: The SROI Network. Accounting for Value; 2012. Disponible en: http://www.socialvalueuk.org/app/ uploads/2016/03/The\%20Guide\%20to\%20Social\%20Return\%20on\%20Investment\%202015.pdf

2. Lindgaard $M$, Thorgaard $P$, Wiene $M$. Is it worth it? How to mesure social return on investment. Kbh.: Gyldendal Business; 2015. Disponible en: https://www2.deloitte.com/content/dam/Deloitte/global/ Documents/gx-is-it-worth-it.pdf

3. Lawlor E, Neitzert E, Nicholls J. Measuring value: a guide to Social Return on Investment (SROI). 2nd edition. London: NEF (the new economics foundation); 2008.

4. Finkelstein EA, Trogdon JG. Public Health Interventions for Addressing Childhood Overweight: Analysis of the Business Case. Am J Public Health. 2008;98(3):411-5.

5. Pokhrel S, Owen L, Lester-George A, Coyle K, Coyle D, West R, et al. Estimating Return on Investment of Tobacco Control: NICE Tobacco ROI Tool. London: National Institute for Health and Care Excellence (NICE); 2014.

6. Muñoz C, Trapero-Bertran M, Cheung KL, Evers S, Hiligsmann M, de Vries H, et al. Herramienta de retorno de la inversión en control del tabaquismo: ¿qué opinan aquellos que toman decisiones? Gac Sanit. 2016;30(2):121-5.

7. Pokhrel S, Owen L, Coyle K, Coyle D. ROI in Public Health Policy. Supporting Decision Making. Springer International Publishing; 2017 [citado 20 de marzo de 2019]. Disponible en: https://doi. org/10.1007/978-3-319-68897-8 


\section{CAPÍTULO}

\section{ASPECTOS}

METODOLÓGICOS

DE UN ANÁLISIS SROI 


\subsection{INTRODUCCIÓN}

Desde una perspectiva estrictamente financiera, el objetivo perseguido con cualquier inversión es maximizar el valor económico o pecuniario de la actividad financiada por la misma. Dicho valor se determina en los mercados mediante los precios a los que se intercambian los bienes, servicios y factores productivos.

En este contexto, el análisis de la rentabilidad financiera de la inversión realizada suele juzgarse empleando el indicador conocido como rendimiento de la inversión (ROI por sus siglas en inglés). El ROI se define en una primera aproximación como la razón o cociente entre los beneficios (los ingresos percibidos por el inversor) y los costes (los desembolsos efectuados por el inversor). Por convención, es habitual expresar el ROI en el ámbito financiero como una variación, de modo que a la ratio anterior se le resta la unidad. Una inversión que no aporte valor tendrá una ROI de cero o, lo que es lo mismo, una ratio beneficio-coste de 1 .

La perspectiva seguida hasta este momento resulta, sin embargo, notablemente insuficiente cuando lo que nos interesa es evaluar el impacto de las intervenciones sanitarias, como pueda ser un programa preventivo del VIH (Virus de la Inmunodeficiencia Humana), un tratamiento de fertilidad o un medicamento oncológico. Y esto por la razón principal de que todas ellas tienen efectos que trascienden los meramente económicos, puesto que el principal beneficio de la asistencia sanitaria son las ganancias de salud.

No cabe hablar en puridad de un auténtico mercado sanitario, por cuanto hay argumentos de eficiencia (fallos del mercado) y de equidad (bienes preferentes o sociales) que en la mayoría de los países han conducido a un esquema de provisión pública (financiación y regulación públicas) con una participación preponderante de la administración en la producción directa de los servicios sanitarios. En consecuencia, no hay un valor de mercado para los efectos de la atención sanitaria sobre la salud, siendo ésta en la práctica un bien intangible o de no mercado, como la polución, el ruido o los espacios naturales ${ }^{[1]}$.

Como ya se anticipó en el capítulo 2, el enfoque conocido como retorno social de la inversión (SROI) se origina a mediados de los años noventa ${ }^{[2]}$ precisamente para ayudar a los inversores sociales o filantrópicos (tercer sector) a determinar el valor generado por sus organizaciones en un sentido amplio. Ese concepto amplio de valor se corresponde en su formulación clásica ${ }^{[3,4]}$ con el valor económico (valor de mercado o pecuniario), el social (valor no pecuniario de los bienes intangibles) y el socioeconómico (generado por el ahorro en gastos públicos y el aumento en ingresos tributarios), y en desarrollos más recientes ${ }^{[5,6]}$ con los costes y beneficios sociales, medioambientales y económicos, tríada conocida como "triple bottom line"[]].

La evaluación de la rentabilidad social de las intervenciones sanitarias se concreta en el marco del SROI en el cálculo de la ratio beneficio-coste del mismo nombre, análoga a la utilizada para estimar el ROI, excepto por el carácter holístico de los costes y beneficios incluidos, para lo cual los recursos (inputs) y resultados (outcomes) intangibles se valoran aplicando equivalencias monetarias que actúan como aproximaciones (denominadas proxies financieros) de los precios de mercado ausentes. Estas valoraciones se realizan aplicando métodos propios del análisis coste-beneficio ${ }^{[8]}$.

En este capítulo ofrecemos en primer lugar una panorámica de los diferentes componentes que puede albergar el valor social de las intervenciones sanitarias para, a continuación, pasar 
revista a los diferentes métodos de valoración de intangibles, explicando su fundamentación y mecánica, brindando además un balance de los pros y contras de cada uno de ellos. Una recopilación de las principales conclusiones alcanzadas cierra el capítulo.

\subsection{SELECCIÓN DE PROXIES FINANCIEROS}

La valoración del impacto que tiene una determinada intervención sobre el bienestar (también denominado utilidad) de las personas e instituciones afectadas por la misma (los stakeholders en la terminología propia del enfoque SROI) requiere adoptar una perspectiva comprehensiva o social ${ }^{[0]}$, donde se consideren todos los costes y beneficios relevantes, con independencia de quién los soporte o perciba.

En el caso de actividades que tienen como resultado la producción de bienes y servicios comercializados, el impacto es recogido por los precios de mercado. Así, las variaciones en los precios de mercado ofrecen una medida monetaria del cambio experimentado en la utilidad total generada por el consumo de un bien, denominado excedente del consumidor.

Sin embargo, dicho excedente no es directamente observable en el caso de los intangibles como son los efectos de las intervenciones sanitarias. Como ya se dijo anteriormente, el principal beneficio que reportan dichas intervenciones son las ganancias de salud que acarrean. Ganancias que no cotizan en ningún mercado, razón por la cual su monetización requiere de una variable proxy que haga las veces de precio de mercado. No en vano tales proxies financieros reciben el nombre de precios sombra en el argot del análisis coste-beneficio[10].

A estos efectos sobre la salud se unen otros efectos indirectos de las intervenciones sanitarias, también intangibles, que recaen sobre los pacientes, familias, voluntarios e incluso sobre otros sectores productivos ajenos al sistema sanitario, y que se reflejan en forma de costes (p.ej. más tiempo de cuidados informales) y beneficios (p.ej. mayor tranquilidad derivada de las pruebas diagnósticas), para cuya monetización también se necesita seleccionar proxies financieros.

Las variables proxies empleadas serán tanto más costosas de obtener cuanto más difícil sean de valorar los outcomes. Así, los outcomes calificados como "duros" son aquellos cuyo valor resulta más fácil de cuantificar, como puede ser la estimación de cambios en la productividad ocasionados por la morbimortalidad. En este caso, puede utilizarse el salario como proxy financiero de la pérdida potencial de producción debida a la reducción del tiempo de trabajo remunerado, tal y como postula el enfoque del capital humano ${ }^{[11]}$. En contraposición, outcomes "blandos" como puedan ser las mejoras en calidad de vida carecen de proxies evidentes, motivo por el cual hay que instrumentar otros métodos de valoración social[6].

La dificultad apuntada aumentará dependiendo de la exhaustividad del análisis, los distintos tipos de stakeholders considerados, así como de la perspectiva adoptada en la medición (ex ante o ex post). En este sentido, el valor total de un bien intangible incluiría no sólo el valor de uso efectivo del mismo (que sería el que tendría para los pacientes actuales), sino también el valor de uso pasivo o no uso ${ }^{[12]}$, que integraría a su vez, para el contexto de las intervenciones sanitarias ${ }^{[13]}$, el valor potencial que tendría para las personas sanas tener la opción de utilizar los servicios sanitarios cuando enfermen (valor de opción o de seguro), así como el que atribuye cada persona a los beneficios que proporciona la sanidad a terceros (valor de existencia o altruista). El valor de uso del bien, asimismo, para ser completo, debería de abarcar todos 
los efectos, directos e indirectos, derivados de la intervención. En el caso de, por ejemplo, un programa de deshabituación tabáquica, su efecto directo radica en la mejora de la salud de los participantes en el programa por dejar de fumar y su efecto indirecto por la mejora adicional provocada por la práctica de ejercicio físico que antes no podía realizarse.

Para capturar adecuadamente todos los efectos señalados, ya sean de salud y de no salud, directos e indirectos, de uso y de no uso, hay que recurrir a métodos de valoración desarrollados en el marco de la metodología evaluativa del análisis coste-beneficio. Estos métodos pueden clasificarse (Tabla 4.1), en un primer nivel, atendiendo al origen de los datos utilizados para estimar los proxies financieros correspondientes (señalados en la fila inferior de la tabla). A su vez, en un segundo nivel, podemos agruparlos según que sus proxies estén basadas en preferencias o no. Dentro de la primera categoría tenemos, por un lado, aquellos métodos basados en las preferencias reveladas por los sujetos en mercados paralelos o subrogados de los cuales puede inferirse la variación en el precio implícito del intangible. Alternativamente tenemos aquellos otros métodos basados en las preferencias que declaran los individuos en encuestas donde se simula un mercado hipotético para obtener de los participantes su máxima disposición a pagar (DAP), (mínima disposición a aceptar) por acceder a una ganancia de salud (por renunciar a ella). Por último, el método de la valoración del bienestar infiere la suma de renta que compensaría al encuestado por una disminución del bien.

\section{TABLA 4.1. MÉTODOS DE VALORACIÓN DE INTANGIBLES Y PROXIES FINANCIEROS QUE ESTIMAN}

\begin{tabular}{|c|c|c|c|}
\hline $\begin{array}{l}\text { MÉTODOS BASADOS EN } \\
\text { DATOS DE MERCADO }\end{array}$ & \multicolumn{3}{|c|}{ MÉTODOS BASADOS EN DATOS DE CUESTIONARIOS } \\
\hline \multicolumn{3}{|c|}{ MÉTODOS BASADOS EN PREFERENCIAS } & \multirow{2}{*}{$\begin{array}{l}\text { MÉTODOS } \\
\text { BASADOS EN } \\
\text { BIENESTAR } \\
\text { SUBJETIVO }\end{array}$} \\
\hline $\begin{array}{l}\text { Métodos de preferencias } \\
\text { reveladas (mercados } \\
\text { subrogados) }\end{array}$ & \multicolumn{2}{|c|}{ Métodos de preferencias declaradas (mercados simulados) } & \\
\hline - Coste de la enfermedad & \multirow{6}{*}{ Valoración contingente } & Valoración multiatributo & \multirow{6}{*}{$\begin{array}{l}\text { Valoración del } \\
\text { bienestar }\end{array}$} \\
\hline $\begin{array}{l}\text { - Función de producción } \\
\text { de la salud }\end{array}$ & & \multirow{5}{*}{$\begin{array}{l}\text { - Análisis conjunto } \\
\text { - Elección discreta }\end{array}$} & \\
\hline - Coste de oportunidad & & & \\
\hline - Coste de reemplazo & & & \\
\hline - Coste del viaje & & & \\
\hline - Precios hedónicos & & & \\
\hline \multicolumn{4}{|c|}{ Proxies financieros estimados por cada método } \\
\hline $\begin{array}{l}\text { Diferencias de precios } \\
\text { implícitos }\end{array}$ & \multicolumn{2}{|c|}{ Disposición a pagar o disposición a aceptar } & $\begin{array}{l}\text { Compensación de } \\
\text { renta }\end{array}$ \\
\hline
\end{tabular}

Fuente: elaboración propia a partir de Pinto-Prades et al. ${ }^{[1]}$ y van den Berg et al..[4]

\subsection{MÉTODOS DE VALORACIÓN DE INTANGIBLES}

En las sucesivas subsecciones de este epígrafe resumiremos las principales características de cada uno de los métodos señalados, utilizando varios ejemplos para ilustrar algunas aplicaciones de estos. Se recomienda a los lectores interesados en profundizar en el conocimiento de estos métodos de valoración que consulten la monografía de Pinto-Prades et al. ${ }^{[1]}$ 


\subsubsection{Métodos de preferencias reveladas}

Los métodos del coste de la enfermedad y de la función de producción de la salud tienen en común la idea de que los efectos de las intervenciones sanitarias pueden aproximarse a partir del conocimiento de los gastos de mitigación de la enfermedad (gastos de diagnóstico y tratamiento). Difieren, no obstante, en el grado de control que reconocen a las personas sobre su salud. Mientras que el método del coste de la enfermedad no supone ninguna capacidad de control a los individuos, el método de la función de producción de la salud asume que las personas, teniendo en cuenta su restricción presupuestaria, incurren en gastos preventivos y defensivos ex ante que reducen la probabilidad de enfermar y, por tanto, de incurrir en gastos de mitigación ex post.

Aunque estos métodos pueden aproximar razonablemente bien los beneficios de algunas intervenciones sanitarias, presentan en general claras limitaciones, como es que ambos obvian las molestias aparejadas a las enfermedades y la repercusión de éstas sobre la calidad de vida de los pacientes ${ }^{[1]}$.

El método del coste de oportunidad se utiliza para valorar el tiempo empleado (o ahorrado) durante, por ejemplo, la convalecencia. La lógica del método es aproximar dicho valor por los beneficios a los que se renuncia (coste de oportunidad) por no dedicar ese tiempo a mejores usos alternativos. En la práctica, el coste de oportunidad se aproxima por el salario de la persona afectada. La medición se complica si los cuidadores están desempleados (como es el caso de las amas de casa), en cuyo caso puede imputarse el salario percibido por personas ocupadas de características sociodemográficas semejantes.

Por su parte, el método del coste del reemplazo o método del bien sustitutorio (proxy good) valora el tiempo empleado al precio de mercado de un bien sustitutivo próximo. Por ejemplo, en el caso de los cuidados informales valoraríamos el tiempo empleado por el salario de un cuidador profesional.

Una crítica común a ambos métodos es que ignoran los impactos, positivos y negativos, que tienen los cuidados informales sobre el bienestar de cuidadores y cuidados ${ }^{[15]}$. Otra crítica concierne a la utilización del salario como proxy. En el caso del método del coste de oportunidad, aplicar sin más el salario puede obviar el hecho de que parte de los cuidados se prestan a costa del tiempo de ocio o son una forma de trabajo no remunerado ${ }^{[16]}$. Asimismo, en relación al método del coste de reemplazo, es cuestionable asumir que el salario refleje la productividad marginal del trabajo, debido al efecto de acuerdos colectivos y regulaciones ${ }^{[14]}$.

Van den Berg et al. ${ }^{[16]}$ estiman el valor de los cuidados informales en los Países Bajos por medio de los dos métodos que acabamos de describir. Los valores monetarios estimados de cuidados a pacientes que han padecido un ictus o que padecen artritis reumatoide, se muestran en la tabla 4.2.

El método del coste del viaje, ampliamente utilizado en el ámbito de la valoración de espacios recreativos, como los parques naturales, apenas ha sido empleado en el contexto de la salud ${ }^{[1]}$. La lógica que subyace a este método es que los costes de desplazamiento en que se incurre para acceder y disfrutar del intangible, en función de la distancia recorrida y tiempo invertido, permiten estimar la función de demanda implícita del bien en cuestión. La crítica, antes formulada, respecto de la incapacidad del salario para reflejar la producti- 
vidad marginal aplica también en este caso, ya que el tiempo invertido suele aproximarse por el salario.

TABLA 4.2. VALOR DE LOS CUIDADOS INFORMALES SEGÚN LOS MÉTODOS DEL COSTE DE OPORTUNIDAD Y DEL COSTE DE REEMPLAZO (EN €)

\begin{tabular}{|c|c|c|c|c|}
\hline & \multicolumn{2}{|c|}{ ICTUS } & \multicolumn{2}{|c|}{ ARTRITIS REUMATOIDE } \\
\hline & Por hora & Semanalmente & Por hora & Semanalmente \\
\hline Coste de oportunidad & 17,34 & 204,64 & 10,64 & 49,18 \\
\hline Coste de reemplazo & 18,24 & 119,80 & 20,24 & 153,51 \\
\hline
\end{tabular}

Fuente: elaboración propia a partir de van den Berg et al. ${ }^{[16]}$

El método de los precios hedónicos se sustenta en el supuesto de existencia de una relación de complementariedad entre el bien intangible y un bien de mercado a partir de la cual puede inferirse el precio implícito del intangible. Tradicionalmente los mercados paralelos o complementarios empleados para aproximar este valor han sido el inmobiliario y el laboral. Cuando se utilizan datos del mercado laboral, entonces se habla de método de los salarios hedónicos ${ }^{[17]}$.

Así, por ejemplo, este método supone que un trabajador, ante dos puestos de trabajo iguales en todas sus características salvo en el riesgo de sufrir un accidente laboral mortal, sólo aceptará el empleo de mayor riesgo si éste ofrece un mayor salario que lo compense, en términos de bienestar, por la mayor exposición al riesgo. Con la información recopilada sobre salarios, características sociodemográficas de los trabajadores y accidentes de trabajo se especifica una función de salarios hedónicos a partir de la cual, aplicando técnicas de inferencia estadística puede estimarse la prima salarial (o precio implícito) por riesgo de accidente mortal, que sería la variable proxy con la que valorar variaciones en la mortalidad.

Martínez et al. ${ }^{[18]}$ estiman la prima salarial por riesgo de accidente mortal con datos de asalariados españoles para el periodo 1995-2001, que combinada con el salario medio da lugar al valor de una vida estadística (VVE) o valoración monetaria que la sociedad atribuye a evitar que una persona cualquiera fallezca. Los resultados principales de sus estimaciones se muestran en la tabla 4.3.

TABLA 4.3. ESTIMACIONES DE LA PRIMA SALARIAL Y DEL VALOR DE UNA VIDA ESTADÍSTICA

\begin{tabular}{|c|c|c|c|c|c|}
\hline \multicolumn{2}{|c|}{ RIESGOS ANUALES } & \multicolumn{2}{|c|}{ RIESGOS MEDIOS 3 AÑOS } & \multicolumn{2}{c|}{ RIESGOS MEDIOS 7 AÑOS } \\
\hline Prima salarial & VVE $(€)$ & Prima salarial & VVE $(€)$ & Prima salarial & VVE $(€)$ \\
\hline 0,067 & 758.000 & 0,132 & 1.447 .000 & 0,125 & 1.407 .000 \\
\hline
\end{tabular}

VVE: Valor de una Vida Estadística.

Fuente: elaboración propia a partir de Martínez et al. ${ }^{[18]}$

El método de los precios hedónicos posee dos limitaciones fundamentales. De una parte, se apoya en unos supuestos poco realistas acerca del funcionamiento de los mercados, que 
distan de ser perfectamente competitivos. Asimismo, dado que sus estimaciones se basan en las decisiones observadas en mercados reales, este método no puede ofrecer valoraciones altruistas o de no uso de los bienes intangibles.

\subsubsection{Métodos de preferencias declaradas}

Los métodos de preferencias declaradas, también denominados de mercados simulados, recaban las preferencias de la población de forma directa, no implícita, mediante la utilización de cuestionarios. Dos son las familias de métodos de este tipo existentes: valoración contingente y valoración multiatributo.

El método de la valoración contingente recrea mediante una encuesta la contingencia de un mercado donde el encuestador representa el papel de la oferta, el encuestado el de la demanda y el precio de mercado viene dado por la máxima cantidad de dinero que el encuestado está dispuesto a pagar (disposición a pagar) por una mejora hipotética en la salud. Esta disposición a pagar representa la suma de dinero que habría que sustraerle al individuo para mantenerlo en su nivel de bienestar previo a dicha mejora (variación compensada). De modo alternativo, podría preguntarse al encuestado por la mínima suma de dinero que estaría dispuesto a aceptar (disposición a aceptar) como compensación por no beneficiarse de la intervención sanitaria. La disposición a aceptar (DAA) representa la cuantía monetaria que habría que darle al sujeto para mantenerlo en su nivel de bienestar posterior a la mejora planteada (variación equivalente). Estos conceptos de variación compensada (VC) y equivalente (VE) no son sino valoraciones monetarias del cambio en el excedente del consumidor. De forma análoga, puede inquirirse por la DAA y la DAP en el caso de un cambio que representa un deterioro en el bienestar. Las cuatro posibles variables proxies resultantes, según se plantee una ganancia o pérdida de bienestar, se resumen en la tabla 4.4.

\section{TABLA 4.4. RELACIÓN ENTRE VARIACIÓN COMPENSADA, VARIACIÓN EQUIVALENTE, DISPOSICIÓN A PAGAR Y DISPOSICIÓN A ACEPTAR}

\begin{tabular}{l|c|c}
\hline & VARIACIÓN COMPENSADA & VARIACIÓN EQUIVALENTE \\
\hline Ganancia de bienestar & DAP por un cambio positivo & DAA por renunciar a un cambio positivo \\
\hline Pérdida de bienestar & DAA por asumir un cambio negativo & DAP por evitar un cambio negativo \\
\hline & \\
\hline DAP: Disposición A Pagar. DAA: Disposición A Aceptar.
\end{tabular}

Fuente: elaboración propia a partir de Drummond et al. ${ }^{[10]}$

Hay una serie de aspectos clave que deben tenerse en cuenta a la hora de diseñar y administrar un cuestionario de valoración contingente ${ }^{[19]}$ :

- Definición del producto (descripción detallada del efecto);

- Perspectiva de la valoración (ex ante, ex post, altruista);

- Definición del modo de pago (impuestos, tasas, precios);

- Elección del tipo de pregunta (abierta, subasta, cartón de pagos, dicotómica);

- Forma de administración de las encuestas (personales, telefónicas, postales, asistidas por ordenador, experimentos de laboratorio);

- Elección de la población relevante (muestras de conveniencia, población general);

- Agregación de las preferencias (media o mediana de las DAP o DAA individuales). 
El método de la valoración contingente ofrece varias ventajas respecto de las técnicas de preferencias reveladas, como es que permite análisis prospectivos y valorar los componentes de no uso de los intangibles. Su principal desventaja radica en los diversos sesgos que pueden afectar a las preferencias declaradas por los encuestados. Algunos de estos sesgos son consustanciales a la naturaleza hipotética de los escenarios planteados en los cuestionarios (sesgo de hipótesis), otros tienen que ver con errores cometidos en el muestreo (sesgo de selección), otros con incentivos que genera el ejercicio a la declaración de valores falsos (sesgo estratégico) y otros, finalmente, guardan relación con la especificación de los escenarios (efecto incrustación) y de las preguntas utilizadas (sesgo del punto de partida).

Van den Berg et al. ${ }^{[20]}$ estiman la DAP y la DAA de cuidadores informales y de los dependientes a su cargo por prestar o recibir (no prestar o renunciar a recibir) una hora adicional de cuidados informales a la semana. Los resultados obtenidos para una muestra de pacientes de artritis reumatoide y sus cuidadores (comparables, por tanto, con los mostrados en la tabla 4.2) se recogen en la tabla 4.5. Como puede apreciarse, la DAA es significativamente superior a la DAP, discrepancia atribuida comúnmente al sesgo conocido como efecto dotación ${ }^{[21]}$ Este sesgo refleja la sobrevaloración otorgada al bien que se posee (la dotación de partida o statu quo), de modo que su precio de venta, para una misma magnitud (1 hora en este caso), excede al de compra. En España, Garrido-García et al. ${ }^{[22]}$ amplían el análisis a la población general, obteniendo DAA de escenarios hipotéticos.

\section{TABLA 4.5. DAP Y DAA POR PRESTAR O RECIBIR UNA HORA ADICIONAL DE CUIDADOS INFORMALES (EN €) Y P-VALUES DE LA DIFERENCIA DAP-DAA}

\begin{tabular}{|l|c|c|c|}
\hline & MEDIA DAP & MEDIA DAA & DAP - DAA \\
\hline Pacientes & 7,84 & 8,22 & $P=0,1789$ \\
\hline Cuidadores informales & 7,80 & 9,52 & $P=0,0077$ \\
\hline
\end{tabular}

DAP: Disposición A Pagar. DAA: Disposición A Aceptar

Fuente: elaboración propia a partir de van den Berg et al. ${ }^{[20]}$

Los métodos de valoración multiatributo permiten en teoría mitigar algunos de los sesgos que origina la valoración explícita de la salud en términos monetarios, al tiempo que posibilitan la valoración relativa de todo tipo de atributos, ya sean atributos de resultado (p.ej. ganancia de esperanza de vida) o de proceso (p.ej. tiempo de espera).

Como su propio nombre sugiere, estos métodos se basan en la descripción de un bien por medio de los atributos o dimensiones que lo caracterizan. Por ejemplo, un medicamento podría describirse como una combinación de atributos como dosis, efectividad, efectos adversos y precio. A continuación, el entrevistado ordena, puntúa o elige entre varias de estas alternativas multiatributo. Las respuestas proporcionadas permiten identificar las relaciones de intercambio que existen entre los diferentes atributos, infiriendo así, por ejemplo, la tasa a la que los encuestados están dispuestos a exponerse a sufrir efectos adversos más graves a cambio de una mayor efectividad del medicamento. Si el precio del tratamiento se incluye como un atributo más, entonces puede estimarse la DAP por cualquiera de los atributos. Si además se incluye entre las alternativas presentadas a los sujetos una representativa del 
statu quo (la situación previa a la intervención), entonces es posible calcular la DAP por el conjunto del bien intangible, definido por la combinación de sus atributos.

El tipo de tareas requeridas en los cuestionarios permite clasificar a los métodos de valoración multiatributo en dos grandes grupos: análisis conjunto y experimentos de elección. El análisis conjunto pide a los encuestados bien que ordenen (ordenación contingente) el conjunto de las alternativas seleccionadas, de más a menos preferida, bien que puntúen (puntuación contingente) una a una cada alternativa sobre una escala. Los experimentos de elección presentan una serie de elecciones entre dos o más alternativas. Cuando las elecciones son dicotómicas la tarea recibe el nombre de comparaciones o elecciones pareadas. Un caso particular lo representan las tareas consistentes en realizar una elección dicotómica, seguida de la puntuación de la opción más preferida.

Pese a las ventajas que parece ofrecer este tipo de métodos, no están exentos de problemas como, por ejemplo, el mayor esfuerzo cognitivo que demandan de los entrevistados ${ }^{[15]}$. Otra potencial limitación radica en que solo las tareas basadas en elecciones son consistentes con la idea de emular el comportamiento de mercado a través de un cuestionario, ya que eso es lo que hacen los consumidores en los mercados, elegir. Las técnicas del análisis conjunto serían, por tanto, cuestionables desde este punto de vista ${ }^{[1]}$.

TABLA 4.6. COMPENSACIÓN MONETARIA DE LOS CUIDADORES INFORMALES

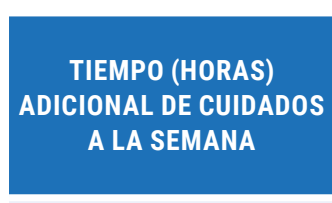

$7 \rightarrow 8$

$14 \rightarrow 15$

$21 \rightarrow 22$

$7 \rightarrow 14$

$14 \rightarrow 21$

$7 \rightarrow 21$

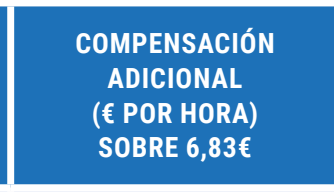

1,25

0,68

0,46

4,43

3,13

5,53

Fuente: elaboración propia a partir de van den Berg et al. ${ }^{[23]}$ experimentan y no por sus preferencias hipotéticas o subrogadas. Para ello se utilizan diferentes medidas de satisfacción con la vida o felicidad. Se añade a esta información las características personales de los encuestados, incluyendo su renta, y los problemas de salud 
que padecen. A continuación, por último, se emplean técnicas econométricas para inferir la cantidad de renta adicional que habría que entregar a los encuestados para compensarles por la pérdida de bienestar ocasionada por una determinada enfermedad ${ }^{[17,24]}$.

La gran ventaja de este método es que para su aplicación no hay que hacer supuestos restrictivos sobre el funcionamiento de los mercados, como ocurre con los métodos de preferencias reveladas, ni tampoco está sujeto a los sesgos propios de los métodos de preferencias declaradas. No obstante, la idoneidad de valorar la salud por medio de medidas de utilidad experimentada es un asunto sujeto a debate y adecuado únicamente para evaluaciones retrospectivas.

La tabla 4.7 recoge los proxies financieros estimados con este método por Powdthavee et al. ${ }^{[25]}$ para una muestra de la población británica. Se ofrecen las estimaciones obtenidas empleando dos medidas de bienestar diferentes, una escala genérica de satisfacción con la vida y otra de salud autorreportada. Como puede apreciarse las valoraciones registradas con estas dos escalas son muy diferentes, lo cual introduce gran incertidumbre en este tipo de ejercicios. Así, por ejemplo, conseguir que alguien que padece de problemas digestivos esté igual de satisfecho con la vida que alguien que no tiene dichos problemas, requiere de una compensación monetaria por año de 77.000 euros. Sin embargo, conseguir que su salud autorreportada sea equivalente a la de alguien que no sufre de problemas digestivos, precisa de una compensación de alrededor de 38 millones de euros.

\section{TABLA 4.7. COMPENSACIÓN NECESARIA PARA ALCANZAR LA SATISFACCIÓN DE UNA PERSONA QUE NO TIENE EL PROBLEMA DE SALUD (EN €)}

\begin{tabular}{|l|c|c|}
\hline \multicolumn{1}{|c|}{ RENTA COMPENSADA } & SATISFACCIÓN CON LA VIDA & SALUD AUTORREPORTADA \\
\hline Problemas respiratorios & 13.000 & 1.586 .000 \\
\hline Problemas digestivos & 77.000 & 38.050 .000 \\
\hline Diabetes & 6.000 & 1.482 .000 \\
\hline
\end{tabular}

Fuente: elaboración propia a partir de Powdthavee et al. ${ }^{[25]}$

\subsection{CONCLUSIONES}

La valoración del impacto social de las intervenciones sanitarias no puede capturarse adecuadamente mediante un análisis estrictamente económico del rendimiento de la inversión realizada o planeada. El enfoque del SROI ofrece un marco cuyo principal objetivo es precisamente evaluar el retorno social de las intervenciones. Para conseguir esta meta es preciso identificar todos los outcomes relevantes, no sólo aquellos que resultan fáciles de medir porque pasan por el mercado. Para monetizar los outcomes intangibles, como es el caso de los impactos de las intervenciones sanitarias, es preciso estimar proxies adecuados.

Los efectos causados por las intervenciones sanitarias pueden estar relacionados directamente con los resultados en salud, pero también pueden guardar relación con el proceso asistencial o incluso rebasar el ámbito sanitario impactando en otros sectores. Los efectos de salud, a su vez, pueden ser directos, pero también indirectos, mediados por característi- 
cas ambientales y personales colaterales al efecto inmediato de la intervención. Por último, el valor total de una intervención también comprende componentes de no uso que pueden resultar relevantes como, por ejemplo, el valor altruista derivado de la provisión de cobertura sanitaria a terceros.

Hay diferentes métodos para determinar los proxies financieros de los bienes intangibles: métodos de preferencias reveladas, de preferencias declaradas y de valoración del bienestar. Recurrir a uno u otro método es una decisión que requiere considerar no sólo cuestiones de oportunidad metodológica, sino también de coste. Es más sencillo valorar el impacto de un tratamiento para una alergia respiratoria por los gastos de mitigación de la enfermedad aparejados que por medio de un estudio de preferencias reveladas en entornos laborales propicios a tales reacciones alérgicas. Sin embargo, en el primer caso no estaremos computando la partida más importante, aquella directamente relacionada con el sufrimiento que provoca la patología, mientras que en el segundo caso la estaremos aproximando, siquiera de forma imperfecta. Únicamente mediremos, eso sí, el valor de uso del tratamiento, ignorando otros impactos sobre terceros. Además, la valoración efectuada será retrospectiva, no prospectiva. Si lo que nos interesa es predecir el valor social creado por una intervención aún no implementada, abarcando además valores de no uso, entonces conviene utilizar métodos de preferencias declaradas. De estos, es la valoración contingente la metodología más extensamente empleada en el ámbito sanitario, si bien los experimentos de elección discreta comienzan a ser muy populares en esta área. Decantarse por uno u otro método depende de cuál sea el objetivo perseguido. Si lo que se pretende exclusivamente es monetizar el intangible, entonces la valoración contingente es la mejor opción. Si, además, quiere conocerse el valor relativo de los diferentes atributos en que podemos descomponer dicho bien intangible, entonces los experimentos de elección son la alternativa. Otro tipo de métodos como la valoración del bienestar también empiezan a despuntar, si bien el volumen de aplicaciones realizadas es aún muy reducido en comparación con métodos consolidados como los ya referidos. 


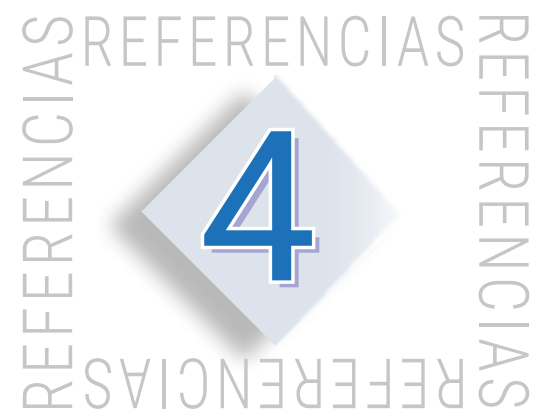

1. Pinto-Prades J-L, Vázquez MX, Lázaro A, Martínez JE. Análisis coste-beneficio en la salud. Métodos de valoración y aplicaciones. Barcelona: Masson; 2003. Disponible en: https://www.libreriaserendipia.com/libro/analisis-coste-beneficio-en-la-salud_66141

2. Emerson J, Twersky F. New Social Entrepreneurs: The Success, Challenge, and Lessons of Non-Profit Enterprise Creation. San Francisco: The Roberts Foundation; 1996. Disponible en: https://www.scirp.org/(S(i43dyn45teexjx455qlt3d2q))/reference/ReferencesPapers.aspx?ReferencelD $=1661181$

3. Emerson J, Wachowicz J, Chun S. Social return on investment: exploring aspects of value creation in the nonprofit sector. En: Social purpose enterprises and venture philanthropy in the new millennium. San Francisco (CA): Roberts Enterprise Development Fund; 1999. p. Vol. 132-173. Disponible en: http://redf.org/app/uploads/2013/10/REDF-Box-Set-Vol.-2-SROI-Paper-2000.pdf

4. Krlev G, Münscher R, Mülbert K. Social Return on Investment (SROI): state-of-the-art and perspectives - a meta-analysis of practice in Social Return on Investment (SROI) studies published 20022012. Heidelberg: (CSI) Centre for Social Investment, Heidelberg University; 2013 nov. Disponible en: http://archiv.ub.uni-heidelberg.de/volltextserver/18758/1/CSI_SROI_Meta_Analysis_2013.pdf

5. Lawlor E, Neitzert E, Nicholls J. Measuring value: a guide to Social Return on Investment (SROI). 2nd edition. London: NEF (the new economics foundation); 2008.

6. Nicholls J, Lawlor E, Neitzert E, Goodspeed T. A guide to Social Return on Investment. UK: The SROI Network. Accounting for Value; 2012. Disponible en: http://www.socialvalueuk.org/app/ uploads/2016/03/The\%20Guide\%20to\%20Social\%20Return\%20on\%20Investment\%202015.pdf

7. Banke-Thomas AO, Madaj B, Charles A, van den Broek N. Social Return on Investment (SROI) methodology to account for value for money of public health interventions: A systematic review. BMC Public Health. 2015;15(1):582-95.

8. Gargani J. The leap from ROI to SROI: Farther than expected? Evaluation and Program Planning. 2017;64:116-26.

9. Gold MR, Siegel JE, Russell LB, Weinstein MC, editores. Cost-Effectiveness in Health and Medicine. New York: Oxford University Press; 1996. 448 p.

10. Drummond MF, Sculpher MJ, Claxton K, Stoddart GL, Torrance GW. Methods for the Economic Evaluation of Health Care Programmes. 4th ed. Oxford University Press; 2015. 461 p.

11. Sánchez Fl, Abellán JM, Martínez JE. Métodos de evaluación económica para la toma de decisiones en el sector sanitario. En: Cabo Salvador J, editor. Gestión sanitaria integral: pública y privada. Madrid: CEF; 2010. Disponible en: https://tienda.cef.udima.es/libros/gestion-sanitaria-integral-publica-privada.html 
12. Freeman AM. The measurement of environmental and resource values: Theory and methods. Washington D.C.: Resources for the Future; 1993.

13. Olsen A, Smith RD. Theory versus practice: a review of «willingness-to-pay» in health and health care. Health Econ. enero de 2001;10(1):39-52.

14. van den Berg B, Brouwer WBF, Koopmanschap MA. Economic valuation of informal care: An Overview of Methods and Applications. HEPAC. 2004;5(1):36-45.

15. van den Berg B, Al M, Brouwer WBF, van Exel NJA, Koopmanschap MA. Economic valuation of informal care: The conjoint measurement method applied to informal caregiving. Soc Sci Med. septiembre de 2005;61(6):1342-55.

16. van den Berg B, Brouwer WBF, van Exel NJA, Koopmanschap MA, van den Bos GAM, Rutten FFH. Economic valuation of informal care: Lessons from the application of the opportunity costs and proxy good methods. Soc Sci Med. febrero de 2006;62(4):835-45.

17. Fujiwara D, Campbell R. Valuation techniques for social cost-benefit analysis: stated preference, revealed preference and subjective well-being approaches: a discussion of the current issues. London: HM Treasury; 2011. Disponible en: http://research.dwp.gov.uk/asd/asd5/greenbook_valuationtechniques.pdf

18. Martínez JE, Méndez I. ¿Qué podemos saber sobre el Valor Estadístico de la Vida en España utilizando datos laborales? Hacienda Pública Española. 2009;191(3):73-93.

19. Pinto JL, Sánchez FI. Métodos para la evaluación económica de nuevas prestaciones. Ministerio de Sanidad y Consumo; 2003. Disponible en: http://www.mspsi.gob.es/va/estadEstudios/estadisticas/docs/metodos_evaluacion.pdf

20. van den Berg B, Bleichrodt $H$, Eeckhoudt $L$. The economic value of informal care: A study of informal caregivers' and patients' willingness to pay and willingness to accept for informal care. Health Econ. abril de 2005;14(4):363-76.

21. Kahneman D, Knetsch JL, Thaler RH. Anomalies: The Endowment Effect, Loss Aversion, and Status Quo Bias. Journal of Economic Perspectives. marzo de 1991;5(1):193-206.

22. Garrido-García S, Sánchez-Martínez FI, Abellán-Perpiñán JM, van Exel J. Monetary Valuation of Informal Care Based on Carers' and Noncarers' Preferences. Value Health. septiembre de 2015;18(6):832-40.

23. van den Berg B, Al M, van Exel NJA, Koopmanschap MA, Brouwer F. Economic Valuation of Informal Care: Conjoint Analysis Applied in a Heterogeneous Population of Informal Caregivers. Value in Health. 1 de diciembre de 2008;11(7):1041-50.

24. van den Berg B, Ferrer-I-Carbonell A. Monetary valuation of informal care: The well-being valuation method. Health Econ. noviembre de 2007;16(11):1227-44.

25. Powdthavee N, van den Berg B. Putting different price tags on the same health condition: Re-evaluating the well-being valuation approach. J Health Econ. septiembre de 2011;30(5):1032-43. 


\section{CAPÍTULO}

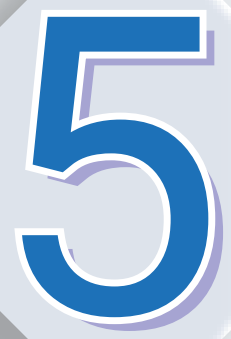

LAS PREFERENCIAS

DEL PACIENTE: VALOR AÑADIDO DEL SROI

Jaime Espín 


\subsection{INTRODUCCIÓN}

Existe un gran número de instrumentos y técnicas que ayudan a los gestores sanitarios a tomar decisiones sobre qué nuevas tecnologías y medicamentos incorporar en los sistemas sanitarios. La evaluación económica ha ocupado un papel muy importante como instrumento para la financiación de nuevas prestaciones sanitarias, pero hay dos críticas habituales al uso de la evaluación económica como instrumento para la toma de decisiones: 1) por un lado, no suele incorporar la preferencia de los pacientes, y 2) no suele cuantificar el valor social de las intervenciones. Si bien esas críticas son legítimas, hay que tener en cuenta la dificultad que tiene la incorporación de las preferencias y del valor social, ya que tradicionalmente se utilizan métodos de valoración.

Como hemos visto en los capítulos anteriores, uno de los principios de SROI (Social Return On Investment) es la involucración de los distintos actores (stakeholders) en el proceso evaluativo ${ }^{[1]}$. Los pacientes son parte de este grupo de actores clave pero, sin embargo, el método SROI tiene un enfoque más amplio y selecciona como actores clave a todos aquellos que pueden verse influenciados en la toma de decisiones. El debate puede surgir si para tener una visión más completa debemos involucrar a los pacientes que son muy buenos conocedores de su patología o, por otro lado, incorporar a la ciudadanía que nos puede dar una visión más objetiva de cuáles deben ser las prioridades en materia de financiación sanitaria.

Sin duda alguna, utilizar el método SROI tiene dos grandes ventajas: por un lado, al medir el impacto social de toda la intervención sanitaria, plantea una visión más amplia y permite una mayor participación de los posibles beneficiarios de la intervención; por otro lado, las intervenciones sanitarias las entiende como una inversión y no como un gasto.

\section{2. ¿QUÉ SON LAS PREFERENCIAS DEL PACIENTE?}

Una vez que se han identificado a los pacientes como uno de los grupos clave, el siguiente paso es clarificar qué entendemos por preferencias de los pacientes. Hay que recordar que los distintos actores que participan en el método SROI nos van a ayudar a definir cuáles son los resultados que queremos medir, que tradicionalmente en evaluación económica son puramente clínicos, más la calidad de vida que se tiene en cuenta cuando hacemos estudios de coste-utilidad (años de vida ajustados por calidad). Si bien las preferencias de los pacientes pueden tenerse en cuenta, hay que tener un equilibrio entre resultados objetivos y subjetivos (hay que resaltar que algunos países del entorno europeo no toman en cuenta los PRO - Patient Reported Outcomes o Resultados Reportados por los Pacientes - debido a la subjetividad de los instrumentos).

Para determinar el estado de salud y la calidad de vida relacionada con éste, vamos a utilizar dos enfoques. El primer enfoque tiene que ver con las preferencias del paciente y el valor que le da al estado de salud (tradicionalmente utilizado en los estudios de coste-beneficio); el segundo enfoque tiene que ver con medir el estado de salud y la calidad de vida (tradicionalmente utilizado en los estudios de coste-utilidad). Véase la figura 5.1 con la descripción de la taxonomía de calidad de vida relacionada con la salud. 


\section{FIGURA 5.1. TAXONOMÍA DE LA CALIDAD DE VIDA RELACIONADA CON LA SALUD}

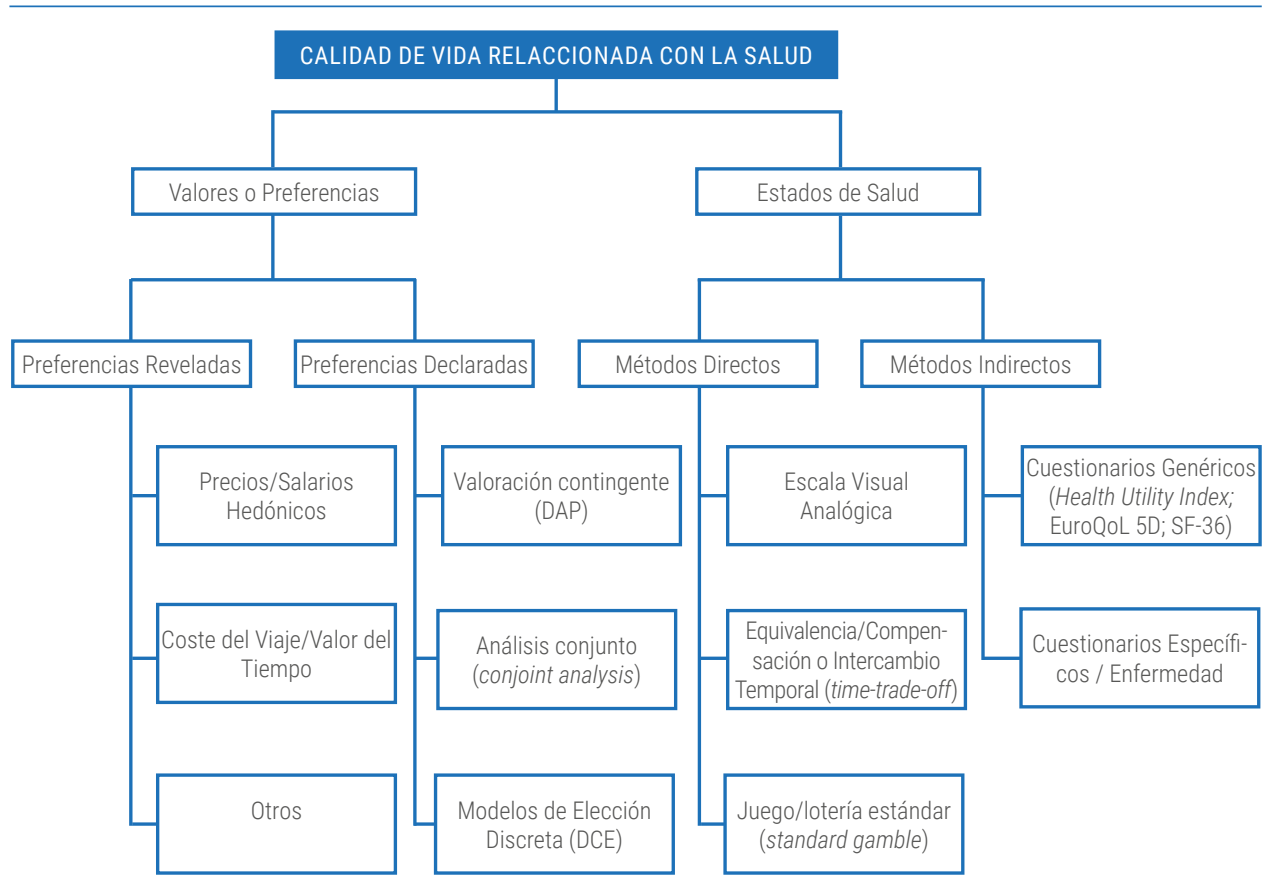

DAP: Disposición A Pagar. DCE: Discrete Choice Experiment.

Fuente: elaboración propia a partir de Yepes-Núñez et al. ${ }^{[2]}$

\section{3. ¿DE QUÉ MÉTODOS DISPONEMOS PARA CONOCER LAS PREFERENCIAS DEL PACIENTE?}

Uno de los ejercicios más complicados que tenemos cuando hacemos cualquier tipo de evaluación es la de asignar un valor a los resultados en salud. En algunos casos, algunos de los inputs que se utilizan en SROI suelen tener una fácil valoración económica (por ejemplo, un día de estancia hospitalaria se puede obtener de las tarifas públicas o a través de la contabilidad analítica del hospital). Sin embargo, para asignar valor a las cosas que tienen más difícil valoración, hay distintas metodologías disponibles que se detallan a continuación.

Adicionalmente, hay que resaltar que el método SROI tiene como uno de sus principios la monetización, asignándole un valor monetario al impacto social que se mide. Sin embargo, asignarle un valor monetario a las intervenciones no es fácil (¿cuál es el valor de la obligatoriedad del uso del casco en la motocicleta o el del cinturón de seguridad en el coche?), por lo que con las preferencias reveladas que veremos más adelante podemos entender que el precio sea una aproximación (proxy) al valor ${ }^{[3]}$.

\subsubsection{Métodos de preferencia revelada}

Los métodos de preferencia revelada son técnicas indirectas para conocer el valor de bienes de difícil valoración, por ser, en la mayoría de las veces, bienes que no pasan por el mercado. En estos casos, se observan las decisiones que toman los individuos y en base a ellas se infiere "su disponibilidad a intercambiar recursos financieros por estas consecuencias sobre el estado de salud"/4]. 
En las decisiones públicas también podemos ver ejemplos donde, de una manera implícita, se le da un valor a la vida, como la obligatoriedad de llevar casco o cinturón de seguridad ${ }^{[5]}$.

Entre los métodos de preferencias reveladas se encuentran los precios/salarios hedónicos, mediante los cuales se puede estimar el riesgo que se quiera asumir en función de la renta/ salario que se solicita. Por ejemplo, en el supuesto caso de que un colectivo concreto solicite una compensación de $600 €$ por desempeñar un empleo que tiene un riesgo anual de $2 \%$ de morir, en este caso el valor monetario de la vida son $30.000 €(=600 / 0,02)$.

Otro método de preferencia revelada es el de coste del viaje/valor del tiempo por el que podemos trasladar a términos monetarios la disponibilidad de la gente a viajar o perder tiempo para tener acceso a bienes o servicios que para ellos tienen valor.

Algunos métodos adicionales son el método de los costes evitados o el método de las aportaciones voluntarias sobre los que se puede encontrar información adicional en la literatura especializada pero que se mencionan aquí para destacar el amplio abanico de opciones metodológicas existentes para las preferencias reveladas.

\subsubsection{Métodos de preferencia declarada}

A diferencia de los métodos vistos anteriormente, existen métodos directos de revelación de preferencias para la valoración de los bienes no-mercado, entre los que se encuentra el método de la valoración contingente y el análisis conjunto.

El método de la valoración contingente es uno de los más utilizados a través de encuestas a los consumidores. Con este tipo de encuestas, a través de preguntas sobre la disposición a pagar (DAP), podemos saber el valor que los ciudadanos están dispuestos a pagar por un conjunto de bienes sobre los que no tenemos valor de mercado. Sin entrar en algunos detalles metodológicos (entrevista personal, telefónica, correo...), sin duda alguna constituye un método bastante utilizado para conocer la opinión directa de los consumidores sobre el valor de un bien. Algunos autores ya han señalado alguna de las limitaciones de utilizar este tipo de métodos, como por ejemplo que las preguntas son hipotéticas y que no hay ningún incentivo para decir la verdad, esto produce un conjunto de sesgos (hipotéticos y estratégicos) bien documentados en la literatura ${ }^{[4]}$.

En esta misma línea de métodos de preferencia declarada se encuentra el método de análisis conjunto (conjoint analysis) en el que las distintas alternativas están descritas con un conjunto de calidades que constituyen los atributos del bien y que pueden combinarse para formar situaciones hipotéticas. Al entrevistado se le pedirá que clasifique las alternativas según esos atributos en su conjunto, con lo que se obtendrán las utilidades que los individuos otorgan a ese bien.

Muy relacionado con el análisis conjunto, pero con algunas diferencias ${ }^{[6]}$, se encuentran los modelos de elección discreta (Discrete Choice Experiment - DCE) que sirven "para estimar la disponibilidad marginal a pagar por un incremento en la provisión del bien"[4]. Quizás una de las principales diferencias entre los métodos de elección discreta y los de análisis conjunto es que en los métodos de elección discreta los participantes tienen que elegir opciones y en los métodos de análisis conjunto tienen que hacer más tareas de clasificación y calificación. 
Existen un número importante de artículos en la literatura en los últimos años que realizan DCE para conocer la DAP, aunque como hemos comentado antes la DAP se puede obtener con otros métodos ${ }^{[7]}$. En el caso de los DCE, en primer lugar se definen una serie de atributos (generalmente a través de una revisión de la literatura - como por ejemplo en Stenehjem et al. $\left.{ }^{[8]}\right)$ junto con los distintos niveles que pueden tener esos atributos. Si utilizamos un ejemplo centrado en oncología, los distintos atributos y niveles pueden ser (Tabla 5.1):

TABLA 5.1. ATRIBUTOS Y NIVELES POSIBLES EN UN DISCRETE CHOICE EXPERIMENT

\begin{tabular}{|c|c|}
\hline ATRIBUTOS & NIVELES \\
\hline Supervivencia (años) & $0,1,2,3,4,5,6$ \\
\hline Toxicidad (\%) & $0,10,20,30$ \\
\hline Vía de administración & Oral, intravenosa, subcutánea \\
\hline Precio (euros mes) & $1.000,5.000,10.000$ \\
\hline
\end{tabular}

Fuente: elaboración propia.

Ese conjunto de atributos y niveles nos ayudarán a configurar cada uno de los escenarios posibles (Tabla 5.2) a través de los distintos programas informáticos disponibles.

TABLA 5.2. EJEMPLO DE DISCRETE CHOICE EXPERIMENT

\begin{tabular}{l|cc}
\hline \multicolumn{1}{c}{ OPCIÓN 1 } & MEDICAMENTO A & MEDICAMENTO B \\
\hline Supervivencia (años) & 3 & 1 \\
\hline Toxicidad (\%) & 30 & 0 \\
\hline Vía de administración & Intravenosa & Oral \\
\hline Precio (euros mes) & 10.000 & 1.000 \\
\hline Preferencia & $\checkmark$ & \\
\hline
\end{tabular}

Fuente: elaboración propia.

\subsection{MEDICIÓN DE LA CALIDAD DE VIDA DE LOS PACIENTES}

Como hemos visto anteriormente, el papel de los pacientes es clave para trasladar sus preferencias a unidades monetarias a través de los distintos métodos que hemos visto anteriormente. Ese tipo de metodología es muy utilizada en los estudios de coste-beneficio, donde los beneficios se trasladan a unidades monetarias.

Sin embargo, en los últimos años los estudios de coste-utilidad han tomado una relevancia mayor y es necesario disponer de diversos instrumentos que midan la calidad de vida de los pacientes. Las utilidades son unidades de efectividad compuestas por dos variables: años de vida y calidad de vida, y que dan como resultado los años de vida ajustados por calidad (AVAC). La calidad de vida se mide en escalas que van de 0 (muerte) a 1 (estado de salud perfecto).

\subsubsection{Métodos directos de medición de calidad de vida}

La escala visual analógica (EVA) es un método directo para medir la calidad de vida de los pacientes, en muchos casos centrado en el dolor (Figura 5.2). Es un método sencillo, pero tiene algunos sesgos (por ejemplo, en las respuestas los pacientes no suelen utilizar los extremos). 
FIGURA 5.2. ESCALA VISUAL ANALÓGICA

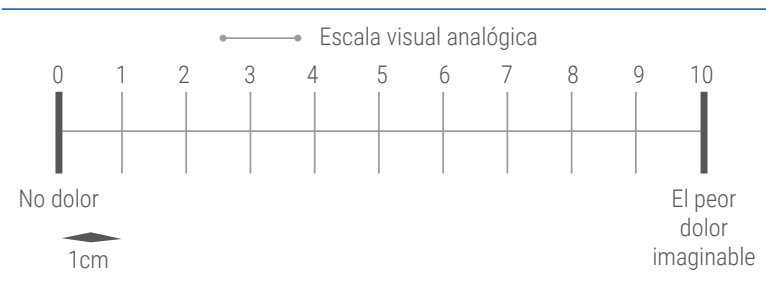

Fuente: elaboración propia.
Existen otros métodos directos de medición de la calidad de vida como son el juego/lotería están dar (standard gamble) "en el que la calidad de vida se mide por el riesgo de muerte que una persona está dispuesta a asumir por evitar un cierto problema de salud"[i]. En la lotería estándar se comparan dos alternativas. En la opción 1 hay dos posibles resultados: el paciente recupera su estado de salud normal durante un número de años (p) o muere (1-p). En la opción 2 el paciente se mantiene en su estado de enfermedad. Se van modificando sus probabilidades hasta que el paciente se muestra indiferente ante ambas alternativas (Figura 5.3).

FIGURA 5.3. EJEMPLO DE LOTERÍA ESTÁNDAR (3 SECUENCIAS)

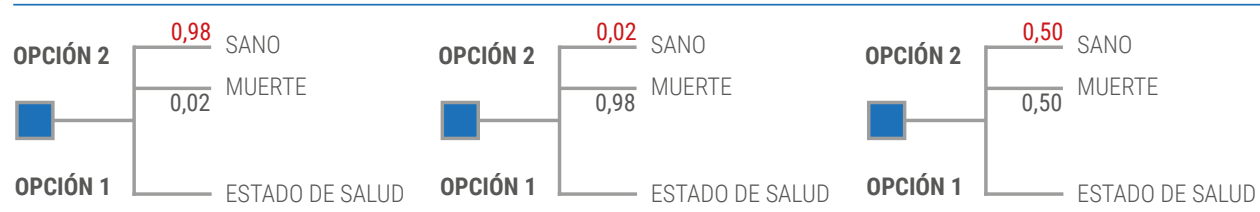

Fuente: elaboración propia.

El tercer método directo para medir la calidad de vida es la equivalencia/compensación o intercambio temporal (time-trade-off), donde se consulta sobre la cantidad de vida que una persona está dispuesta a ceder para mejorar su calidad de vida. La literatura ${ }^{[0]}$ señala algunos ejemplos que pueden representarse en la figura 5.4: si una persona con una esperanza de vida de 30 años está dispuesta a ceder 6 años para no estar ciega, esa preferencia nos indica que la utilidad de estar ciego es $0,8(24 / 30=0,8)$.

FIGURA 5.4. ESQUEMA DE LA COMPENSACIÓN TEMPORAL

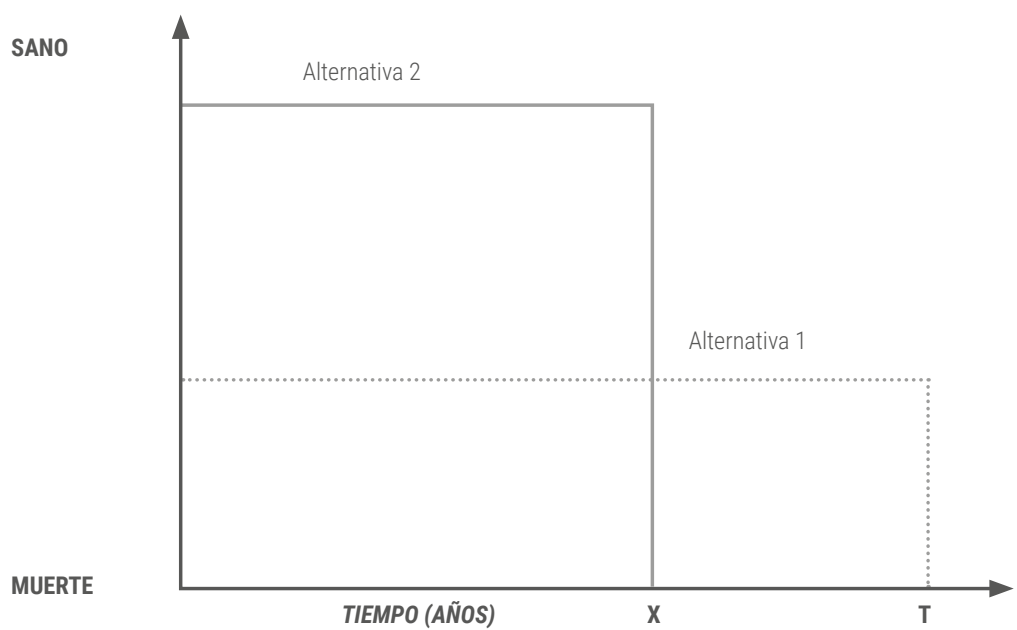

Fuente: elaboración propia. 
La elección de un método directo de medición de calidad de vida u otro nos dará resultados distintos ante la misma pregunta, tal y como nos ha demostrado la literatura ${ }^{[10]}$.

\subsubsection{Métodos indirectos de medición de calidad de vida}

Los métodos indirectos de calidad de vida son principalmente cuestionarios, generales o específicos, que se utilizan para conocer el estado de salud. Existen principalmente tres cuestionares generales (Health Utilities Index [HUI], SF-36 y el EQ-5D) y un número importante de cuestionarios específicos según enfermedades concretas. Este tipo de cuestionarios se consideran como indirectos porque se selecciona una muestra de la población, a la que se le hace una valoración directa de los estados de salud con los cuestionarios comentados anteriormente (Figura 5.5), y mediante técnicas estadísticas, se estiman unas tarifas (también conocidas como "utilidades") para la población general. Este tipo de cuestionarios son muy utilizados cuando queremos realizar estudios de coste-utilidad.

\section{FIGURA 5.5. CUESTIONARIO DE CALIDAD DE VIDA EUROQOL-5D}

CUESTIONARIO DE SALUD EUROQOL -5D

Marque con una cruz la respuesta de cada apartado que mejor describa su estado de salud en el día de HOY.

\section{Movilidad}

No tengo problemas para caminar

Tengo algunos problemas para caminar

Tengo que estar en la cama.

\section{Cuidado Personal}

No tengo problemas con el cuidado personal.

Tengo algunos problemas para lavarme o vestirme

Soy incapaz de lavarme o vestirme

Actividades cotidianas (p. ej, trabajar, estudiar, hacer las tareas domésticas,

actividades familiares 0 actividades durante el tiempo libre)

No tengo problemas para realizar mis actividades cotidianas.

Tengo algunos problemas para realizar mis actividades cotidianas

Soy incapaz de realizar mis actividades cotidianas....

\section{Dolor/Malestar}

No tengo dolor ni malestar

Tengo moderado dolor o malestar ....

Tengo mucho dolor o malestar......

\section{Ansiedad/Depresión}

No estoy ansioso ni deprimido

Estoy moderadamente ansioso o deprimido

Estoy muy ansioso o deprimido .....

Fuente: www.euroqol.org 


\subsection{CÓMO SE INCORPORAN EN EL SROI: EMPODERAMIENTO DEL PACIENTE}

La reciente literatura sobre SROI ${ }^{[11]}$ no habla expresamente del papel del paciente sino que tiene una perspectiva más amplia y menciona a todos los beneficiarios de la intervención sanitaria que se piensa evaluar como participantes en el proceso. Un trabajo reciente de Nicholls ${ }^{[12]}$ comparando SROI con otros enfoques (por ejemplo, estudios de coste-beneficio) demuestra que una de las principales ventajas es la participación de los beneficiarios. El método SROI menciona el concepto de stakeholders, que puede ser traducido como "partes interesadas" o "grupos de interés", siendo éste un concepto más amplio que beneficiarios ( $y$, sin duda, que pacientes). Hay que destacar en este aspecto que la primera fase de toda evaluación realizada con SROI conlleva un establecimiento del alcance de la evaluación y una selección de los actores clave de la intervención.

Un estudio publicado por Durán Piñeiro et al. ${ }^{[13]}$ en que realiza un análisis con el método SROI sobre "e-interconsulta de cardiología en un área" clarifica que los stakeholders beneficiarios son los pacientes, los acompañantes, los profesionales sanitarios y la organización sanitaria. Para los pacientes, los principales beneficios que se esperan con esta intervención son el acceso de forma rápida y sencilla a los especialistas, la reducción del número de visitas y del nivel de ansiedad, evitar gastos de desplazamiento y el ahorro en tiempo (productividad); adicionalmente, se calcula el impacto económico de esos cambios. Como se puede observar, el planteamiento es más amplio que con una evaluación tradicional de tecnologías sanitarias. Como señalan Kennedy et al. ${ }^{[14]}$, el método SROI ofrece la capacidad de medir impactos de las intervenciones sanitarias más amplios y más centrados en el paciente.

\subsection{VENTAJAS E INCONVENIENTES}

Como hemos visto a lo largo de este capítulo, la utilización del método SROI nos permite tener una visión más amplia de la tecnología sanitaria a evaluar incorporando la opinión de todos los posibles beneficiarios de la intervención. Por otro lado, para la medición y valoración de las preferencias de los pacientes se puede utilizar un número importante de técnicas, todas ellas con sus puntos fuertes y también con sus limitaciones.

Sin duda alguna, una de las ventajas más importantes de utilizar el método SROI es tener en cuenta, a través de los distintos instrumentos de valoración, todos los afectados por la intervención sanitaria. Esa característica es también la que más diferencia al SROI de otras técnicas de evaluación donde generalmente solo se tiene en cuenta la perspectiva del pagador y, en contadas ocasiones, se utiliza una perspectiva más social.

Sin embargo, esta visión más amplia también tiene sus inconvenientes. Por un lado, el trabajo de valoración de los beneficios es más complicado, no solo por la diversidad de técnicas a seleccionar, sino por el gran número de afectados a los que se tiene que tener en consideración.

Por otro lado, nos encontramos con una técnica con poca experiencia en el ámbito sanitario, con lo que podemos encontrar la "resistencia" de algunos pagadores sanitarios ante lo desconocido, teniendo en cuenta que además en algunos contextos todavía no se ha avanzado, ni siquiera, en la introducción de la evaluación económica (con sus distintos instrumentos) como instrumento de ayuda a la toma de decisiones. 


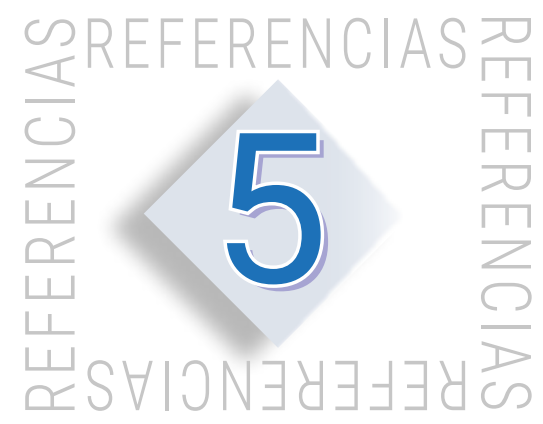

1. Nicholls J, Lawlor E, Neitzert E, Goodspeed T. A guide to Social Return on Investment. UK: The SROI Network. Accounting for Value; 2012. Disponible en: http://www.socialvalueuk.org/app/ uploads/2016/03/The\%20Guide\%20to\%20Social\%20Return\%20on\%20Investment\%202015.pdf

2. Yepes-Nuñez JJ, García García HI. Preferencias de estados de salud y medidas de utilidad. latreia. 2011;24(4):365-77.

3. Narrillos Roux H. El SROI (social return ot investment): un método para medir el impacto social de las inversiones. Análisis Financiero. 2010;(113):34-43.

4. Puig-Junoy J, Pinto JL, Ortún V. El análisis coste-beneficio en sanidad. Atención Primaria. 1 de enero de 2001;27(6):422-7.

5. Cabasés Hita JM. Análisis coste-beneficio. Granada: Escuela Andaluza de Salud Pública; 1994. (Documentos Técnicos EASP). Report No.: 7.

6. Louviere JJ, Flynn TN, Carson RT. Discrete Choice Experiments Are Not Conjoint Analysis. Journal of Choice Modelling. 31 de octubre de 2010;3:57-72.

7. Kleinman L, Mclntosh E, Ryan M, Schmier J, Crawley J, Locke GR, et al. Willingness to pay for complete symptom relief of gastroesophageal reflux disease. Arch Intern Med. 24 de junio de 2002;162(12):1361-6.

8. Stenehjem DD, Au TH, Ngorsuraches S, Ma J, Bauer H, Wanishayakorn T, et al. Immunotargeted therapy in melanoma: patient, provider preferences, and willingness to pay at an academic cancer center. Melanoma Res. 25 de enero de 2019;

9. Pinto-Prades JL, Puig-Junoy J, Ortún-Rubio V. Análisis coste-utilidad. Atención Primaria. 15 de mayo de 2001;27(8):569-73.

10. Hallan S, Asberg A, Indredavik B, Widerøe TE. Quality of life after cerebrovascular stroke: a systematic study of patients' preferences for different functional outcomes. J Intern Med. septiembre de 1999;246(3):309-16.

11. Banke-Thomas AO, Madaj B, Charles A, van den Broek N. Social Return on Investment (SROI) methodology to account for value for money of public health interventions: A systematic review. BMC Public Health. 2015;15(1):582-95.

12. Nicholls J. Social return on investment - Development and convergence. Eval Program Plann. 2017;64:127-35.

13. Durán Piñeiro G, Sánchez Carreira M del C, Peña Gil C, Paredes Galán E, Gómez Ruíz R, Lado Sestayo $\mathrm{R}$, et al. El retorno económico y social de la e-interconsulta de cardiología en el área de Vigo. ICEDE Working Paper Series. abril de 2015;11:1-28.

14. Kennedy R, Phillips J. Social return on investment (SROI): a case study with an expert patient programme. SelfCare. 2011;2(1):10-20. 


\section{CAPÍTULO}

\section{APLICACIONES}

PRÁCTICAS

DEL MÉTODO SROI

Beatriz González López-Valcárcel 


\subsection{INTRODUCCIÓN}

Este capítulo revisa aplicaciones prácticas del método SROI (Social Return On Investment) en el ámbito de la salud. EI SROI, cuya quintaesencia es un simple número, sirve para justificar ante los financiadores la "rentabilidad" de la inversión, y en este sentido su gran atractivo es hablar el mismo lenguaje que los análisis de viabilidad de proyectos empresariales que estiman el retorno de la inversión.

Siendo una metodología nacida en torno a la economía social, para empresas no lucrativas socialmente responsables que buscan el desarrollo sostenible, muy vinculado al tercer sector, el salto a las aplicaciones en sanidad implica una cierta translocación de foco. Porque utilizar SROI para evaluar tratamientos específicos o la atención sanitaria a determinadas enfermedades implica un gran salto. Por una parte, son tratamientos generalmente ofertados por empresas lucrativas. Por otra parte, los outcomes en estos ejercicios intramurales de la sanidad tienen un alcance más limitado que en los análisis SROI habituales. En las primeras aplicaciones, se utilizó el método SROI para evaluar a entidades de economía social. En el ámbito de la salud, distinguimos tres tipos de análisis. El primero consiste en ejercicios en los que la salud es uno entre varios outcomes y no necesariamente el más relevante. El segundo se caracteriza porque se evalúan programas o intervenciones de promoción de la salud y otras de salud pública poblacional; en ellos, la salud es el outcome principal; por último, el tercer tipo de aplicaciones son intramurales de la sanidad, y evalúan intervenciones sobre determinadas enfermedades o tratamientos específicos. Estos últimos tipos de aplicación son los que compiten directamente con las evaluaciones tradicionales de tecnologías sanitarias.

\subsection{APLICACIONES SROI EN SALUD PÚBLICA}

Una revisión sistemática de estudios SROI en salud pública, incluyendo publicaciones revisadas por pares y literatura gris, entre enero de 1996 y diciembre de 2014 [1] identificó 40 estudios que cumplen criterios de calidad (según una escala de 12 puntos desarrollada por $\mathrm{Krlev}^{[2]}$ ). El primero se publicó en 2005, y ha habido una tendencia creciente hasta 2011, año con el máximo número anual de estudios publicados. Solo cuatro de los estudios (10\%) se habían publicado en revistas científicas con revisión por pares. 28 de los 40 estudios son de alta calidad (más del 70\% en la escala de Krlev), mientras que 12 son de baja calidad. La calidad no parece haber mejorado con el tiempo. La mayor parte son para países desarrollados, destacando el Reino Unido con el 70\% de los estudios. Los demás países desarrollados apenas aportaban uno (Estados Unidos, Canada, Países Bajos), o como máximo dos (Australia). Por áreas, predominan los de promoción de la salud (12) y salud mental (11). 26 estudios son evaluativos y 14 son predictivos. Llama la atención la falta de consenso sobre qué beneficiarios considerar (21 estudios solo incluyeron a los beneficiarios y, por el otro extremo, 12 estudios incluyeron a todos, beneficiarios, promotores, implementadores y financiadores), en qué horizonte temporal, y cómo manejar los contrafactuales. La heterogeneidad de los tipos de datos manejados -cuantitativos, cualitativos o mixtos- es notable. Los autores concluyen recomendando que se limite la lista de stakeholders a considerar, poniendo más atención a las valoraciones de los beneficiarios que a las del resto de agentes, que se justifiquen las tasas de descuento empleadas, que se homogeneicen las unidades monetarias con paridades de poder de compra, y que se utilicen diseños validados en ciencia, como casos-controles o los diseños antes-después para estimar los resultados. Uno de los puntos clave del diseño es qué método se emplea para cuantificar el "peso muerto", con grupo de control, con diseño 
antes-después o basado en apreciaciones subjetivas. Transparencia y honestidad son elementos básicos, a veces ausentes, en los estudios SROI.

El hecho de que la mayor parte de los estudios sean para el Reino Unido es consistente con los estímulos para emplear esa metodología, en el contexto de los esfuerzos del gobierno para mejorar la rendición de cuentas sobre los beneficios sociales, económicos y medioambientales en sentido amplio, dentro del tercer sector. Incluso se dictó una ley, la Public Services (Social Value) Act 2012, que entró en vigor en 2013 y requiere de las autoridades públicas que consideren en los contratos de la Administración esos tres tipos de impactos sobre el bienestar. A raíz de dicha ley, se ofrecen guías metodológicas y pautas para la correcta elaboración de los informes SROI. En este sentido, el Reino Unido es el gran impulsor de la metodología, ligada a la legitimación ante el financiador público, y por tanto extremadamente necesitada de estándares metodológicos que resten holgura y discrecionalidad a los autores. Los avances metodológicos y la estandarización se están produciendo más a través de circuitos de acreditación profesional y de grupos de práctica (clubs) que por los canales habituales de comunicación científica. Se podría decir que es más un movimiento de abogacía ("tenemos todos la misma ambición, cambiar la forma en que la sociedad calcula el valor"). Ese movimiento se está organizando y consolidandoii, con instituciones que acreditan a las organizaciones y proyectos de economía socialiii. En algunos casos, una organización reconocida valida estudios específicos desarrollados por las organizaciones interesadas ${ }^{[3]}$.

Además, en el Reino Unido los cambios en el control de la toma de decisiones de salud pública y en la financiación de los proyectos sociales desde las autoridades sanitarias hacia las administraciones locales han introducido un nuevo "elemento político en la toma de decisiones de salud pública"[4] y han cambiado las reglas del juego y los incentivos a la investigación. En su revisión sistemática para el Reino Unido desde 2010, Kneale et al|[4] encuentran que la toma de decisiones en salud pública se basa cada vez más en datos y valores locales que globales.

En cuanto a los resultados de las aplicaciones en salud pública entre 2005 y 2014 revisados por Banke-Thomas ${ }^{[1]}$, son muy variables, con ratios SROI entre 1,1:1 y 65:1 $1^{\text {iv }}$. Aunque el gran atractivo del método, a priori, es poder decidir si acometer o no una inversión con impacto social y en caso positivo por cuál o cuáles decidirse en un contexto de restricción presupuestaria, la revisión citada advierte que debido a la heterogeneidad en la forma de realizar los estudios SROI y a la teoría económica que subyace en cada elección metodológica, no se deben confundir las intervenciones con mayor impacto -ratio más alta- con las que consiguen más "value for money".

La Oficina Europea de la Organización Mundial de la Salud (OMS) participa en la corriente de aceptar el SROI como criterio para la toma de decisiones en salud pública con la mejor evidencia disponible, que recoge a través del Health Evidence Network para la inversión en salud y bienestar. En su informe sobre el valor social de la salud y el bienestar en Europa ${ }^{[5]}$, se afirma que las 12 políticas de salud clave seleccionadas como mapa de ruta para el desarrollo sostenible de Europa en 2030 han demostrado elevadas ratios SROI. No obstante,

\footnotetext{
Public Services (Social Value) Act 2012: http://www.legislation.gov.uk/ukpga/2012/3/enacted

Programa del congreso anual 2018 del Reino Unido en: http://www.socialvalueuk.org/app/uploads/2018/11/Agenda-V4.pdf

Social Value UK: http://www. socialvalueuk.org

v En el siguiente enlace puede consultarse en detalle cada uno de los 40 trabajos de la revisión de Banke-Thomas et al. ${ }^{[1]}$. https:// www.springermedizin.de/resource/supplementary/12889_2015_1935_MOESM3_ESM.xIsx/9749692
} 
la revisión de los 62 estudios seleccionados se basa en evaluaciones económicas clásicas y no en estudios SROI y en su mayor parte son fuentes secundarias que refieren a estudios originales previos. Es muy significativo el giro de la OMS hacia la legitimación conceptual del retorno social de la inversión, más amplio que el mero retorno económico de las inversiones. Las 12 políticas de salud son:

1. Afrontar los determinantes sociales, económicos y ambientales de la salud con un enfoque de universalismo proporcionado.

2. Asegurar la equidad de género.

3. Asegurar el mejor comienzo en la vida, sin dejar a ningún niño atrás.

4. Garantizar la educación temprana y juvenil, la alfabetización en salud y empleo decente.

5. Garantizar un envejecimiento sano y activo.

6. Reducir el hábito de fumar, el abuso del alcohol, la obesidad, la dieta poco saludable y la inactividad física.

7. Abordar las enfermedades no transmisibles y las enfermedades transmisibles.

8. Garantizar la cobertura de salud universal y minimizar los gastos de bolsillo.

9. Fortalecer los sistemas, capacidades y servicios de salud pública.

10. Transformar, expandir y optimizar los recursos humanos para la salud.

11. Entornos naturales y urbanos saludables.

12. Asegurar una economía verde y circular, minimizando el desperdicio y los impactos negativos, con producción, consumo y distribución sostenibles.

Menos de media docena de países han creado redes nacionales de SROI. A nivel internacional, colaboran en una red, Social Value International ${ }^{\vee}$ que trata de legitimar académicamente el método ${ }^{[6]}$. De momento hay muchas más publicaciones explicando en qué consiste el método que aplicándolo.

Las aplicaciones en salud pública comparten generalmente otros objetivos sociales además de la salud. Es el caso de los programas dirigidos a grupos vulnerables, con problemas de salud mental, de vivienda, de falta de integración en la sociedad y de preparación para el trabajo. El movimiento de Clubhouses, por ejemplo, es un movimiento internacional que ofrece a las personas con problemas graves y duraderos de salud mental oportunidades para contribuir e integrarse en el mundo en el que viven. Deliberadamente, se restringen las plantillas para que los beneficiarios colaboren en la marcha del programa, desdibujando la frontera entre trabajador y cliente. Una experiencia notable, evaluada con método SROI, es la del Scotia Clubhouse, en Glasgow ${ }^{[7]}$, donde el entorno laboral es pesimista para todos, más aún para las personas con problemas mentales. La evaluación se ha planteado como un trabajo multidimensional de salud mental, integración social y preparación para el trabajo, pero el punto de partida ha sido la preocupación de la Glasgow Association for Mental Health (GAMH) por la pérdida progresiva de financiación y la necesidad de justificar el retorno social de su inversión. 
Entre 2015 y 2018, es decir, más allá de la revisión de Banke-Thomas y hasta el momento actual, nuestra propia búsqueda en publicaciones académicas -Pubmed, WoS- y de literatura gris sobre aplicaciones SROI en salud nos aporta 14 estudios adicionales (Anexo). De ellos, 10 son extramurales a la sanidad y 4 intramurales.

\subsubsection{Aplicaciones extramurales $2015-2018$}

Algunos análisis SROI sobre uso de sustancias ya habían sido incluidos en la revisión de Banke-Thomas, como el uso de sustancias por jóvenes en Leicester ${ }^{[8]}$. Posteriormente, se han realizado estudios para otras áreas del Reino Unido. El estudio SROI de la organización Turning Point sobre su servicio destinado a reducir el abuso de sustancias consumidas por los adultos ${ }^{[0]}$ se caracteriza por incluir un gran número de stakeholders, entre ellos la autoridad local que financia el servicio, los pacientes (beneficiarios directos, n=1.136 adultos) y sus familiares y comunidades, el personal de Turning Point, los proveedores de atención sanitaria, las prisiones y el sector de justicia. Se hace un esfuerzo importante de recogida de información de todos ellos. En este estudio hay que valorar tres outcomes fundamentales de la reducción de uso de sustancias: la mejora de la salud física, de la salud mental y de la criminalidad. Para estimar el valor individual del alivio de librarse de las drogas y mejorar su salud, utilizaron los valores obtenidos con un método de análisis llamado Wellbeing Valuation (WV), incorporando los valores incluidos en una base de datos nacional, el HACT social value bank $k^{\text {vi }}$. Aunque esa base está creada para análisis SROI de vivienda, algunos outcomes de este estudio tienen conexión con los que se generan en programas de mejora del hábitat, como el alivio de la situación financiera, los sentimientos acerca del vecindario, la sensación de recuperar el control sobre la propia vida, los valores relacionados con empleo y formación o la mejora de la depresión y ansiedad. El horizonte temporal es de un año pero los autores dicen que puede extenderse fácilmente. El SROI resultante en el escenario base es de 7,17 libras por cada libra invertida.

La salud mental forma parte de un bloque de intervenciones enfocadas hacia el consumo de alcohol, drogas y crimen que han captado el interés tanto de las organizaciones de salud como de la administración de justicia. El departamento de salud del Reino Unido (PHE) está elaborando un instrumento específico que las autoridades locales puedan aplicar para evaluar con metodología SROI las intervenciones dirigidas a prevenir, tratar y rehabilitar a

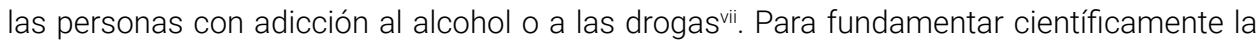
evaluación de resultados, ha hecho un importante estudio estadístico junto con el Ministerio de Justicia ${ }^{[10]}$. El estudio enlaza dos grandes bases de microdatos a nivel nacional, la del departamento de salud sobre consumo de drogas y la del departamento de justicia sobre delitos, en total 132.909 personas consumidoras de sustancias que iniciaron tratamiento en 2012 y a las que se ha seguido durante dos años. La intervención (tratamiento) consiguió una reducción del 33\% en los delitos.

Una notable aplicación evaluativa del método SROI en Canadá es el programa H.E.R. (Healthy, Empowered, Resilient) Pregnancy Program ${ }^{[11]}$, que tiene por objetivo asistir a las mujeres embarazadas en situación de vulnerabilidad (viven en la calle) en el área de Edmonton (Alberta), dándoles acceso a la atención sanitaria y a recursos sociales. El programa, iniciado en 2010, se

https://www.hact.org.uk/social-value-bank

vii https://www.ndtms.net/resources/public/SP0T\%20factsheet\%20050716.pdf 
lleva a cabo con la colaboración de 22 organizaciones no lucrativas que operan en la comunidad y es financiado por el gobierno de Alberta; en 2016 atendió a 66 mujeres viii. Utilizan indicadores del entorno social de las mujeres y sobre ellas mismas (conectividad, abuso de sustancias, prácticas sexuales, empoderamiento, seguridad) y de salud percibida materna e infantil. Los resultados indican que se recuperan más de 8 dólares por cada uno que se ha invertido.

En algunos casos se ha aplicado SROI a programas que llevaban décadas en marcha, con el objetivo de legitimar su existencia en el marco de las nuevas prioridades estratégicas del gobierno británico. Es el caso de dos programas en Irlanda del Norte llamados Let's Talk Parents Promoting Sexual Health y Breast and Cervical Screening Awareness.

Aunque el Reino Unido es la mayor fuente de estudios SROI en salud pública, en los últimos años se han publicado informes de evaluación de programas para países en desarrollo, en muchos casos apoyados metodológicamente desde el Reino Unido. La evaluación del programa de nutrición Maternal, Infant and Young Child Nutrition (MIYCN) para Kenia, publicado en 2018 en una revista científica de salud pública ${ }^{[12]}$ es un buen ejemplo. Con datos cualitativos y cuantitativos de diferentes fuentes, utiliza juegos para estimar el valor de los outcomes no comercializables. El estudio encuentra un altísimo impacto positivo en términos de salud materna e infantil (el SROI global es 71 dólares por cada dólar gastado). Valoran 34 outcomes, 11 de ellos negativos, y encuentran impactos no previstos del programa como el mayor apoyo conseguido de los padres. Una conclusión interesante de este estudio es la necesidad de encontrar diseños de estudios SROI que impongan un coste en tiempo y en dinero menor para evaluar las intervenciones nutricionales.

Una revisión sistemática reciente de evaluaciones económicas completas de intervenciones en la escuela (niños entre 4 y 12 años), relacionadas con la actividad física, sedentarismo y dieta $^{[13]}$, ha encontrado únicamente 23 (hasta marzo de 2017), entre ellas solo una que utiliza el método SROI ${ }^{[14]}$. Los autores de la revisión recomiendan los análisis SROI como método de elección en estudios basados en ensayos, porque adoptan una perspectiva más amplia e incluyen otros stakeholders además de la población objetivo de beneficiarios del programa, incorporando así efectos spillover.

Entre los outcomes de los ejercicios de evaluación de la actividad física se considera la salud y el bienestar, pero hay otros (redes sociales y recursos comunitarios, educación) más relevantes y que suelen aportar más valor. Así, en un reciente estudio para el Reino Unido[ ${ }^{[15]}$, las mejoras en los indicadores de los outcomes de conectividad y recursos comunitarios (28\%) y en educación (29\%) fueron sustancialmente mayores que las conseguidas en los indicadores de salud y bienestar (15\%).

Finalmente, destacamos en este apartado que si bien la estimación del retorno de la inversión con análisis coste-beneficio sigue interesando en la literatura científica de salud pública, pues una revisión reciente encontró 52 estudios desde 2010 que cuantifican el ROI (Return On Investment) de intervenciones en salud pública en países desarrollados ${ }^{[16]}$, todavía el SROI no se está consolidando como método de elección. Llama la atención que en promedio los

viii Hay un informe de evaluación del programa de diciembre de 2013 https://fasdprevention. files.wordpress.com/2014/02/her-final-summary-report-2014.pdf. En el libro recopilatorio de casos para Canadá[11], publicado en 2018, se actualizan algunos datos. 
resultados de SROI parecen menos favorables que los ROI, pues el ROI mediano de los 52 estudios de esa revisión sistemática es 14,3 a 1 (4,1 a 1 para las intervenciones locales, 27,2 a 1 para las de ámbito nacional) mientras que la mediana del SROI de los 40 estudios revisados por Banke-Thomas, idéntica a la de los siete estudios extramurales para países desarrollados revisados en este capítulo es 5,2 a 1 .

\subsubsection{La salud como outcome secundario en estudios SROI}

Algunos análisis SROI incluyen la salud como un outcome entre otros muchos, no siendo el principal. Por ejemplo, en Alberta, Canadá, un programa llamado New Ways For Families (NWFF)ix tiene por objetivo la prevención de conflictos y maltrato a los niños en las familias con problemas de pareja de los padres y procesos de divorcio.

Una evaluación SROI del deporte en el Reino Unido ${ }^{[17]}$ cuyos stakeholders son el gobierno y agencias públicas, autoridades locales, institutos de enseñanza media y universidades, proveedores comerciales de artículos deportivos, clubs y equipos de voluntarios, considera seis outcomes de salud, pero no son los principales; otros son la reducción de incidencia de delitos, las mejoras de capital humano y productividad por la vía de la educación de las personas, mejoras en el capital social y voluntariado, y mejoras en el bienestar de las personas. De hecho, el valor de los outcomes de salud (reducción de incidencia de demencia, ictus, diabetes tipo 2 y aumento de la prevalencia de buena salud percibida) es casi la mitad que el valor del resto de outcomes, en particular el capital social es el que resulta más valorado en el estudio.

\subsubsection{Aplicaciones SROI extramurales para grupos específicos de pacientes o enfermedades}

Las personas con demencia se benefician de los grupos de apoyo formados por otros pacientes, como demuestra un estudio que analiza con metodología SROI tres grupos en el sur de Londres ${ }^{[3]}$. Aunque las ratios de retorno social de la inversión no son muy altas (entre 1,17 libras y 5,18 libras por cada libra gastada), se consigue mejorar la estimulación mental de las personas con demencia, la reducción de su aislamiento, la reducción de la carga y el estrés de los cuidadores y el aumento del conocimiento de la demencia por los voluntarios.

Una evaluación reciente publicada en una revista científica ${ }^{[18]}$ sobre el potencial de las artes visuales para las personas con demencia y sus cuidadores concluye que se pueden recuperar 5,18 libras por cada libra invertida.

Varios programas dirigidos a personas mayores han demostrado conseguir grandes retornos de la inversión, aunque los retornos internos para el sistema sanitario son menores que los que valoran la mejora de bienestar o calidad de vida, y sobre todo la reducción del aislamiento social y la soledad, que es su principal objetivo. En un análisis reciente para Leeds $^{[19]}$ del programa Together for Health, por ejemplo, no se encontraron cambios significativos en la hospitalización o las visitas a urgencias, incluso aumentaron las visitas ambulatorias, aunque este hecho puede reflejar simplemente un sesgo de selección (entran en el programa las personas mayores en el momento del alta hospitalaria por su mayor

ix Programa NWFF: https://static1.squarespace.com/static/5707d49f37013bb703041a49/t/5799095c8419c2e66a-

513bac/1469647196715/MHFS+NWFF+SROI+Exec+Summary_FINAL.pdf 
necesidad de ayuda). El SROI resultante es 4,84 libras por cada libra invertida, pero en el análisis de sensibilidad se llega hasta 24,19 libras.

En una parte importante de las aplicaciones extramurales a la sanidad, la salud es un outcome entre otros y la implicación de la comunidad es una característica esencial (véanse, por ejemplo, los siete casos que presenta el informe de Dates ${ }^{[20]}$ para el Reino Unido).

\subsubsection{Aplicaciones intramurales en sanidad: medicina clínica y organización}

Este tipo de aplicaciones intramuros de la sanidad son recientes. En un estudio SROI evaluativo sobre asma infantil en el hospital de Boston ${ }^{[2]}$, ya incluido en la revisión de Banke-Thomas de 2015, se evaluó la gestión de casos de base comunitaria. Se compararon los resultados del grupo de pacientes afiliados al programa $(n=102)$ y otro grupo de pacientes no afiliados $(n=559)$ en cuanto a uso de urgencias y hospitalizaciones, días de ausencia a clase y calidad de vida. Una evaluación a 3 años con tasa de descuento del 1\% encuentra ratios moderadas de retorno social de la inversión $(1,85)$. Aunque este estudio sigue el método SROI en tanto considera los outcomes positivos para los cuidadores por reducirse los días de ausencia a clase del niño, su perspectiva es relativamente estrecha, de hecho el estudio se realiza como extensión de otro de coste-beneficio al que añade los impactos sobre los cuidadores. No deja de ser curioso que en la actualización del estudio, publicada en la misma revista en 2017 [22] no se haga la extensión SROI sino únicamente el análisis coste-beneficio y cálculo del ROI.

En España, se han realizado en los últimos años varias aplicaciones del método SROI intramuros de la sanidad para abordar problemas de salud específicos, definiendo una propuesta de mejoras para que el abordaje de esa enfermedad fuera óptimo, con acceso ilimitado a todos los tratamientos disponibles en un contexto de información clínica perfecta, coordinación entre niveles y reparto adecuado de responsabilidades entre profesionales, además de implicación del paciente y sus familiares por la vía de la formación y el autocuidado. Uno de esos estudios SROI intramuros aborda la psoriasis ${ }^{[23]}$. Se trata de un estudio prospectivo con el objetivo de definir cuál sería el abordaje ideal de la psoriasis en España y estimar el retorno social de la inversión de dicho abordaje, diferenciando entre diagnóstico y tratamiento y por grupos definidos de gravedad -leve, moderado, grave-. En tanto que afectados por el hipotético cambio hacia el abordaje ideal, se reconocen como stakeholders el SNS (Sistema Nacional de Salud) en su conjunto, los servicios de dermatología, los clínicos de atención primaria, el personal de enfermería (atención primaria y hospitalaria), la farmacia hospitalaria, psicología, los servicios de nutrición y el paciente con psoriasis. Los beneficiarios directos -pacientes- son los únicos stakeholders cuyo impacto se cuantifica. Las estimaciones de los impactos se basan en los datos recogidos mediante una encuesta por internet con muestreo de conveniencia a 1.053 pacientes vinculados a la asociación Acción Psoriasis, en la que contestan, entre otras, a preguntas relativas a su disposición a pagar. Se ha contado también con la opinión de un grupo multidisciplinar de expertos. También se analiza el impacto asistencial y organizativo de cada acción propuesta, en caso de implantarse. El horizonte temporal es un año, por lo que no es preciso emplear tasas de descuento. El análisis de sensibilidad considera dos fuentes de incertidumbre: se valoran cambios en la disposición a pagar de los pacientes y en los plazos de amortización de las inversiones de implantación de tele-dermatología y equipos de fototerapia. La ratio SROI resultante del estudio es 5,04 euros por cada euro gastado globalmente. La ratio oscila entre 1,95 para psoriasis moderada y 15,81 para psoriasis leve. En el análisis de sensibilidad esos valores no cambian sustancialmente (entre 4,78 euros y 7,42 euros para la ratio SROI global). 
El método SROI también se ha aplicado para evaluar prospectivamente el abordaje ideal de la insuficiencia cardiaca en España ${ }^{[24]}$, definido a través de 28 propuestas que se determinaron mediante la consulta a un grupo multidisciplinar de expertos, y una encuesta a 558 pacientes y sus cuidadores informales principales. Las propuestas incluyen la generalización de la historia clínica compartida, la receta electrónica, la enfermería gestora de casos, las unidades de rehabilitación cardiaca, la mejora del acceso al ecocardiograma y la formación y orientación psicológica a pacientes. El impacto se midió en cinco áreas clínicas: urgencias y hospitalización, atención primaria, cardiología y medicina interna. Globalmente, el retorno social de la inversión fue de 3,52 euros por cada euro invertido. Por áreas, las urgencias y hospitalización multiplican por 2,5 esa ratio (9,05 euros), mientras que medicina interna y atención primaria están por debajo.

Una de las aplicaciones intramurales más recientes se centra en el abordaje ideal de la esclerosis múltiple ${ }^{[25]}$ presentada en el congreso ISPOR (International Society for Pharmacoeconomics and Outcomes Research) en Barcelona en 2018 ${ }^{[26]}$. Con metodología similar a los otros estudios, se describe el abordaje ideal mediante 18 propuestas repartidas equiproporcionalmente en tres áreas: una de diagnóstico y dos de abordaje que distinguen entre la esclerosis múltiple remitente-recidivante (EMRR) y la esclerosis múltiple en sus formas progresivas (EMFP). La lista de stakeholders es muy amplia, en el SNS se incluyen los distintos servicios y profesiones dentro de la atención especializa y la atención primaria, así como los gestores y la farmacia hospitalaria, además de los pacientes (incidentes y prevalentes, con los distintos tipos y grados de enfermedad, reciban o no tratamiento) y sus cuidadores informales. Las propuestas en el área de diagnóstico buscan la detección precoz y la mejora del acceso para el paciente a través de formación y de intensificación de recursos. En las otras dos áreas, las propuestas se refieren a una mejor coordinación entre niveles asistenciales y entre especialidades, mejorar los protocolos de seguimiento, a la equidad en el acceso a los tratamientos, a la educación para el autocuidado de los pacientes. Se añade, en la EMFP, la rehabilitación integral y la mejora de la protección social de los pacientes. La ratio SROI global resultante de los 148 millones de euros que habría que invertir en un año es de 1,83 euros por cada euro invertido.

En el área de organización y gestión, se ha analizado con el método SROI la e-interconsulta de cardiología del área de Vigo ${ }^{[2]}$. El estudio es evaluativo, considera un horizonte temporal de 5 años y una tasa de descuento del 3,5\%. Los stakeholders considerados son los pacientes y sus acompañantes, los profesionales sanitarios y la organización sanitaria en general. Los cambios para el paciente son la mejora de acceso al especialista, mejora de calidad de vida y ahorro de coste y tiempo de transporte. Los indicadores del cambio se valoran con el coste medio de una visita en el modelo convencional y en tele-consulta, los costes medios de desplazamiento en ambos. Para los profesionales se ha considerado la mejora de comunicación entre niveles, pero no se cuantifica; en cuanto al valor del cambio para la organización sanitaria, se mide y valora únicamente el ahorro de coste de visitas médicas, por reducción tanto en la cantidad como en el coste unitario. Como en los demás ejercicios, en este se cuantifica el impacto aplicando las recomendaciones de las guías (peso muerto, desplazamiento y atribución), aunque en este caso no se hace análisis de sensibilidad. Obtienen una ratio SROI de 32,55 euros por cada euro invertido.

\subsection{CONCLUSIONES}

Desde que en 2005 se publicó el primer informe SROI en el área de la salud se ha avanzado en estandarización metodológica, con vocación de consolidar el método como alternativa 
válida académicamente, pero todavía queda mucho por avanzar en ese terreno. El Reino Unido, con su ley de 2013, ha puesto en la agenda política el retorno social de las inversiones en salud y atención sociosanitaria; la devolución de competencias de salud pública a las autoridades locales en ese país ha impulsado la colaboración interdepartamental.

El interés académico por el SROI en salud va en aumento, como señala el protocolo de revisión sistemática de aplicaciones en salud y atención sociosanitaria publicadas en revistas académicas entre 2000 y $2018^{[28]}$.

El método SROI busca legitimarse en dos frentes, el del financiador (resultados creíbles sobre el value-for-money de su inversión) y el académico. A su vez, pueden distinguirse dos tipos de legitimación, la conceptual -aceptar como principio el retorno social de la inversión, más allá del retorno meramente económico- y como método riguroso y estandarizado que deje poca holgura a la manipulación de resultados a favor del que encarga el estudio. De momento, a pesar de existir algún retorno negativo en alguna parte del análisis, no hemos encontrado ni una sola aplicación SROI que reporte resultados globales negativos, ni siquiera en el escenario más desfavorable del análisis de sensibilidad. Y eso a pesar de que el método se ocupa de no exagerar los beneficios ni contabilizarlos doblemente con mecanismos como el peso muerto, el desplazamiento, la atribución y el decremento. A pesar de los avances en la estandarización, que son la forma de legitimar académicamente el análisis SROI, todavía se está lejos de lograr un consenso metodológico similar al que existe para las evaluaciones económicas, el Consolidated Health Economic Evaluation Reporting Standard (CHEERS), y los abogados del SROI tienen que enfrentar la tendencia al sesgo de sobreestimación de beneficios.

El gran avance en la legitimación conceptual del retorno social de la inversión ha venido desde las organizaciones internacionales, específicamente la OMS, que ha integrado el retorno social de la inversión como uno de sus principios.

La categorización del análisis SROI como una especie de "forma pragmática de análisis Coste-Beneficio"[18] contribuye a integrarlo en una corriente de continuidad con la evaluación económica.

Con todo, hoy en día hay muchas más publicaciones sobre el método en sí que con aplicaciones, y la proporción entre las que se publican en revistas académicas y la literatura gris está muy sesgada hacia las segundas. El movimiento SROI se ha dotado de organizaciones e instrumentos de acreditación de la calidad de los análisis como medio para su legitimación científica.

Las aplicaciones extramurales de la sanidad son más abundantes que las intramurales, y entre las primeras destacan aquellas en las que la salud es solo un outcome entre otros muchos, y el valor de los resultados de salud es inferior al del resto de componentes. La salud mental destaca considerablemente sobre la física, en los análisis que integran la marginalidad, pobreza, crimen y otros problemas asociados. Las aplicaciones intramurales de la sanidad son muy escasas, y España destaca en el panorama internacional por sus contribuciones. Con más estudios de aplicación intramural se podría enriquecer el marco de conocimiento para las decisiones de asignación de recursos sobre tratamientos y enfermedades. 


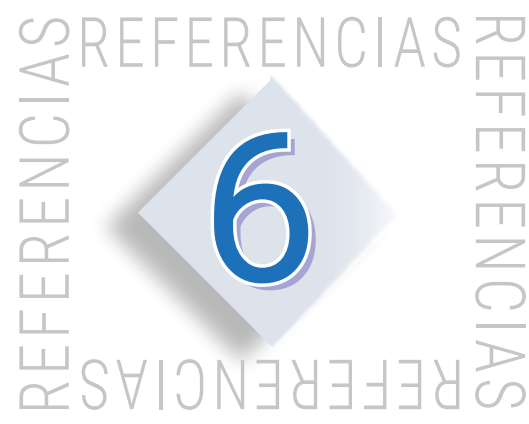

1. Banke-Thomas AO, Madaj B, Charles A, van den Broek N. Social Return on Investment (SROI) methodology to account for value for money of public health interventions: A systematic review. BMC Public Health. 2015;15(1):582-95. Disponible en: https://doi.org/10.1186/s12889-015-1935-7

2. Krlev G, Münscher R, Mülbert K. Social Return on Investment (SROI): state-of-the-art and perspectives - a meta-analysis of practice in Social Return on Investment (SROI) studies published 20022012. Heidelberg: (CSI) Centre for Social Investment, Heidelberg University; 2013 nov. Disponible en: http://archiv.ub.uni-heidelberg.de/volltextserver/18758/1/CSI_SROI_Meta_Analysis_2013.pdf

3. Willis $E$, Semple AC, de Waal H. Quantifying the benefits of peer support for people with dementia: A Social Return on Investment (SROI) study. Dementia (London). abril de 2018;17(3):266-78. Disponible en: https://doi.org/10.1177/1471301216640184

4. Kneale D, Rojas-García A, Raine R, Thomas J. The use of evidence in English local public health decision-making: a systematic scoping review. Implementation Science. 20 de abril de 2017;12(1):53. Disponible en: https://doi.org/10.1186/s13012-017-0577-9

5. Dyakova M, Hamelmann C, Bellis MA, Besnier E, Grey CNB, Ashton K, et al. Investment for health and well-being: a review of the social return on investment from public health policies to support implementing the Sustainable Development Goals by building on Health 2020. Copenhagen: WHO Regional Office for Europe; 2017. (Health Evidence Network (HEN) synthesis report 51). Disponible en: http://www.ncbi.nlm.nih.gov/books/NBK453553/

6. Nicholls J. Social return on investment - Development and convergence. Eval Program Plann. 2017;64:127-35. Disponible en: http://www.sciencedirect.com/science/article/pii/S0149718916 302361

7. GAMH Glasgow Association for Mental Health. Social Return On Investment What is the value to society of the impact of the relationship between members and the Clubhouse as a multi-faceted working environment on mental health, social integration and work readiness? Glasgow: GAMH Glasgow Association for Mental Health; 2011 p. 20. Disponible en: https://www.gamh.org.uk/ wp-content/uploads/Annual-Report-2011-12.pdf

8. Bradly J, Bolas C. Social Return on Investment (SROI) of Substance Misuse Work Leicestershire Youth Offending Service. Leicester: Leicestershire County Council; 2013 nov p. 32. Disponible en: http://www.Isr-online.org/uploads/sroi-substance-misuse-final.pdf

9. Goodspeed T, Turning Point Wakefield staff. Value of Substance. A Social Return on Investment evaluation of Turning Point's Substance Misuse Services in Wakefield. Wakefield: Turning Point; 2014 jul p. 37. Disponible en: http://www.socialvalueuk.org/app/uploads/2016/03/Value\%20of\%20 Substance\%20FINAL.pdf 
10. Ministry of Justice (MoJ) and Public Health England (PHE). The impact of community-based drug and alcohol treatment on re-offending. Londres: Ministry of Justice and Public Health England 2017 oct p. 33. Disponible en: https://assets.publishing.service.gov.uk/government/uploads/system/uploads/attachment_data/file/674858/PHE-MoJ-experimental-MoJ-publication-version.pdf

11. Mcmurchy D. Co-created, co-delivered, co-lived: Toward Better Health and Care for Inner-City Populations. A Canadian Casebook. Ottawa: Canadian Foundation for Healthcare Improvement.; 2018 mar p. 92. Disponible en: https://www.cfhi-fcass.ca/PublicationsAndResources/ResearchReports/ ArticleView/2018/06/27/co-created-co-delivered-co-lived-toward-better-health-and-care-for-inner-city-populations

12. Goudet S, Griffiths PL, Wainaina CW, Macharia TN, Wekesah FM, Wanjohi M, et al. Social value of a nutritional counselling and support program for breastfeeding in urban poor settings, Nairobi. BMC Public Health. 4 de febrero de 2018;18(1):424. Disponible en: https://doi.org/10.1186/s12889-0185334-8

13. Oosterhoff M, Bosma H, van Schayck OCP, Evers SMAA, Dirksen CD, Joore MA. A systematic review on economic evaluations of school-based lifestyle interventions targeting weight-related behaviours among 4-12 year olds: Issues and ways forward. Prev Med. septiembre de 2018;114:115-22. Disponible en: http://www.sciencedirect.com/science/article/pii/S0091743518302044

14. Jones M, Pitt H, Oxford L, Orme J, Gray S, Salmon D, et al. Food for Life: a Social Return on Investment Analysis of the Locally Commissioned Programme. Full Report. Bristol: UWE Bristol; 2016. Disponible en: http://eprints.uwe.ac.uk/31897/1/12_Jones_et_al_\%282016\%29_Food_for_Life_ LCs_SROI_Full\%20Report_v05.pdf

15. Baker C, Courtney P, Kubinakova K, Ellis L, Loughren E, Crone D. Gloucestershire Active Together Evaluation. Cheltenham: University of Gloucestershire, School of Health and Social Care; 2017 p. 51. Report No.: Final Report. Disponible en: http://eprints.glos.ac.uk/4321/

16. Masters R, Anwar E, Collins B, Cookson R, Capewell S. Return on investment of public health interventions: a systematic review. J Epidemiol Community Health. 2017;71(8):827-34. Disponible en: https://jech.bmj.com/content/71/8/827

17. Davies L, Taylor P, Ramchandani G, Christy E. Social Return on Investment in Sport: a participation wide model for England. Sheffield Hallam University \& Sport Industry Research Centre; 2016 abr p. 15. Disponible en: https://www4.shu.ac.uk/_assets/pdf/research/sirc/Final-SIRC-SROI-EnglandWeb-report.pdf

18. Jones C, Windle G, Edwards RT. Dementia and Imagination: A Social Return on Investment Analysis Framework for Art Activities for People Living With Dementia. Gerontologist. 23 de noviembre de 2018; Disponible en: https://academic.oup.com/gerontologist/advance-article/doi/10.1093/geront/gny $147 / 5203293$

19. Bagnall A-M, Raine G, Kinsella K, Southby K, Spoor C, South J, et al. Meausring well-being outcomes in older people receiveing help from the age UK «Together for Health» initiative: a Social Return on Investment Analysis. The Centre for Health Promotion Research, Institute for Health and Wellbeing Leeds: Leeds Beckett University; 2016 p. 64. Report No.: Final Report. Disponible en: http://eprints. leedsbeckett.ac.uk/2887/1/FINAL\%20TFH\%20FULL\%20REPORTJULY\%202016.pdf

20. Dates M, Mallender J, Pritchard C, Rtveladze K. Community Engagement - approaches to improve health and reduce health inequalities. Review of Social Return on Investment (SROI) evaluations. (NICE) National Institute for Health and Care Excellence; 2015 jul p. 64. (Health Economics). Report No.: 4. Disponible en: https://www.nice.org.uk/guidance/ng44/evidence/health-economics-4-review-of-sroi-evaluations-pdf-2368262416

21. Bhaumik U, Norris K, Charron G, Walker SP, Sommer SJ, Chan E, et al. A Cost Analysis for a Community-Based Case Management Intervention Program for Pediatric Asthma. Journal of Asthma. abril de 2013;50(3):310-7. Disponible en: https://doi.org/10.3109/02770903.2013.765447 
22. Bhaumik U, Sommer SJ, Giller-Leinwohl J, Norris K, Tsopelas L, Nethersole S, et al. Boston children's hospital community asthma initiative: Five-year cost analyses of a home visiting program. Journal of Asthma. 7 de febrero de 2017;54(2):134-42. Disponible en: https://doi.org/10.1080/027 70903.2016.1201837

23. González A, Ivanova Y, Jiménez M, Merino M, Hidalgo Á, Alfonso S, et al. Retorno Social de la Inversión de un abordaje ideal de la psoriasis. Majadahonda, Madrid: Instituto Max Weber; 2016. 164 p. Disponible en: http://weber.org.es/publicacion/informe-el-valor-social-de-un-abordaje-ideal-de-lapsoriasis-sroi-psoriasis/

24. Merino Ventosa M, Jiménez Torres M, Manito Lorite N, Casariego Vales E, Ivanova Markova Y, González Domínguez A, et al. 4013-4 - RETORNO SOCIAL DE LA INVERSIÓN DE UN ABORDAJE IDEAL EN INSUFICIENCIA CARDIACA EN EL SISTEMA NACIONAL DE SALUD ESPAÑOL. Revista Española de Cardiología. 2017;70(Supl 1):500. Disponible en: http://www.revespcardiol.org/es/congresos/ sec-2017-el-congreso/51/sesion/eficiencia-prevencion-seguridad-los-procedimientos/3327/retorno-social-inversion-un-abordaje/37812/

25. Merino M, Jiménez M, Gómez-García T, Ivanova $Y$, Hidalgo-Vega Á, Moral Torres E, et al. Proyecto SROI-EM. Impacto clínico, asistencial, económico y social del abordaje ideal de la esclerosis múltiple en comparación con el abordaje actual. Madrid: Fundación Weber; 2018. Disponible en: http:// weber.org.es/publicacion/sroiem_impacto_clinico_asistencial_economico_social_escleroris_multiple/

26. Moral E, Fernández O, Carrascal P, Merino M, Jiménez-Torres M, Gómez-García T, et al. Social return on investment of an ideal approach to multiple slerosis within the Spanish National Health System. ISPOR, Barcelona; 2018. Disponible en: https://tools.ispor.org/ScientificPresentationsDatabase/ Presentation/88191?pdfid=57244

27. Durán Piñeiro G, Sánchez Carreira M del C, Peña Gil C, Paredes Galán E, Gómez Ruíz R, Lado Sestayo $\mathrm{R}$, et al. El retorno económico y social de la e-interconsulta de cardiología en el área de Vigo. ICEDE Working Paper Series. abril de 2015;11:1-28.

28. Hutchinson CL, Berndt A, Gilbert-Hunt S, George S, Ratcliffe J. Valuing the impact of health and social care programmes using social return on investment analysis: how have academics advanced the methodology? A protocol for a systematic review of peer-reviewed literature. BMJ Open. 9 de diciembre de 2018;8(12):e022534. 


\section{CAPÍTULO}

SROI EN LA TOMA DE DECISIONES: LA VISIÓN DEL GESTOR

Cristina Ibarrola 


\subsection{SISTEMA NACIONAL DE SALUD: LOGROS Y RETOS DE FUTURO}

El sistema sanitario en España es uno de los mayores logros que ha contribuido al bienestar de la ciudadanía. Los cambios sociodemográficos, el envejecimiento de la población, el incremento de enfermedades crónicas y de personas con dependencia, así como la innovación tecnológica, suponen un incremento progresivo del gasto sanitario que amenaza la solvencia del sistema. Esta situación se agrava por el incremento preocupante de la deuda pública, que además es netamente inferior a la cifra presentada por los pasivos no financiados, es decir, la promesa de prestaciones por pensiones y asistencia sanitaria a generaciones futuras ${ }^{[1]}$.

La transformación del sistema sanitario hacia un modelo de atención integrada centrado en la persona, la evaluación orientada a resultados en salud y la gestión responsable de los recursos públicos con transparencia y rendición de cuentas, sin medidas populistas ni demagógicas, son la mejor manera de defender una sanidad universal, pública y de calidad para las generaciones futuras.

\subsubsection{Logros del Sistema Nacional de Salud}

España tiene uno de los sistemas sanitarios con mejores resultados de la Organización para la Cooperación y el Desarrollo Económicos (OCDE) y además uno de los más eficientes, con un menor gasto total per cápita que la media de los países de la OCDE.

El índice de eficiencia en salud que elabora Bloomberg sitúa al sistema sanitario español como el más eficiente de toda Europa y el tercero en el ranking mundial, tan solo por detrás de Hong Kong y Singapur ${ }^{[2]}$. Este índice mide la eficiencia de los sistemas sanitarios a través de la esperanza de vida, el gasto en salud per cápita y el peso relativo del gasto sanitario sobre el producto interior bruto (PIB).

La esperanza de vida en la mayoría de países de la OCDE se ha incrementado en más de 10 años desde 1970, reflejando mejoras tanto en el sistema sanitario como en otros muchos ámbitos: cambios en los estilos de vida, en condiciones socioeconómicas, condiciones laborales, sistema educativo o de protección social. El éxito en el aumento de la esperanza de vida es fruto de inversiones apropiadas tanto dentro como fuera del sistema de salud.

España es el cuarto país más longevo del mundo, con una esperanza de vida media de 83 años. De mantenerse la tendencia actual, se estima que ocupará el primer puesto en 2040, superando a Japón, Suiza y Singapur, gracias a un aumento estimado de 2,8 años ${ }^{[3]}$.

España se encuentra entre los países de la OCDE con mejor percepción de la salud, menor prevalencia de enfermedades crónicas y cáncer. Asimismo, tiene una de las menores tasas de mortalidad por cardiopatía isquémica, enfermedad cerebrovascular, cáncer y mortalidad infanti ${ }^{[4]}$. Cabe destacar en el lado opuesto, una mayor prevalencia de diabetes, demencias y de tabaquismo que la media de países de la OCDE.

Tras la reciente crisis económica sufrida, no se ha objetivado en el sistema sanitario español impacto negativo en la mayoría de indicadores de resultados en salud, incluyendo esperanza de vida, mortalidad prematura, mortalidad evitable por enfermedades cardiovasculares y cerebrovasculares. Los años de crisis no han tenido impacto negativo tampoco en la salud autopercibida de la población española ${ }^{[5]}$. Como impactos negativos durante el periodo de 
crisis, aumentó la prevalencia de trastornos mentales atribuibles al desempleo y se incrementaron las listas de espera ${ }^{[6]}$.

\subsubsection{Retos de futuro}

En la actualidad, el 19,2\% de la población española tiene 65 años de edad o más ${ }^{[7]}$. De acuerdo a las previsiones del Instituto Nacional de Estadística, uno de cada cuatro españoles tendrá más de esa edad en el año 2035 y será uno de cada tres en 2052. Se espera que la población española de más de 80 años de edad crezca a más del doble en los próximos 30 años. El incremento de la esperanza de vida y la reducción progresiva de la tasa de natalidad en los últimos años hace que las poblaciones sean cada vez más envejecidas, con incremento de enfermedades crónicas, personas con dependencia, fragilidad, complejidad y múltiples patologías. Estas circunstancias además de producir un incremento de costes sanitarios precisan una transformación del modelo asistencial que se adapte mejor a las necesidades de la sociedad, con una visión holística, centrado en las personas, que proporcione una respuesta integral a sus necesidades clínicas, de cuidados, sociales y emocionales. Se hace necesario un modelo de integración sanitaria y sociosanitaria y una atención más humanizada.

Los cambios sociodemográficos y la innovación tecnológica en el sector salud producen un incremento progresivo del coste sanitario. El gasto sanitario en España suponía en 1990 un $6,5 \%$ del PIB, inferior a la media de los países de la OCDE, pero en 2012 alcanzó la media de la OCDE, situada en un 9,3\%. En la figura 7.1 se refleja la aportación al gasto público en sanidad total consolidado en España entre 2002 y $2017^{[8]}$.

\section{FIGURA 7.1. GASTO SANITARIO PÚBLICO EN ESPAÑA (EN €). PERIODO 2002-2017}

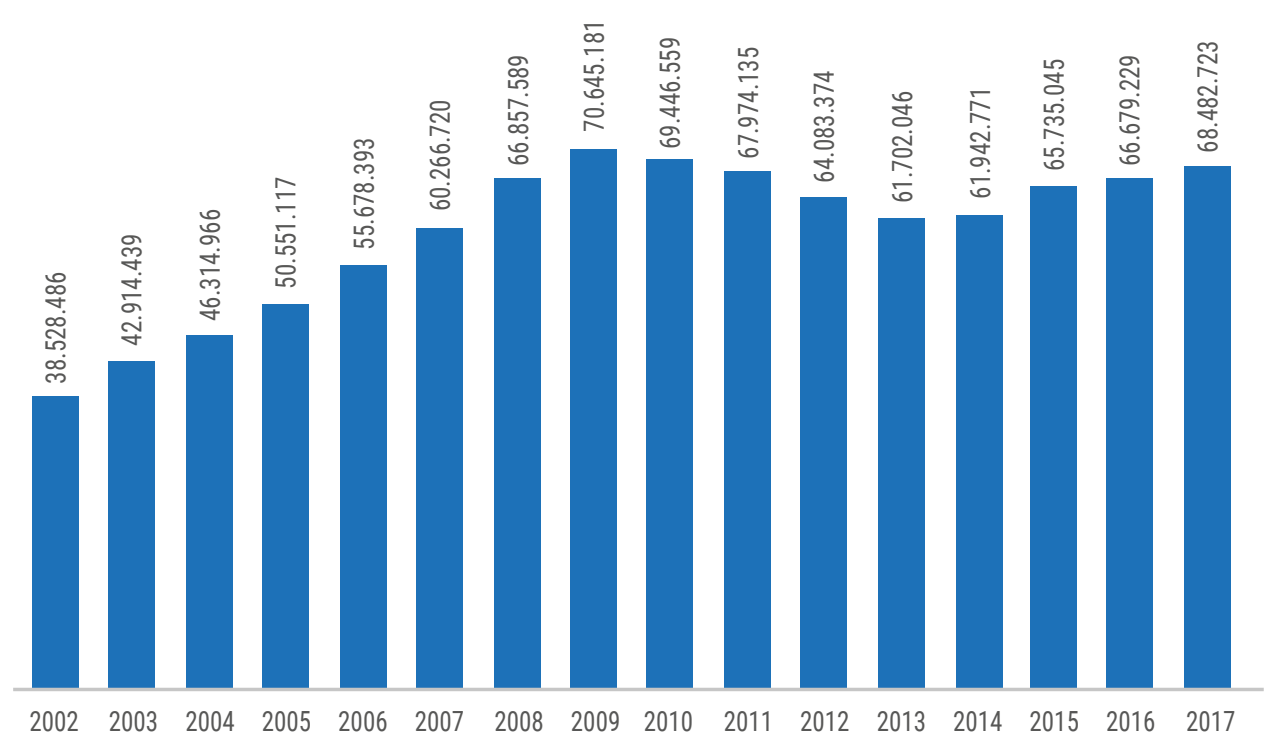

Fuente: elaboración propia con datos del Ministerio de Sanidad, Consumo y Bienestar Socia[ ${ }^{[8]}$.

La innovación tecnológica es responsable de entre un 30\% y un 50\% del incremento del gasto sanitario. 
Dar respuesta a las nuevas necesidades requiere una transformación del modelo asistencial que minimice la fragmentación asistencial, a través de modelos de atención integrados sanitarios y sociosanitarios centrados en las personas y sus necesidades de forma integral. El modelo actual de atención, excesivamente especializado y orientado a procesos agudos, no se adecúa a las necesidades reales de los pacientes crónicos. No resulta ni sanitariamente idóneo, ni socialmente eficiente, especialmente en pacientes pluripatológicos. Los cuidados integrados permiten una estrategia efectiva para mejorar la calidad de los cuidados y reducir los costes en pacientes crónicos. Algunas estrategias ya han demostrado dicha posibilidad en patologías específicas como diabetes, enfermedades cardiovasculares y respiratorias ${ }^{[0]}$, pero dada la heterogeneidad de las estructuras asistenciales, la validación externa en diferentes ámbitos debe ser cautelosa y siempre adaptada a las características de las estructuras locales. Independientemente del modelo de atención a pacientes crónicos utilizado, en algunos sectores poblacionales concretos algunos factores clave son comunes, como la coordinación efectiva a través de los diferentes estamentos, y cómo todos los proveedores de cuidados pueden coordinarse para asegurar la continuidad de los cuidados ${ }^{[10]}$.

El sistema sanitario debe, además, impulsar estrategias de humanización de la asistencia sanitaria, apostar por la mejora de la calidad y la seguridad de pacientes y estar orientado hacia resultados en salud, minimizando las desigualdades en resultados en salud. Todo ello contando con la participación activa de pacientes y sus familias, a través de estrategias de participación ciudadana, con acciones como el impulso de decisiones compartidas, la participación en la definición y evaluación de las estrategias en salud o la participación en la toma de decisiones de gestión sanitaria en los órganos de gobierno de centros y organizaciones sanitarias.

La transformación del modelo sanitario debe contar necesariamente con la participación e implicación de los profesionales sanitarios, verdaderos valores del sistema.

\subsection{AYUDA A LA TOMA DE DECISIONES EN GESTIÓN SANITARIA}

El desarrollo tecnológico ha contribuido a la mejora en resultados en salud, pero si no se toman las decisiones adecuadas a nivel de política y gestión sanitaria, puede amenazar la sostenibilidad del sistema. Las necesidades son siempre mayores que los recursos y es preciso realizar una priorización que ayude a la toma de decisiones.

Un reciente estudio de la OCDE ha estimado que el 20\% de las intervenciones que se realizan en los sistemas sanitarios no aportan valor en salud, fundamentalmente debido a pruebas diagnósticas o tratamientos innecesarios, así como a ingresos evitables ${ }^{[11]}$. Estos resultados son similares a estudios previos que estiman las ineficiencias en los sistemas de salud entre un $20 \%$ y un $30 \%{ }^{[12,13]}$.

La identificación de estas intervenciones o procedimientos inadecuados que no aportan valor en salud, es fundamental para poder reinvertir en otras intervenciones o procedimientos con mayor ganancia en salud.

La evaluación de tecnologías sanitarias ayuda a la toma de decisiones en relación a la priorización de tecnologías a invertir o desinvertir para poder obtener la mayor ganancia en salud desde una perspectiva poblacional, entendiendo que siempre existe un coste-oportunidad en cada decisión, por la mejora en resultados en salud que se deja de obtener si hubiéramos priorizado intervenciones diferentes. Por tecnología sanitaria se entiende cualquier tipo de 
intervención o procedimiento utilizado con la finalidad de mejorar la salud o prevenir, diagnosticar, tratar o rehabilitar las secuelas de una enfermedad.

La evaluación de tecnologías considera, además de la seguridad, eficacia y calidad de las intervenciones, su efectividad, idoneidad, aplicabilidad, coste-efectividad, impacto económico, así como las consideraciones éticas, legales, sociales y organizativas de su implementación.

En 2012 se crea la Red Española de Agencias de Evaluación de Tecnologías Sanitarias y Prestaciones del SNS (Sistema Nacional de Salud), con el objetivo de generar información que ayude a la toma de decisiones.

Considerar el beneficio en salud que deja de obtenerse en la mejor alternativa razonablemente disponible constituye una forma de asegurarse que se obtiene el máximo resultado, en términos de impacto en el bienestar, a partir de unos recursos determinados. El verdadero coste de la atención sanitaria no es el dinero, ni los recursos que el dinero mide, sino los beneficios sanitarios que podrían haberse conseguido si en esa inversión económica se hubiera utilizado la mejor alternativa[14].

Una herramienta complementaria para la decisión que puede incorporar sistemáticamente, además de costes y beneficios, otras dimensiones como aspectos éticos, organizativos, legales y sociales, junto con las perspectivas de las diferentes partes interesadas (pacientes, pagadores...) es el análisis de decisión multi-criterio ${ }^{[15]}$.

La orientación a resultados en salud de las organizaciones sanitarias permite cuantificar, analizar e interpretar los resultados en salud que generan las intervenciones sanitarias en condiciones de vida real, con el objetivo de evaluar si dichas intervenciones consiguen mejoras en resultados en cantidad o calidad de vida, o de rediseñar dichas intervenciones para mejorar dichos resultados.

La gestión basada en valor tiene como objetivo garantizar la mayor ganancia en salud al menor coste posible. En definitiva, conseguir mayor salud a coste razonable. El valor en salud relaciona los resultados en salud que son importantes para el paciente, con los costes. Entre los resultados en salud, además de dimensiones de proceso, calidad, seguridad de paciente, mortalidad y efectividad, se debe incluir la perspectiva de paciente, con valoración de satisfacción, experiencia de paciente, preferencias de paciente, calidad de vida, experiencia vital o impacto emocional.

Se requiere además que las organizaciones tengan información pormenorizada y fiable de costes por paciente.

Los resultados en salud y la gestión basada en valor facilitan la toma de decisiones sobre asignación y reorganización de recursos.

En España ha existido un bajo arraigo de la cultura evaluativa en la toma de decisiones en política sanitaria ${ }^{[16]}$. La falta de profesionalización en la gestión sanitaria genera problemas para que esta cultura impregne en las organizaciones. Además, las escasas evaluaciones económicas que se realizan tienen en su mayoría una perspectiva de sistema sanitario, siendo muy relevantes en muchas ocasiones otro tipo de costes que se necesitaría evaluar de forma adecuada desde una perspectiva social. 


\subsection{MÉTODO SROI EN EL ABORDAJE IDEAL DE LA INSUFICIENCIA CARDIACA}

Para valorar el método SROI (Social Return On Investment) en evaluación económica de intervenciones sanitarias, vamos a utilizar como ejemplo el análisis SROI realizado en relación con el abordaje ideal de la insuficiencia cardiaca (IC) en el SNS ${ }^{[17]}$, como ya se mencionó en el capítulo anterior. Se hizo una revisión de la literatura científica y de datos oficiales, así como en una encuesta a 558 pacientes y sus cuidadores informales, valorando el impacto de la enfermedad en su vida cotidiana y su calidad de vida. La edad media de los pacientes en el análisis fue de 64 años, 60,6\% hombres, siendo 62\% leves y 38\% moderado-graves.

La prevalencia en España de la IC se estima entre un 4,7\% y un 6,8\%. Es la primera causa de hospitalizaciones en mayores de 65 años, siendo el motivo del 3-5\% de las hospitalizaciones totales, $2 \%$ de urgencias y $2 \%$ del gasto sanitario total. Uno de cada cuatro pacientes reingresa a los tres meses y hasta dos de cada tres reingresan en el primer año. Los pacientes con IC presentan limitaciones para su actividad laboral, mantener relaciones sociales, con pérdida progresiva de autonomía y afectación de la calidad de vida relacionada con la salud (CVRS).

En el análisis realizado, nueve de cada diez pacientes encuestados presentaban además de IC otras patologías crónicas, aproximadamente dos de cada tres presentaban dificultad para respirar después de hacer ejercicio o al realizar algún esfuerzo, necesidad nocturna de ir al baño, fatiga, dolor o malestar y, algo más de la mitad, depresión o ansiedad.

En cuanto al impacto social, más del 50\% refiere algún cambio en la actividad sexual, y en la relación con familia o amigos.

El 9,1\% de los pacientes recibieron cuidados profesionales y el 50,9\% tenían un cuidador informal, siendo este de una edad media de 56 años, 71\% mujeres, 52\% cónyuge del paciente y con una media de ocho años ejerciendo el rol de persona cuidadora, y una media de 1.348 horas al año.

Para la mayoría de cuidadores informales, el impacto de la IC sobre sus vidas es positivo, con sentimiento de orgullo y satisfacción, reconocimiento por los demás e incremento de la cercanía con el paciente. Frente a esto, dos de cada tres ven afectado su ocio, tiempo libre, vida familiar y laboral, el 44\% presenta cambios emocionales, el 33\% trastornos del sueño, el $27 \%$ problemas laborales, el 25\% aislamiento social y el 20\% carga económica.

Además, se constituyó un comité multidisciplinar de expertos con todos los agentes implicados, entre los que se encuentran médicos de las diferentes especialidades que atienden a pacientes con IC (Cardiología, Medicina Interna, Urgencias y Atención Primaria), Enfermería, pacientes, personas cuidadoras, asociaciones y gestores sanitarios. Los comités de expertos definieron el abordaje actual de la patología y sus carencias. Asimismo, consensuaron el abordaje ideal con la descripción de las propuestas necesarias para su implementación, así como los retornos esperables al hacerlas efectivas.

Las propuestas se priorizaron en función del impacto positivo que podrían tener en la vida de pacientes y personas cuidadoras. En pacientes se tuvieron en cuenta cambios en signos y síntomas, autocuidado, enfermedades concomitantes, relaciones sociales, tareas de la vida 
diaria, movilidad, ámbito emocional y vida laboral. En las personas cuidadoras, se valoró el impacto emocional, social y económico.

Entre los objetivos de este análisis, además de consensuar el abordaje ideal de la IC en el SNS, estaba evidenciar el impacto clínico, asistencial, económico y social de la IC, así como favorecer la planificación estratégica óptima de los recursos sanitarios.

Entre las propuestas definidas en el modelo de abordaje ideal se incluyeron la optimización de la historia clínica electrónica y la receta electrónica, implantación de enfermeras gestoras de casos, educación sanitaria a pacientes y cuidadores, programas de rehabilitación cardiaca, acceso a ecocardiografía desde atención primaria o urgencias, acceso rápido al especialista, agilización de recursos sociales o la implantación de cuidados paliativos.

Como retornos esperados con la implantación de las propuestas para el abordaje ideal se incluyen la mejora en la adherencia terapéutica, mayor seguridad en tratamiento y seguimiento, reducción de reingresos hospitalarios, reducción de visitas innecesarias, reducción de pérdidas de productividad laboral, mejora en la autonomía del paciente, mejora en la calidad de vida de pacientes y cuidadores, freno de la progresión a estadios avanzados, mejora de la satisfacción de pacientes, reducción de la carga familiar del cuidador, mejora del estado emocional, económico y social de las personas cuidadoras, mejora de la eficiencia del sistema sanitario y mejora de la calidad de la atención.

La inversión total en España necesaria para el abordaje ideal definido en IC sería de 548,08 millones de euros y el retorno social esperado tras su implantación ascendería a 1.931,71 millones de euros.

Este abordaje podría mejorar la calidad de vida de pacientes y cuidadores, así como contribuir a la racionalización de la utilización de recursos sanitarios.

El retorno social con el método SROI es de 3,52 euros por cada euro invertido, que podría incrementarse hasta 4,16 euros bajo condiciones más favorables variando la amortización de los equipamientos técnicos contemplados en el abordaje ideal.

En los últimos años se han producido grandes avances en el diagnóstico, seguimiento y tratamiento de pacientes con IC. El método SROI ha contribuido además a que representantes de todos los grupos de interés en el abordaje del proceso de la IC reflexionen y definan un modelo de atención ideal, así como a estimar el valor sanitario y social que puede tener ese nuevo abordaje, partiendo del análisis de áreas de mejora del abordaje actual. La fortaleza de este análisis ha sido contar con personas de los diferentes ámbitos de atención, contando con diferentes perfiles y niveles asistenciales, así como con perfiles de gestión, pacientes, asociaciones y cuidadores, con una gran involucración e interés en la mejora del proceso. Dado el alto impacto de la IC no solo en la pérdida de salud de las personas afectadas sino de otros aspectos como el impacto social o el absentismo laboral de pacientes y cuidadores, esta metodología aporta mucho más valor que un análisis económico con una perspectiva sanitaria. La implementación del nuevo abordaje definido de IC podría permitir generar retorno social de las inversiones a realizar a través de diferentes impactos: 
- Mejora del estado de salud y calidad de vida de pacientes y cuidadores.

- Reducción de costes sanitarios en relación con una redistribución de recursos sanitarios a través de nuevas modalidades asistenciales y reducción de ingresos hospitalarios.

- Reducción de pérdidas de productividad laboral en pacientes y cuidadores.

\subsection{FORTALEZAS Y DEBILIDADES DE SROI COMO HERRAMIENTA EN LA TOMA DE DECISIONES EN GESTIÓN SANITARIA}

El método SROI se basa en el análisis coste-beneficio, pero además de una evaluación económica tiene en cuenta los impactos sociales y medioambientales.

SROI es la comparación entre el valor que se genera de una intervención y la inversión requerida para conseguir dicho impacto[18].

A diferencia de otras metodologías de evaluación, SROI ofrece una forma de asignar valor a resultados personales, sociales y comunitarios, además de a resultados económicos ${ }^{[19]}$.

\subsubsection{Fortalezas}

La utilización del método SROI en salud puede resultar de enorme interés al identificar e implicar de forma activa los denominados grupos de interés. Se fomenta la participación e implicación de todos los agentes involucrados, como equipos multidisciplinares y diferentes perfiles profesionales asistenciales con diferentes visiones complementarias, gestores, pacientes, asociaciones de pacientes, ciudadanos, cuidadores, sociedades científicas u otros grupos profesionales. Esta participación e implicación desde el inicio favorece el análisis exhaustivo de ámbitos de mejora y la identificación de nuevas intervenciones o necesidades de recursos, así como la estimación del impacto que puede tener cada una de esas intervenciones o inversiones en el valor social de cada grupo de interés. Se facilita la confianza mutua y la visión integrada y se tiene en cuenta desde el inicio el interés y la perspectiva de pacientes, familiares y cuidadores, tanto desde la perspectiva sanitaria como desde otras implicaciones como el impacto emocional, en el ocio, en el ámbito laboral, en pérdida de autonomía, calidad de vida, etc. Se pueden valorar asimismo mejoras en la satisfacción de profesionales implicados en la atención, al contemplar acciones de mejora definidos y propuestos por ellos mismos.

El método SROI mejora la capacidad de tomar decisiones en el diseño de políticas sanitarias y la redistribución de recursos sanitarios. Haber participado en la definición mejora su implicación posterior en la implementación y en el éxito de los resultados, maximizando el valor social.

La utilización de este método puede acercar posturas y visiones entre profesionales sanitarios y gestores, así como suponer una verdadera estrategia de participación ciudadana en las políticas sanitarias.

La evaluación no contempla únicamente elementos cuantitativos. Los elementos cualitativos complementan el análisis necesario en intervenciones complejas.

La perspectiva social, aunque es más compleja de estimar, da una mayor información que la perspectiva desde el sistema sanitario. Esta visión más amplia permite hacer una me- 
jor priorización, ya que intervenciones que desde el ámbito sanitario puedan generar un incremento de coste, pueden tener un mayor beneficio desde la perspectiva social, como podría ser la prevención de la dependencia y discapacidad o la reducción en el absentismo laboral de pacientes y/o familiares o cuidadores, que pueden tener un alto impacto social. Estimar únicamente costes y beneficios en salud pueden minusvalorar ahorro en otros costes para la sociedad, a los que habría que añadir mejoras en calidad de vida o satisfacción de pacientes, familiares, cuidadores y profesionales sanitarios. El objetivo es la medición y mejora de los cambios producidos por las intervenciones en la sociedad y no solo la ganancia en salud.

SROI facilita la estimación del valor social de las inversiones y al involucrar a los grupos de interés, permite maximizar el valor social logrado por la organización.

La herramienta supone una ayuda en la identificación de intervenciones que aportan valor, así como en la priorización de inversiones de acuerdo al valor social estimado con su implementación. El propio método intenta además minimizar el impacto social que no es atribuible a la propia organización.

Desde el ámbito de gestión sanitaria, puede suponer una ayuda en la toma de decisiones y en la planificación estratégica, aunque se necesita altura de miras y una visión integral en los gestores, para considerar impactos que no son exclusivos del sistema sanitario y que tienen en consideración decisiones de redistribución de recursos que afectan a diferentes departamentos de las Administraciones públicas.

SROI puede contribuir a una mayor ganancia en salud y social, a reducir costes y a la sostenibilidad del sistema.

Este método resulta de especial interés en el ámbito sociosanitario o en evaluaciones de intervenciones que tengan implicaciones sociales relevantes.

\subsubsection{Debilidades}

A la vez que una fortaleza, la participación de los grupos de interés en algunos casos puede llegar a ser una debilidad de SROI, si la selección de participantes es inadecuada, lo que puede ocurrir por falta de implicación o de interés en el tema, por responder a intereses personales por encima de los intereses de la organización o por selección sesgada y dirigida de los participantes por parte de la organización, primando otros intereses sobre búsqueda de la mejora continua y de elementos objetivos de ayuda a la toma de decisiones.

Tanto los supuestos de partida como las estimaciones del impacto de las intervenciones, aunque basadas en gran parte en la literatura científica, son subjetivas y dependen del grado de conocimiento de los grupos de interés, hecho que puede llegar a sobreestimar o infraestimar el retorno social esperado.

En intervenciones sanitarias, en muchas ocasiones resulta complicado asignar valores monetarios a la mejora en resultados en salud, razón por la cual, el análisis coste-beneficio tiene una baja utilización en la evaluación de prestaciones sanitarias. 
En algunas ocasiones, si las organizaciones no disponen de fuentes de datos para el análisis SROI y dependiendo del valor del retorno social estimado, el coste de aplicar el método podría ser un obstáculo para su utilización.

Así como el análisis coste-utilidad de intervenciones distintas tiene valor en la priorización y toma de decisiones de tecnologías o procedimientos sanitarios, SROI no permite la comparabilidad de análisis de diferentes proyectos o intervenciones, lo que supone una limitación para su utilización en gestión sanitaria.

Se trata, no obstante, de un método complementario a otro tipo de evaluaciones y con interés creciente en la evaluación de intervenciones sanitarias con otras implicaciones de valor social. 


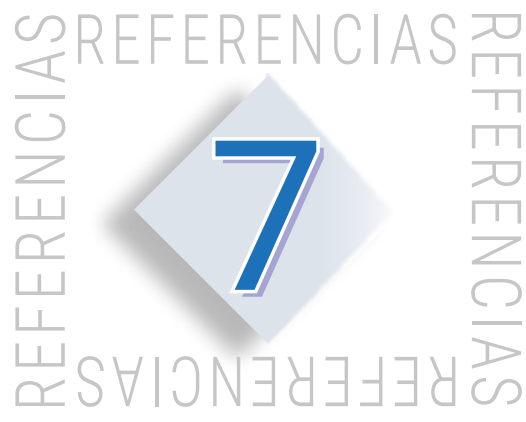

1. Mas N, Wisbaum W. La Triple Meta para el futuro de la sanidad. Papeles de Economía Española. 2014;142:2-6.

2. Miller iller LJ, Lu W. These Are the World's Healthiest Countries. 2019. [citado 26 de abril de 2019]; Disponible en: https://www.bloomberg.com/news/articles/2019-02-24/spain-tops-italy-as-worlds-healthiest-nation-while-u-s-slips

3. Lim SS, Updike RL, Kaldjian AS, Barber RM, Cowling K, York H, et al. Measuring human capital: a systematic analysis of 195 countries and territories, 1990-2016. Lancet. 06 de 2018;392(10154):1217-34.

4. OECD. Panorama de la Salud 2017: Indicadores de la OCDE. Paris: OECD Publishing; 2017. Disponible en: https://doi.org/10.1787/9789264306035-es

5. Regidor E, Barrio G, Bravo MJ, de la Fuente L. Has health in Spain been declining since the economic crisis? J Epidemiol Community Health. marzo de 2014;68(3):280-2.

6. Oliva Moreno J, Peña Longobardo LM, González López-Valcárcel B, Urbanos Garrido R, Barber Pérez P, Zozaya González N. Crisis económica y salud en España. Madrid: Ministerio de Sanidad, Consumo y Bienestar Social; 2018. (Informes, estudios e investigación). Disponible en: https://www. mscbs.gob.es/estadEstudios/estadisticas/docs/CRISIS_ECONOMICA_Y_SALUD.pdf

7. Instituto Nacional de Estadística. INEbase / Fenómenos demográficos / Indicadores demográficos básicos / Crecimiento y Estructura de la Población / Indicadores de Estructura de la Población / Proporción de personas mayores de 65 años o más [Internet]. 2018 [citado 4 de abril de 2019]. Disponible en: https://www.ine.es/jaxiT3/Datos.htm?t=1417

8. Ministerio de Sanidad, Consumo y Bienestar Social. Estadística de Gasto Sanitario Público (EGSP) [Internet]. [citado 26 de abril de 2019]. Disponible en: https://www.mscbs.gob.es/estadEstudios/ estadisticas/inforRecopilaciones/gastoSanitario2005/home.htm

9. Huber CA, Reich O, Früh M, Rosemann T. Effects of Integrated Care on Disease-Related Hospitalisation and Healthcare Costs in Patients with Diabetes, Cardiovascular Diseases and Respiratory Illnesses: A Propensity-Matched Cohort Study in Switzerland. Int J Integr Care. 8 de abril de 2016;16(1):11.

10. Béland F, Hollander MJ. Integrated models of care delivery for the frail elderly: international perspectives. Gac Sanit. diciembre de 2011;25 Suppl 2:138-46.

11. OECD/EU. Health at a Glance: Europe 2018: State of Health in the EU Cycle. París: OCDE Publishing; 2018. Disponible en: https://doi.org/10.1787/health_glance_eur-2018-en

12. Erlandsen E. Improving the Efficiency of Health Care Spending: Selected Evidence on Hospital Performance. Paris: OECD Publishing; 2007 jun p. 38. (Economics Department Working Papers). Report No.: 555. Disponible en: https://www.oecd-library.org/economics/improving-the-efficiency-of-health-care-spending_177838636311 
13. Institute of Medicine. Best Care at Lower Cost: The Path to Continuously Learning Health Care in America. Washington, DC: The National Academies Press; 2013. Disponible en: https://www.nap. edu/catalog/13444/best-care-at-lower-cost-the-path-to-continuously-learning

14. Ortún-Rubio V, Pinto-Prades JL, Puig-Junoy J. La economía de la salud y su aplicación a la evaluación. Atención Primaria. 1 de enero de 2001;27(1):62-4.

15. Bayón Yusta JC, Gutiérrez Iglesias A, Galnares-Cordero L, Gutiérrez-Ibarluzea I. Proyecto metodológico. Síntesis de información relevante de apoyo a los MCDA (análisis de decisión multicriterio) para la toma de decisiones. Ministerio de Sanidad, Servicios Sociales e Igualdad. Servicio de Tecnologías Sanitarias del País Vasco; 2019. Informe de Evaluación de Tecnologías Sanitarias: OSTEBA. Disponible en: http://www.ogasun.ejgv.euskadi.eus/r51-catpub/es/k75aWebPublicacionesWar/ k75aObtenerPublicacionDigitalServlet?R01HNoPortal=true\&N_LIBR=052312\&N_EDIC=0001\&C_ IDIOM=es\&FORMATO=.pdf

16. Oliva Moreno J, Worbes Cerezo M, López Bastida J, Serrano Aguilar P. Impacto de la evaluación económica de tecnologías sanitarias en las decisiones sanitarias. Madrid, Sta. Cruz de Tenerife: Ministerio de Ciencia e Innovación, Servicio Canario de Salud; 2010. (Informes de Evaluación de Tecnologías Sanitarias SESCS). Report No.: 2007/03. Disponible en: https://www3.gobiernodecanarias.org/sanidad/scs/contenidoGenerico.jsp?idDocument=5e949b81-22e4-11e0-964e-f5f3323 ccc4d\&idCarpeta=993a9b1d-7aed-11e4-a62a-758e414b4260

17. Merino M, Jiménez M, Ivanova Y, González A, Villoro R, Hidalgo Á, et al. Valor social de un abordaje ideal en insuficiencia cardiaca. Madrid: Instituto Max Weber; 2017. Disponible en: http://weber.org. es/publicacion/informe-proyecto-sroi-insuficiencia-cardiaca/

18. Narrillos Roux H. El SROI (social return ot investment): Un método para medir el impacto social de las inversiones. Análisis Financiero. 2010;(113):34-43.

19. Hutchinson CL, Berndt A, Gilbert-Hunt S, George S, Ratcliffe J. Valuing the impact of health and social care programmes using social return on investment analysis: how have academics advanced the methodology? A protocol for a systematic review of peer-reviewed literature. BMJ Open. 9 de diciembre de 2018;8(12):e022534. Disponible en: https://bmjopen.bmj.com/content/8/12/e022534 


\section{CAPÍTULO}

\section{SROI: LA UTILIDAD}

PARA LOS PACIENTES

Santiago Alfonso

Maite San Saturnino 
En una sociedad en que aumentan las enfermedades crónicas, en la que los recursos son limitados y en la que el éxito de la medicina ha hecho que la población viva más y aumenten sus necesidades, no tenemos más remedio que conseguir que la población se implique en el cuidado de la salud, si queremos garantizar la calidad y universalidad de nuestro sistema sanitario público.

Dr. Albert Jovell (1962-2013)

Fundador y primer presidente del Foro Español de Pacientes 


\subsection{EL PAPEL DE LAS ORGANIZACIONES DE PACIENTES}

El movimiento organizativo de pacientes nace con la voluntad de trabajar por las necesidades no cubiertas de los pacientes a través de la defensa de sus derechos como ciudadanos y de la prestación de servicios necesarios. Unas organizaciones se decantan por ser ellas quienes asuman la prestación de servicios, otras por revindicar estas necesidades, especialmente al Estado, y otras por un modelo mixto de actuación y reivindicación.

Cualquier modelo organizativo con estas propuestas es "políticamente" bien recibido, pero nunca apoyado y respaldado suficientemente.

Para las organizaciones de pacientes ha sido, y es, un reto ser consideradas como parte del sistema sanitario, como un agente más, clave hoy, aunque muchas de ellas incluso están reconocidas y declaradas como entidades de utilidad pública. Este reconocimiento parece ser útil únicamente en relación a los beneficios que la Ley de Mecenazgo concede en cuanto a deducciones fiscales para los donantes.

Este marco de mecenazgo ha permitido establecer alianzas importantes con otros agentes - como las sociedades científicas, agrupaciones profesionales o la industria farmacéuticapero no ha sido una llamada a la activación de las organizaciones de pacientes en el marco del SNS (Sistema Nacional de Salud), a pesar del ofrecimiento y capacitación de las organizaciones y responsables.

Existen muchos porqués a este (no contar) con las organizaciones de pacientes desde las administraciones, quizás sea un tema socio-político que muchas veces hemos calificado como despotismo sanitario: todo para el paciente, pero sin el paciente.

Por suerte, las organizaciones de pacientes no han desistido en el intento y desde su independencia han sabido luchar por su encaje - quizás lento- en el sistema. Seguimos reivindicando tener voz y voto.

Actualmente vemos cómo parece incrementarse la participación de los pacientes en la toma de decisiones, pero aún es más una tendencia política que una práctica real.

Defendemos y luchamos por la democratización del sistema, por la libertad de los pacientes, y por su plena participación en todas aquellas decisiones que afecten a su salud y no solo como derecho fundamental sino como un acto responsable que favorezca los mejores resultados terapéuticos, de salud y sociales.

Parece que hemos asumido que el paciente participa en las decisiones médicas, en cambio no hemos abierto las decisiones político-sanitarias a los pacientes-ciudadanos.

\subsection{SROI COMO HERRAMIENTA PARA APORTAR VALOR}

La participación de las organizaciones de pacientes en el Sistema Nacional de Salud ha ejercido de palanca de cambio para que las propias entidades se profesionalicen, para estar a la altura de las expectativas y necesidades reales que depositan en ellas sus asociados, los pacientes y familiares con enfermedades crónicas, recordemos, aquellas que más recursos consumen del sistema sanitario. 
Por eso muchas de ellas han dado un paso adelante liderando iniciativas que demuestren el valor social de un determinado abordaje, con el objetivo de mejorar la calidad de los pacientes a los que representan, por demostrar la viabilidad de muchas acciones y por un acto de solidaridad social.

En este sentido, la aplicación del método SROI (Social Return on Investment), puede ser una herramienta muy importante para organizaciones que plantean nuevas actuaciones y modelos, y que quieran contrastar o demostrar la viabilidad económica y el impacto social. Para esto, SROI se rige como una buena herramienta, se trata de un método contrastado y avalado a nivel internacional, con el rigor exigible y los estándares necesarios.

En esas incipientes propuestas de implantación del método SROI, dos colectivos de pacientes han sido punta de lanza: psoriasis e insuficiencia cardiaca, de la mano de Acción Psoriasis y CardioAlianza, respectivamente.

Bajo el paraguas de estas iniciativas se fraguaron dos propuestas muy interesantes que han sentado las bases para otras patologías y organizaciones.

\subsubsection{A propósito de la psoriasis}

En el porqué de este método y no otro, la reflexión desde el punto de vista de la psoriasis, emana de la necesidad de adaptarnos a las nuevas realidades de la enfermedad, en cuanto a enfoque de la patología y en cuanto a los tratamientos y abordaje del paciente.

A propuesta de las organizaciones estatales de pacientes de psoriasis -entre ellas, Acción Psoriasis-, la 67ª Asamblea Mundial de la Salud, celebrada en mayo de 2014, aprobó una resolución que describe la psoriasis como «una enfermedad crónica, no contagiosa, dolorosa, desfigurante e incapacitante para la que no hay cura».

La propia resolución instruyó al Director General de la OMS (Organización Mundial de la Salud), para que emitiera un informe global de la psoriasis. Dicho informe en su capítulo de recomendaciones insta a los políticos, a los prestadores de servicios de salud y a las organizaciones de pacientes a que desarrollen actividades que mejoren la calidad de vida de los pacientes con psoriasis de acuerdo con las nuevas realidades de la enfermedad, que se facilite el acceso a la innovación y que se disponga de los recursos necesarios para la consecución de estos objetivos, entre otras medidas.

España fue uno de los primeros países en adherirse al acuerdo de la OMS, pero no propuso ni activó la participación de estos agentes en órganos de análisis para conocer cuáles debían ser nuestras propuestas de mejora.

Si bien es verdad que la atención sanitaria y el acceso a la sanidad pública de los pacientes con psoriasis en España es de la mejores en los rankings internacionales, todavía son muchas las oportunidades de mejora.

El propio informe anexo a la resolución describe las nuevas realidades de la psoriasis: enfermedad inmunomediada con afectación sistémica.

Este concepto ya se venía trabajando y difundiendo por la comunidad científica, con evi- 
dencia y literatura que lo respalda, pero no se había traducido en el modelo de atención, ni evaluado su implementación.

La crisis de la primera década de este siglo, sirvió de pretexto para no avanzar y también las luchas de los pacientes se tuvieron que centrar en no perder algunos de los derechos adquiridos.

\subsubsection{A propósito de la insuficiencia cardiaca}

La insuficiencia cardiaca (IC) es una epidemia global, afecta a más de 1,5 millones de personas en España. Es una enfermedad muy gravosa, que ocasiona más de 100.000 ingresos hospitalarios al año, el $2 \%$ de las visitas a urgencias y una mortalidad anual del $10 \%$. Los costes asociados alcanzan los 2.500 millones de euros anuales, hasta el $2 \%$ del gasto sanitario totali.

El tratamiento de la IC ha experimentado grandes cambios, tanto desde el punto de vista de la terapia farmacológica como de la no farmacológica, y todo ello ha contribuido a mejorar el mal pronóstico de este problema. Pero no dejemos de tener en cuenta la mortalidad asociada.

En todos estos avances, aunque positivos, no se había concretado un modelo ideal de su abordaje que tuviera en cuenta las necesidades y preferencias de pacientes y la experiencia de la práctica clínica de los expertos.

Somos conscientes de las diferencias en la atención a la enfermedad en las diferentes comunidades autónomas e incluso dentro de la propia comunidad. Tenemos que estar preparados para la previsión del aumento de la incidencia de la IC en los próximos años, tal como apuntan los diferentes estudios.

Este reto lo asumimos desde CardioAlianza y en colaboración con los agentes sanitarios y sociales implicados en la gestión y tratamiento de la enfermedad. Y además de poner sobre la mesa propuestas concretas para el abordaje de la IC, cuantificamos el retorno social de la inversión. Para ello utilizamos el método SROI. Esta aproximación del retorno social se tuvo en cuenta además por tres vías: asumiendo una mejora del estado de salud y la calidad de vida de pacientes y cuidadores, racionalizando el consumo de recursos y reduciendo las pérdidas de productividad laboral asociadas.

\subsection{LA PERSPECTIVA DE LOS PACIENTES ANTE EL MÉTODO SROI}

En las propuestas de mejora de la atención de las patologías que las organizaciones lideran, destaca la necesidad de implantar un nuevo abordaje acorde con las nuevas realidades clínicas que describen los especialistas en sus publicaciones científicas o guías de práctica clínica.

El nuevo abordaje de la patología debía partir de preguntar al paciente cómo vive, qué expectativas tiene, cómo quiere ser tratado o, entre otras cuestiones, qué papel quiere asumir. Esta

Merino M, Jiménez M, Ivanova Y, González A, Villoro R, Hidalgo Á, et al. Valor social de un abordaje ideal en insuficiencia cardiaca. Madrid: Instituto Max Weber; 2017. Disponible en: http://weber.org.es/publicacion/informe-proyecto-sroi-insuficiencia-cardiaca/ 
es nuestra clave \#1.

\section{\#1 Preguntar a los pacientes}

Preguntamos a los pacientes, mediante una encuesta como método de recogida, para conocer el impacto de la enfermedad en la salud y el impacto social, laboral y emocional, y lo medimos en resultados económicos. Pretendíamos poner de manifiesto la relevancia social de la enfermedad, más allá de lo que está acostumbrado el sistema de salud.

\section{\#2 Participación de todos los agentes de interés}

Las organizaciones de pacientes siempre hemos apostado por sumar y, en este caso, sumamos junto con otros agentes de interés, aquellos que también tienen que aportar sobre la enfermedad: médicos de primaria, médicos especialistas, de urgencias, de medicina interna, enfermería, gestores sanitarios o economistas de la salud.

Se trataba de crear consenso entre todas las partes implicadas sobre cómo debía ser el abordaje ideal de la psoriasis y de la insuficiencia cardiaca.

\section{\#3 Evidenciar dónde se genera impacto}

Aunque podría parecer utópico a la hora de buscar un abordaje ideal de la psoriasis y de la insuficiencia cardiaca, todos los participantes eran conscientes de los recursos económicos y humanos que se podrían destinar a las nuevas propuestas de atención. Somos corresponsables en el sistema sanitario.

Aunque algunas de las propuestas parecían surgir del sentido común, lo cierto es que nunca habían sido planteadas por el sistema sanitario por no disponer de los recur sos humanos, técnicos o económicos necesarios y porque, principalmente, no se les había preguntado a los pacientes cómo querían ser atendidos.

A modo ilustrativo, se evidenció cómo el ofrecer información y educación sanitaria a los pacientes en fases tempranas, podía ayudar a mejorar los resultados en salud. Se demostró que es efectivo y además rentable. Más vale medicina preventiva que reactiva.

\section{\#4 El resultado debe comunicarse}

En ambos casos, se alcanzó un retorno social positivo del nuevo abordaje propuesto. En el caso de la psoriasis, invertir (que no gastar) 1 euro en el modelo suponía un retorno de 5,04 euros para todos los agentes implicados, mientras que en el caso de la IC el resultado fue de 3,52 euros.

Invertir en mejorar la atención sanitaria en estas enfermedades crónicas que tienen un alto impacto en la vida de los pacientes y sus familias es rentable en términos económicos y sociales.

Estos proyectos abren la puerta para poder generar modelos similares en otras patologías o procesos de la asistencia sanitaria. Ahora tocaba explicarlo y debatir con 
los decisores sanitarios y ambas entidades planteamos diferentes reuniones territoriales que nos permitieran establecer un debate en el abordaje de las patologías y poder trasladar nuestras propuestas de mejora y estudiar su implantación en el territorio local.

Si bien ambas entidades consensuamos que la acogida ha sido buena, vemos cómo la implementación de algunas propuestas va a ser lenta y gradual teniendo en cuenta condicionantes políticos y una cierta resistencia al cambio ya instalada en nuestro sistema.

\subsection{REFLEXIONES}

Tanto Acción Psoriasis como CardioAlianza hemos querido, con esta iniciativa, poner a disposición de los planificadores y gestores políticos una herramienta para la toma de decisiones con propuestas que redundan en los resultados terapéuticos, en la calidad de vida de los pacientes, en la redistribución de recursos y en la visión global de las enfermedades.

Esta visión global de la enfermedad requiere la colaboración y distribución de los recursos entre departamentos/consejerías.

Lo explicamos fácil: cuando un tratamiento/abordaje demuestra que de forma directa o indirecta disminuye bajas labores (Instituto Nacional de la Seguridad Social) y, por tanto, aumenta la productividad laboral (impuestos), evita complicaciones (trasplantes o nuevas patologías), las administraciones deben poder facilitar aumentar el presupuesto de sanidad, porque la vida de las personas no se mide en "economía, sanidad, social, infraestructuras, etc.", sino en supervivencia y calidad de vida. ¿En qué departamentos/consejerías se trata esto?

Se pone de manifiesto la necesidad de aumentar la participación y la democratización de la salud. Se abren muchos interrogantes sobre quién ha de decidir qué recursos se destinan, qué modelo se debe seguir, qué presupuestos dotar... Se debe articular la participación real de los pacientes a través de sus órganos colegiados, las organizaciones de pacientes.

Hace años que el modelo de atención está en crisis y es necesario replantear nuestra asistencia hacia la cronicidad. Entender sus necesidades, presentes y futuras, y aplicar las medidas necesarias para que las aportaciones ciudadanas tengan un retorno que revierta en la propia sociedad.

Queremos agradecer la oportunidad que también esta publicación nos brinda a las organizaciones de pacientes y felicitarnos porque esta publicación es el resultado del trabajo conjunto y de la ilusión de muchas personas por seguir teniendo una atención sanitaria de excelencia y participativa. 


\section{CAPÍTULO}

\section{CONCLUSIONES FINALES}

María Merino

Yoana Ivanova

Álvaro Hidalgo 
U no de los elementos diferenciadores del sector sanitario es que normalmente la innovación supone un desembolso presente muy importante y, al contrario de lo que sucede en otros sectores industriales, no suele estar acompañado de una reducción de costes, al menos a corto plazo. Por este motivo, la clasificación contable de la innovación del sector sanitario como un gasto hace que se adopte una óptica cortoplacista y deje de lado la concepción de la atención sanitaria como un elemento esencial en la creación e incremento del capital humano, aspecto ligado íntimamente con el crecimiento económico a largo plazo. Desde ese enfoque, el del capital humano, los desembolsos producidos en la mejora de la asistencia sanitaria deberían ser considerados como una inversión y, por lo tanto, medir su rentabilidad en función del retorno que dicha inversión produce para la sociedad. Ese abordaje es lo que lleva a cabo el método SROI (Social Return On Investment).

Dicho método busca cuantificar el valor social creado por distintas alternativas de inversión disponibles para mejorar la asistencia sanitaria, lo que puede contribuir a orientar la toma de decisiones hacia estrategias que permitan preservar la sostenibilidad del SNS (Sistema Nacional de Salud). Esta fórmula no pretende desplazar a otros métodos de evaluación económica, sino que se incorpora para ser un método complementario que incluye la perspectiva social de todos los agentes involucrados en una patología o intervención determinada.

En este sentido, hay que señalar que la valoración del impacto social de las intervenciones sanitarias no puede capturarse adecuadamente mediante un análisis estrictamente económico del rendimiento de la inversión realizada o planeada. El enfoque del SROI ofrece un marco cuyo principal objetivo es precisamente evaluar el retorno social de las intervenciones. Para conseguir esta meta es preciso identificar todos los retornos (outcomes) relevantes, no sólo aquellos que resultan fáciles de medir porque pasan por el mercado. Para monetizar los outcomes intangibles, como es el caso de los impactos de las intervenciones sanitarias, es preciso estimar proxies adecuados e incluso rebasar el ámbito sanitario impactando en otros sectores. Los efectos de salud, a su vez, pueden ser directos, pero también indirectos, mediados por características ambientales y personales colaterales al efecto inmediato de la intervención. Por último, el valor total de una intervención también comprende componentes de no uso que pueden resultar relevantes como, por ejemplo, el valor altruista derivado de la provisión de cobertura sanitaria a terceros.

Este enfoque es muy relevante, dada la situación actual de nuestra sociedad. Recordemos, que, según estimaciones del Instituto Nacional de Estadística, en 2050 más del 36\% de la población tendrá más de 65 años. Un panorama que implica más cronicidad y más dependencia y, por tanto, un mayor consumo de recursos sanitarios. Sin embargo, incluso incrementando la financiación dedicada a sanidad, el presupuesto siempre es limitado y susceptible de usos alternativos. En este sentido, el concepto de coste de oportunidad es esencial para comprender la necesidad de tomar decisiones adecuadas a la hora de asignar recursos en la asistencia sanitaria. Ante esta situación, la pregunta que surge es cómo asegurar la sostenibilidad del sistema, cómo distribuir los recursos para maximizar los beneficios que podemos obtener de ellos y, por lo tanto, maximizar el retorno social del presupuesto. Parte de la respuesta puede ofrecérnosla el método SROI.

A la hora de analizar la sostenibilidad del sistema, como hemos señalado anteriormente es importante pensar en las personas y no solo en el gasto sanitario. El objetivo no es solo mejorar los resultados en salud, sino también valorar el impacto positivo o negativo en otras partidas y actores que van más allá de lo sanitario como, por ejemplo, el impacto en los cuidado- 
res y familiares de los pacientes o en la productividad laboral de la población trabajadora. Por ello, es crucial adoptar medidas holísticas que aseguren la sostenibilidad del sistema a largo plazo. No es suficiente implantar una o dos medidas, sino que debemos buscar un enfoque capaz de detectar y definir las carencias del SNS para, solo entonces, poder identificar las posibles soluciones. Posteriormente, debemos también analizar la viabilidad de esas soluciones en la vida real, la factibilidad e idoneidad de su puesta en marcha y la comprobación de que estas propuestas consiguen realmente el objetivo que buscamos. Para ello, necesitamos un mapa de impacto que muestre el camino de una inversión desde su planteamiento hasta su resultado efectivo en salud y aquí es donde encaja el método SROI.

En definitiva, el SROI se muestra como un método válido tanto para la evaluación como para la planificación de intervenciones sanitarias, ya que plantea y detalla el proceso que sigue cada inversión hasta lograr el impacto perseguido, siempre teniendo en cuenta los costes invisibles de las patologías mediante una toma de decisiones racional y holística.

Entre sus principales fortalezas podemos señalar que es una metodología que fortalece la relación con los grupos de interés (stakeholders), es de utilidad para cubrir distintos objetivos en las organizaciones sanitarias, enlaza con la economía del bienestar al monetizar el impacto social integrándolo dentro de la evaluación económica como un análisis coste-beneficio desde la perspectiva social, favorece la comunicación interna, y recopila y sistematiza información del valor que generan las diferentes alternativas evaluadas, lo que es especialmente relevante si queremos un sistema que oriente el pago y la financiación al valor y no al uso.

En el otro lado de la balanza se encuentran las debilidades, entre las que caben mencionar la necesidad de disponer de una información ingente, detallada y pormenorizada de las diferentes alternativas, sus costes (tangibles e intangibles) y sus retornos. Esta limitación puede ser cada vez menor si se emplea el Real World Evidence para llevar a cabo este tipo de evaluaciones; por otro lado, este método no esta exento de subjetividad, especialmente en la selección de los diferentes stakeholders decisores sobre el proceso, así como en la selección de los Ilamados financial proxies o la cuantificación de los intangibles. Sin embargo, el análisis de sensibilidad puede reducir esta limitación.

En definitiva, la utilización del método SROI nos permite tener una visión más amplia de la tecnología sanitaria a evaluar incorporando la opinión de todos los posibles beneficiarios de la intervención. Por ello, una de las ventajas más importantes de utilizar el método SROI es tener en cuenta, a través de los distintos instrumentos de valoración, todos los afectados por la intervención sanitaria. Esa característica es también la que más diferencia al SROI de otras técnicas de evaluación donde generalmente solo se tiene en cuenta la perspectiva del pagador y, en contadas ocasiones, se utiliza una perspectiva más social. Ahora bien, como bien se señala a lo largo de este libro, esta visión más amplia también tiene sus inconvenientes. Por un lado, el trabajo de valoración de los beneficios es más complicado, no solo por la diversidad de técnicas a seleccionar, sino por el gran número de afectados a los que se tiene que tener en consideración.

Como bien ha quedado de manifiesto a lo largo del libro, desde que en 2005 se publicó el primer informe SROI en el área de la salud se ha avanzado en estandarización metodológica, en número de trabajos publicados y en su influencia práctica. En esta línea, la devolución de competencias de salud pública a las autoridades locales en el Reino Unido ha supuesto introducir el retorno social de la inversión en salud y atención sociosanitaria en el marco jurídico 
de dicho país con la aprobación de su Ley de 2013. Sin embargo, el impulso definitivo y su legitimación conceptual se ha producido con la integración del método SROI como uno de los principios de la OMS (Organización Mundial de la Salud).

En resumen, el método SROI se consolida como una herramienta clave para cuantificar la inversión en salud, desde una perspectiva holística, y con una vocación de servir en la toma de decisiones en la gestión y planificación sanitaria. La estandarización metodológica e iniciativas como el presente libro permiten acercar a los profesionales, a los pacientes y a los decisores un método que enlaza con la evaluación económica y que en el futuro está llamado a tener un protagonismo cada vez más importante en la evaluación de los sistemas sanitarios. 


\section{ANEXO}

\section{RESUMEN DE \\ APLICACIONES SROI EN SALUD}

Beatriz González López-Valcárcel 


\section{\begin{tabular}{|l|l|}
\hline \multicolumn{2}{|c|}{ PUBLICACIÓN } \\
\hline AUTOR & AÑO \\
\hline
\end{tabular}}

Goodspeed 2014 et al. ${ }^{[1]}$

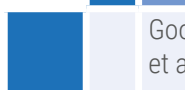

1

\begin{tabular}{|c|c|c|c|c|c|c|}
\hline $\begin{array}{l}\text { Davies } \\
\text { et al. }{ }^{[2]}\end{array}$ & 2016 & EV & $\begin{array}{l}\text { Higher } \\
\text { Education } \\
\text { Investment } \\
\text { Fund (HEIF), } \\
\text { Department }\end{array}$ & $\begin{array}{l}\text { Reino } \\
\text { Unido }\end{array}$ & $\begin{array}{l}\text { Valor social } \\
\text { del deporte }\end{array}$ & $\begin{array}{l}\text { No se evalúan } \\
\text { intervenciones, sino } \\
\text { la participación en } \\
\text { actividades deportivas } \\
\text { no profesionales }\end{array}$ \\
\hline
\end{tabular}

\begin{tabular}{|c|c|c|c|}
\hline $\begin{array}{l}\text { Bagnall } \\
\text { et al. }{ }^{[3]}\end{array}$ & 2016 & EV & $\begin{array}{l}\text { Age UK Sup- } \\
\text { port Services } \\
\text { Yorkshire \& } \\
\text { Humber) }\end{array}$ \\
\hline
\end{tabular}

$\begin{array}{ll}\text { Goudet } & 2016 \\ \text { et al. }{ }^{[4]} & \text { (informe); } \\ & 2018 \\ & \text { (BMC } \\ \text { Public } \\ \text { Health) }\end{array}$

\begin{tabular}{l|l|l}
$\begin{array}{l}\text { Harrison } \\
\text { et al. }{ }^{[5]}\end{array}$ & 2017 & $\begin{array}{l}\mathrm{EV}^{*} \\
\mathrm{y} \mathrm{PR}\end{array}$
\end{tabular}

No consta
en el
documento

for Culture

Media and

Sport (DCMS)

y Sport

England

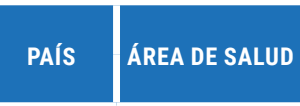

Reino

Unido

Abuso

de sustancias

programa Turning

Point Wakefield

Substance Misuse durante un año. Amplio conjunto de servicios para ayudar a la gente a superar la adicción al alcohol y las drogas

a

$\begin{array}{ll}\text { Reino } & \begin{array}{l}\text { Atención a } \\ \text { Unido }\end{array} \\ \text { las personas } \\ \text { mayores }\end{array}$

Centro de
investigación
(APHRC) y
gobierno
(Ministerio
de Salud).
Financiado
por Wellcome
Trust

\begin{tabular}{l|l} 
Kenia & $\begin{array}{l}\text { Nutrición } \\
\text { materna e } \\
\text { infantil }\end{array}$ \\
\hline \\
\hline
\end{tabular}

$\begin{array}{ll}\text { Reino } & \text { Abuso de } \\ \text { Unido } & \text { sustancias }\end{array}$

Together for Health, programa que ayuda a la gente mayor a comprar, limpiar, acompañar, con la medicación, acompañarles al médico entre otras actividades Maternal, Infant and Young Child Nutrition (MIYCN) project ${ }^{* \star}$. Consejos en casa sobre nutrición a las madres

Programa Give it
up para ayudar a
la deshabituación
de toxicómanos en
cuatro localidades del
Reino Unido, mediante
comunidades de
deshabituación

STAKEHOLDERS

CONSIDERADOS

Amplia lista de

stakeholders,

incluyendo la autoridad

local que financia el

servicio, los pacientes

(beneficiarios directos,

$n=1.136$ adultos)

y sus familiares y

comunidades, el

personal del servicio,

los proveedores de

atención sanitaria, las

prisiones y el sector de justica, etc.

Gobierno central y gobiernos locales, participantes,

voluntarios,

organizaciones

deportivas y educativas

\section{Beneficiarios}

del proyecto,

organizaciones no

lucrativas, voluntarios,

y profesionales

colaborando en el

programa

Madres, abuelas,

voluntarios de los

centros comunitarios,

centros de día,

proveedores sanitarios, comunidad de

empresas

Beneficiarios

y organización

proveedora 


\section{STAKEHOLDERS INCLUIDOS EN EL ANÁLISIS}

Todos los stakeholders

\section{DESCRIPCIÓN DE LA MUESTRA}

Amplia lista

de personas y organizaciones representativas de los stakeholders

No hay muestra

Todos los

stakeholders

Solo

beneficiarios

Todos los stakeholders

Solo

beneficiarios
Todos los clientes del programa. Se les evalúa con la Life Essentials Assessment Framework (LEAF) a la entrada y a las 6 y 12 semanas

Diseño aleatorizado con grupo de control de 1.100 mujeres y sus bebés

\section{Clientes del} programa en las cuatro áreas (en una de ellas no se ha podido calcular el SROI). Muestras pequeñas (un participante en cada grupo focal por 14 beneficiarios del programa)

\section{FUENTES DE DATOS}

Mezcla de datos cualitativos y cuantitativos, de fuentes primarias y secundarias (registros de la propia organización y otros)

Secundarias cuantitativas

Cuantitativas primarias del programa; entrevistas

cualitativas a

clientes y personal del programa

Método mixto con grupos focales, entrevistas en profundidad a informantes clave, encuestas cuantitativas

a stakeholders

y juegos de preferencias reveladas

Fuentes cuantitativas primarias del programa; entrevistas cualitativas a clientes y personal del programa

\section{HORIZONTE TEMPORAL \\ ANÁLISIS DE SENSIBILIDAD \\ TASA DE
DESCUENTO}

1 año (puede extenderse a más años desde la salida del programa)

1 año

\section{Sí}

Sí, sobre 5 outcomes: mejora de salud física (12\%), mejora de salud mental (15\%), reducción de la preocupación de la familia (13\%), mejora de la confianza de los hijos (15\%), reducción de delitos (24\%)

Sí

1 año

Hasta 1 año después de nacer el hijo

Sí, aunque no explica cómo; dice que los resultados son muy sensibles a la valoración del juego de preferencias reveladas

2 años

Sí

4,84 libras por

No

Sí, pero no dice cuál

No

No

$3,50 \%$

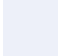

9 libras por libra invertida

Literatura gris libra invertida Literatura
gris Literatura
gris

71 dólares por Revista dólar invertido científica

7,17 libras por en la solución base; 8,88 sensibil Sí,

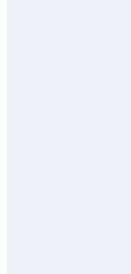
No

\section{Entre 5,12 y Literatura 9,24 libras por gris libra invertida}


$\mathrm{N}^{\circ}$

\begin{tabular}{|l|r|}
\hline \multicolumn{2}{|c|}{ PUBLICACIÓN } \\
\hline AUTOR & AÑO \\
\hline
\end{tabular}

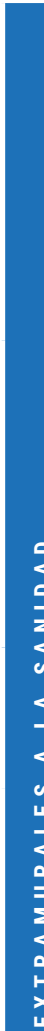

Wodinski 2013

et al. ${ }^{[6]}$

McMurchy ${ }^{[7]} 2018$

(actualizado)

et al. ${ }^{[8]}$

9

\begin{tabular}{|c|c|c|c|}
\hline $\begin{array}{l}\text { Willis } \\
\text { et al. }{ }^{[9]}\end{array}$ & 2018 & EV & $\begin{array}{l}\text { Health Innova- } \\
\text { tion Network } \\
\text { del Sur de } \\
\text { Londres }\end{array}$ \\
\hline
\end{tabular}

\begin{tabular}{|l|l|l|l|}
$\begin{array}{l}\text { Jones } \\
\text { et al. }{ }^{[10]}\end{array}$ & 2016 & EV & $\begin{array}{l}\text { Autoridad } \\
\text { local (Bristol) }\end{array}$
\end{tabular}

et al. [10]

\begin{tabular}{l|l|l|l|}
\hline $\begin{array}{l}\text { Jones } \\
\text { et al. }{ }^{[11]}\end{array}$ & 2018 & EV & $\begin{array}{l}\text { Cross-Council } \\
\text { Connected } \\
\text { Communities } \\
\text { Programme }\end{array}$ \\
\hline
\end{tabular}

Improvement

(IHI)

de salud

pública de

Gloucester-

shire

10

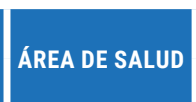

Salud materna y atención social a

mujeres

vulnerables

embarazadas

(pregnancy

program)

Reino

Unido

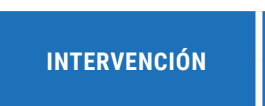

STAKEHOLDERS CONSIDERADOS

Evaluación del programa H.E.R. (Healthy, Empowered, Resilient) Pregnancy Program

Reino Ejercicio físico

Unido

Ejercicio físico Programa Active

Together (AT), para

fomentar la actividad física

\section{Reino \\ Grupos de}

apoyo a las

personas con

demencia

Programa de

nutrición en

escuelas (Food

for Life). Forma

parte de una

intervención

más amplia de

la autoridad

local que in-

cluye también

hospitales y

residencias

Demencia

Programa Dementia and Imagination study de artes visuales para personas con demencia (12 semanas)
Tres grupos de apoyo en el sur de Londres, en los que participan los propios pacientes

Acciones coordinadas entre redes de escuelas, productores de alimentos, stribuidores de alimentos, caterings y otras agencias
No se mencionan más que los clientes y el staff. Participan en el programa como miembros un total de 22 organizaciones de distinto tipo

Gloucestershire County Council (GCC) y todas las organizaciones que habían pedido fondos al GCC (clubs deportivos, organizaciones no lucrativas, etc.), así como los usuarios

Pacientes, cuidadores, voluntarios

47 (escuelas, sociedad civil, padres y

cuidadores, negocios locales, autoridades locales, autoridad de salud pública)

9 stakeholders, incluyendo el Sistema Nacional de Salud, beneficiarios del programa y familiares, personal del programa, los artistas participantes, otros residentes en los hogares donde viven los beneficiarios, etc. 


\section{STAKEHOLDERS INCLUIDOS EN EL ANÁLISIS}

No se explicitan

stakeholders

Personas y
organizaciones
representativas de
los stakeholders

Todos los

stakeholders

Todos los

stakeholders

Solo

beneficiarios,

cuidadores

familiares y

cuidadores del

programa

\section{DESCRIPCIÓN DE LA MUESTRA}

No hay muestra
Grupos focales y entrevistas

Grupos focales y entrevistas

125 personas con demencia y 146 cuidadores

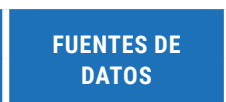

\section{HORIZONTE TEMPORAL}

Mezcla de datos cualitativos y cuantitativos, del propio programa (staff, clientes, financiadores, profesionales)

\section{Entrevistas semiestructura- das, entrevistas individuales} $(n=27)$

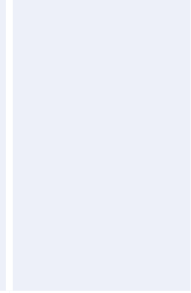

2 años

Grupos focales y

entrevistas

No se
especifica

Entrevistas a 48

3 años

participantes

(profesores,

cocineros,

gerentes de

catering,

proveedores,

negocios locales

de distribución y

producción entre

otros)

Datos cualitativos y cuantitativos

de calidad de
1 año No

ANÁLISIS DE

vida, apoyo y

percepciones del

programa

obtenidos

mediante

entrevistas
1 año

(2 años en el

análisis de

sensibilidad) SENSIBILIDAD

\section{DESCUENTO}

\section{No}

Sí

$3,50 \%$

No se

menciona

RATIO SROI

OBTENIDA

8,24 dólares por dólar

invertido

7,25 libras por libra invertida

\section{Entre 1,17y}

5,18 libras por libra invertida

Sí

$3,50 \%$

4,41 libras por libra invertida (dos casos de estudio con variación en la ratio entre ellos)

Sí

$3,50 \%$

5,18 libras por libra invertida
Literatura gris

Revista gris Revista

FUENTE

Literatura gris

científica

Literatura

científica 


\section{$\mathbf{N}$}

\begin{tabular}{|l|r|r|}
\hline \multicolumn{2}{|c|}{ PUBLICACIÓN } & TIPO \\
\hline AUTOR & AÑO & SROI \\
\hline
\end{tabular}

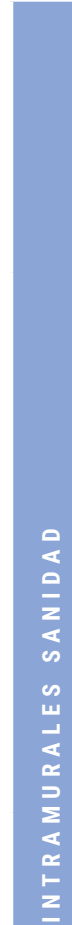

Durán 2015

Piñeiro

et al. ${ }^{[12]}$

11

12

González

et al. ${ }^{[13]}$

Merino

EV

et al. ${ }^{[14]}$

\section{ENCARGADO \\ POR}

Organización

sanitaria

pública
2017

P

2016

PR

Novartis

Farmacéutica

España Psoriasis

Novartis
Farmacéutica

España

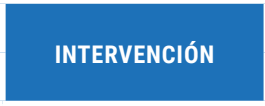

E-consulta de cardiología para mejorar la coordinación entre atención primaria y especializada y mejorar la satisfacción del paciente Tratamiento "ideal" de la psoriasis, que consta de 22 propuestas, considerando las intervenciones sanitarias a nivel del diagnóstico de la enfermedad, así como en el tratamiento y seguimiento de la psoriasis, teniendo en cuenta los distintos niveles de gravedad de la psoriasis

Tratamiento "ideal" de la insuficiencia cardiaca, que consta de 28 propuestas incluyendo la generalización de la historia clínica compartida, la receta electrónica, la enfermería gestora de casos, las unidades de rehabilitación cardiaca, la mejora del acceso al ecocardiograma y la formación y orientación psicológica a pacientes, entre otras
STAKEHOLDERS

CONSIDERADOS

Los pacientes y sus acompañantes, los profesionales sanitarios y la organización sanitaria en general

\section{Sistema Nacional de} Salud en su conjunto, los servicios de dermatología, los clínicos de atención primaria, el personal de enfermería (atención primaria y hospitalaria), la farmacia hospitalaria, psicología, los servicios de nutrición y el paciente con psoriasis

Sistema Nacional de Salud en su conjunto, en atención especializada los servicios de cardiología, medicina interna, urgencias, los clínicos de atención primaria, enfermería gestora de casos, y en atención primaria medicina y enfermería, psicología, trabajo social y el paciente con psoriasis y sus cuidadores informales 


\section{STAKEHOLDERS \\ INCLUIDOS EN \\ EL ANÁLISIS}

Pacientes, organización sanitaria
Pacientes, diferenciando niveles de gravedad
Pacientes,

diferenciando

cuatro niveles

de asistencia:

urgencias y

hospitalización,

atención

primaria,

cardiología y

medicina interna

\section{DESCRIPCIÓN DE LA MUESTRA}

No hay muestra

Pacientes (muestra
de conveniencia
de 1053 pacientes,
por internet, con
la colaboración de
Acción Psoriasis,
asociación de
pacientes) y expertos
(a través de los
comité científico,
comité de expertos
y colaboradores). A
los pacientes se les
pidió su disposición
a pagar

\section{Pacientes y sus}

cuidadores infor-

males principales

(muestra de tamaño

558), con la colabo-

ración de Cardioal-

ianza

\section{Revisión de la}

literatura; fuentes

secundarias

públicas oficiales,

encuesta a

pacientes, y

panel de expertos

multidisciplinar

(dermatología,

medicina de

atención primaria,

enfermería,

farmacia

hospitalaria y

asociación de

pacientes)

\section{Revisión de la}

literatura; Fuentes

secundarias

públicas oficiales,

encuesta a 558

pacientes con

insuficiencia

cardiaca y sus

cuidadores, y

panel de expertos

multidisciplinar

(cardiología,

medicina interna,

atención primaria,

enfermería y

asociación de

pacientes)

\section{HORIZONTE TEMPORAL}

5 años

\section{1 año}

Sí. Se valoran

cambios en la

disposición a

pagar de los

pacientes y en

los plazos de

amortización de

las inversiones de

la implantación de

teledermatología

y los equipos de

fototerapia

Sí. Se valoran

cambios en

las asunciones

incluidas en el

modelo (ante la

falta de datos

oficiales): por

ejemplo, porcen-

taje de reducción

de la discapaci-

dad gracias al

diagnótico precoz

o disminución

de las horas de

cuidado informal

gracias al freno de

la progresión

\section{TASA DE \\ DESCUENTO}

$3,50 \%$

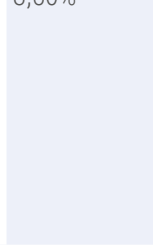

No

No

\section{RATIO SROI \\ OBTENIDA}

32,55 euros

FUENTE

Literatura gris

Globalmente, Literatura

5,04 euros por gris

euro invertido.

La ratio oscila

entre 1,95

euros para

psoriasis

moderada y

15,81 euros

para psoriasis

leve

Globalmente, Literatura

3,52 euros por gris

euro invertido.

Por áreas,

las urgencias

y hospital-

ización

multiplican

por 2,5 esa

ratio

( 9,05 euros) 
$\mathrm{N}^{\circ}$

PUBLICACIÓN

AUTOR AÑO

Merino

2018

et al. [15]

14

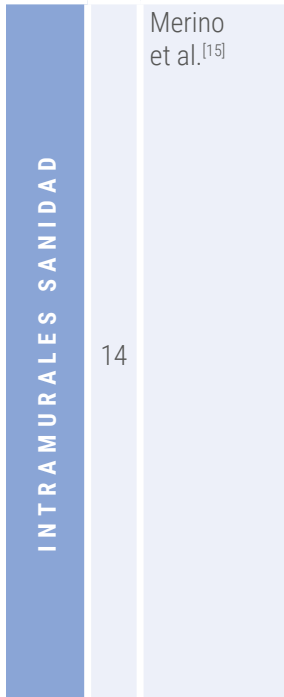

TIPO

ENCARGADO
POR

SROI

POR

PAís

Roche Farma

España

PR

España

\section{ÁREA DE SALUd}

Esclerosis

múltiple

\section{INTERVENCIÓN}

Tratamiento "ideal" de la esclerosis

múltiple, que consta

de 18 propuestas

divididas en tres

áreas (diagnóstico,

esclerosis múltiple

remitente-recidivante

y esclerosis múltiple

en sus formas

progresivas)

\section{STAKEHOLDERS}

CONSIDERADOS

Amplia lista de stakeholders del

Sistema Nacional de Salud por servicios y profesiones (atención especializa y atención primaria, gestores, farmacia hospitalaria) y los pacientes y sus cuidadores informales 


\section{STAKEHOLDERS \\ INCLUIDOS EN \\ EL ANÁLISIS}

Pacientes, diferenciando entre tipología de enfermedad

\section{DESCRIPCIÓN DE \\ LA MUESTRA}

Encuesta a pacientes Revisión de la para determinar la disposición a pagar. Se usa la mediana y no la media para las estimaciones. No se menciona el tamaño de la muestra ni el método de muestreo (que se reporta en un informe de resultados de la encuesta) con esclerosis

\section{FUENTES DE DATOS}

literatura; fuentes secundarias públicas oficiales, encuesta a 532 pacientes múltiple, paneles de expertos multidisciplinares (neurología, farmacia hospitalaria, enfermería hospitalaria, fisioterapia, medicina de atención primaria, trabajo social y asociación de pacientes)

,

\section{HORIZONTE TEMPORAL}

1 año

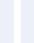

amortización de
los ecógrafos atención primaria urgencias) y del equipamiento en las Unidades de portátiles (en y servicios de Rehabilitación Cardiaca

Sí. Se valoran cambios en los plazos de

\section{TASA DE DESCUENTO OBTENIDA}

No

Globalmente, Literatura 1,83 euros por gris euro invertido. Análisis de sensibilidad: entre 1,59 euros y 2,15 euros 


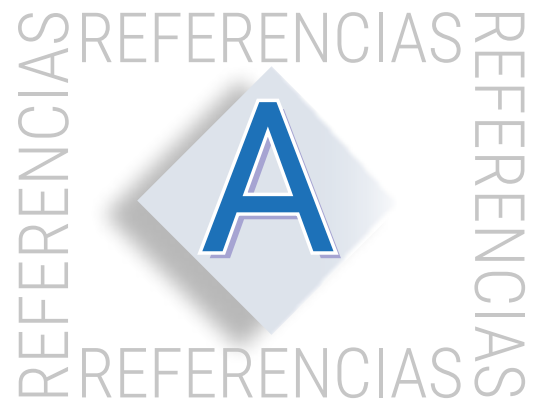

1. Goodspeed T, Point Wakefield staff. Value of Substance. A Social Return on Investment evaluation of Turning Point's Substance Misuse Services in Wakefield. Wakefield: Turning Point; 2014 jul p. 37. Disponible en: http://www.socialvalueuk.org/app/uploads/2016/03/Value\%20of\%20Substance\%20FINAL.pdf

2. Davies L, Taylor P, Ramchandani G, Christy E. Social Return on Investment in Sport: a participation wide model for England. Sheffield Hallam University \& Sport Industry Research Centre; 2016 abr p. 15. Disponible en: https://www4.shu.ac.uk/_assets/pdf/research/sirc/Final-SIRC-SROI-EnglandWeb-report.pdf

3. Bagnall A-M, Raine G, Kinsella K, Southby K, Spoor C, South J, et al. Meausring well-being outcomes in older people receiveing help from the age UK «Together for Health» initiative: a Social Return on Investment Analysis. The Centre for Health Promotion Research, Institute for Health and Wellbeing: Leeds: Leeds Beckett University; 2016 p. 64. Report No.: Final Report. Disponible en: http://eprints. leedsbeckett.ac.uk/2887/1/FINAL\%20TFH\%20FULL\%20REPORTJULY\%202016.pdf

4. Goudet S, Griffiths PL, Wainaina CW, Macharia TN, Wekesah FM, Wanjohi M, et al. Social value of a nutritional counselling and support program for breastfeeding in urban poor settings, Nairobi. BMC Public Health. 4 de febrero de 2018;18(1):424.

5. Harrison R, Cochrane M, Pendlebury M, Noonan R, Eckley L, Sumnall H, et al. Evaluation of Four Recovery Communities across England: Final report for the Give it Up project. Liverpool: Liverpool John Moores University; 2017.

6. Wodinski L, Wanke MI. Impact evaluation of the H.E.R. Pregnancy Program - Photovoice Final Report Prepared by Charis Management Consulting Inc. (Charis). Alberta: Alberta Centre for Child, Family \& Community Research (ACCFCR); 2013 p. 43. Report No.: Final Report. Disponible en: https://policywise.com/wp-content/uploads/resources/2016/07/HERFINALReportFebruary282014pdf.pdf

7. McMurchy D. Co-created, Co-delivered, co-lived: Toward Better Health and Care for Inner-City Populations. A Canadian Casebook. Ottawa: Canadian Foundation for Healthcare Improvement.; 2018 mar p. 92. Disponible en: https://www.cfhi-fcass.ca/ PublicationsAndResources/ResearchReports/ArticleView/2018/06/27/co-created-codelivered-co-lived-toward-better-health-and-care-for-inner-city-populations

8. Baker C, Courtney P, Kubinakova K, Ellis L, Loughren E, Crone D. Gloucestershire Active Together Evaluation [Internet]. Cheltenham: University of Gloucestershire, School of Health and Social Care; 2017 p. 51. Report No.: Final Report. Disponible en: http://eprints.glos.ac.uk/4321/

9. Willis E, Semple AC, de Waal H. Quantifying the benefits of peer support for people with dementia: A Social Return on Investment (SROI) study. Dementia (London). abril de 2018;17(3):266-78. 
10. Jones M, Pitt H, Oxford L, Orme J, Gray S, Salmon D, et al. Food for Life: a Social Return on Investment Analysis of the Locally Commissioned Programme. Full Report. Bristol: UWE Bristol; 2016. Disponible en: http://eprints.uwe.ac.uk/31897/1/12_Jones_et_al_\%282016\%29_Food_for_Life_ LCs_SROI_Full\%20Report_v05.pdf

11. Jones C, Windle G, Edwards RT. Dementia and Imagination: A Social Return on Investment Analysis Framework for Art Activities for People Living With Dementia. Gerontologist. 23 de noviembre de 2018; Disponible en: https://academic.oup.com/gerontologist/advance-article/doi/10.1093/geront/gny $147 / 5203293$

12. Durán Piñeiro G, Sánchez Carreira M del C, Peña Gil C, Paredes Galán E, Gómez Ruíz R, Lado Sestayo $\mathrm{R}$, et al. El retorno económico y social de la e-interconsulta de cardiología en el área de Vigo. ICEDE Working Paper Series. abril de 2015;11:1-28.

13. González A, Ivanova Y, Jiménez M, Merino M, Hidalgo Á, Alfonso S, et al. Retorno Social de la Inversión de un abordaje ideal de la psoriasis. Majadahonda, Madrid: Instituto Max Weber; 2016. Disponible en: http://weber.org.es/publicacion/informe-el-valor-social-de-un-abordaje-ideal-de-lapsoriasis-sroi-psoriasis/

14. Merino M, Jiménez M, Ivanova Y, González A, Villoro R, Hidalgo Á, et al. Valor social de un abordaje ideal en insuficiencia cardiaca. Madrid: Instituto Max Weber; 2017. Disponible en: http://weber.org. es/publicacion/informe-proyecto-sroi-insuficiencia-cardiaca/

15. Merino M, Jiménez M, Gómez-García T, Ivanova Y, Hidalgo-Vega Á, Moral Torres E, et al. Proyecto SROI-EM. Impacto clínico, asistencial, económico y social del abordaje ideal de la esclerosis múltiple en comparación con el abordaje actual. Madrid: Fundación Weber; 2018. Disponible en: http:// weber.org.es/publicacion/sroiem_impacto_clinico_asistencial_economico_social_escleroris_multiple/ 


\section{AUTORES}




\section{María Merino}

Directora del Área de Resultados en Salud. Weber.

Licenciada en Sociología. Experta en estadística, análisis de datos y gestión de datos aplicados a las Ciencias de la Salud. Máster en Evaluación de Intervenciones Sanitarias. Responsable del Área de Investigación de Resultados en Salud de Weber, llevando a cabo proyectos de retorno social de la inversión (SROI), carga de la enfermedad, coste-efectividad, coste-utilidad... Su experiencia laboral previa está vinculada a la consultoría de investigación socioeconómica.

\section{Yoana Ivanova}

Consultora Senior del Área de Farmacoeconomía y Acceso al Mercado. Weber.

Licenciada en Administración y Dirección de Empresas. Máster en Evaluación de Intervenciones Sanitarias y Máster en Investigación Sociosanitaria. Experta en modelos de impacto presupuestario. Como consultora lleva a cabo proyectos de retorno social de la inversión (SROI), impacto presupuestario, coste-efectividad y calculadoras de costes, entre otros.

\section{Álvaro Hidalgo \\ Profesor Titular de Fundamentos del Análisis Económico. Universidad Castilla-La Mancha. \\ Presidente. Fundación Weber.}

Doctor en Ciencias Económicas y Empresariales por la Universidad de Castilla-La Mancha (UCLM). Profesor de Teoría Económica en la UCLM, director del Grupo de Investigación de Economía de la Salud y Gestión Sanitaria (GIES) de la UCLM y presidente de la Fundación Weber. Sus principales líneas de investigación son la economía de la salud, la evaluación de tecnologías sanitarias, la economía del medicamento, los sistemas de información sanitaria y los estudios de discriminación por género. Ha publicado numerosos artículos y libros sobre economía de la salud y farmacoeconomía.

\section{Yolanda Rueda}

Socia-Directora. Nephila Health Partnership.

Secretaria de la Junta Directiva de la Asociación ESIMPACT.

Diplomada en Estadística. Licenciada en Investigación de Mercados. Máster en e-business. Desde hace más de 20 años trabaja en el sector de la salud desarrollando y gestionando iniciativas de valor añadido para la mejora de la calidad de vida de las personas con enfermedad crónica. Cuenta con más de 10 años de experiencia en la aplicación de metodologías cualitativas y cuantitativas para la gestión y medición de impacto social. 


\section{Marta Trapero-Bertran}

Profesora Titular de la Universitat Internacional de Catalunya e investigadora del Instituto de Investigación en Evaluación y Políticas Públicas (IRAPP).

Sus principales líneas de investigación son las técnicas de modelización, la evaluación económica en el contexto de tecnologías y programas de salud pública en los países de rentas bajas y altas, la transmisión del comportamiento y estilos de vida saludables, y la incorporación de efectos externos en la evaluación económica. Una de sus áreas de especialización es la Economía de Programas de Salud Pública. Tiene más de 30 artículos publicados en revistas académicas nacionales e internacionales con alto Factor de Impacto y también libros. Ha participando en proyectos europeos H2020 y en proyectos nacionales competitivos y no competitivos. Fue presidenta de la Asociación de Economía de la Salud (AES) y miembro fundador de la Asociación Europea de Economía de la Salud (EuHEA). Es miembro de la Comisión del CFT-SISCAT del CatSalut y del Comité Asesor para la Financiación de la Prestación Farmacéutica del Ministerio de Sanidad, Consumo y Bienestar Social, dando su visión técnica desde el punto de vista de la eficiencia.

\section{José María Abellán}

Profesor Titular de Economía Aplicada. Universidad de Murcia.

Tesorero y presidente de la Asociación de Economía de la Salud (AES) entre 2011 y 2017 y uno de los Coordinadores del Grupo de Interés en Evaluación Económica de la misma asociación. Vicerrector de Economía, Infraestructuras y Ciencias de la Salud de la Universidad de Murcia entre 2014 y 2017. Experto asesor del Comité Regional de Evaluación de Tecnologías Sanitarias de la Región de Murcia desde 2012 y miembro del Instituto Murciano de Investigación Biomédica (acreditado por el Instituto Carlos III) desde 2015.

\section{Jaime Espín}

Profesor. Escuela Andaluza de Salud Pública.

Licenciado en Derecho y Doctor en Economía. Actualmente trabaja como Profesor en la Escuela Andaluza de Salud Pública (EASP). Ha sido profesor visitante en universidades de prestigio como London School of Economics, Chicago, Columbia o Harvard. En la EASP realiza actividades docentes centradas en la evaluación económica de medicamentos y tecnologías sanitarias, y coordina proyectos de investigación y consultoría en materias como economía de la salud, evaluación económica y políticas farmacéuticas. Es autor de varias publicaciones en esas materias. Asimismo, es experto en política farmacéutica y ha sido asesor externo independiente de la Comisión Europea, de la Organización Mundial de la Salud y del Banco Mundial en este ámbito. 


\section{Beatriz González López-Valcarcel}

Catedrática de Métodos Cuantitativos en Economía y Gestión.

Universidad de Las Palmas de Gran Canaria.

Doctora en Economía. Profesora de posgrado y doctorado en decenas de universidades españolas y extranjeras. Investigación en Economía de la Salud. Presidenta de la Asociación de Economía de la Salud (2004-2006), de la sección de Public Health Economics de la Asociación Europea de Salud Pública, EUPHA (2011-2012) y de SESPAS (2015-2017). Consultora internacional en México, Brasil, Argentina, Chile, Uruguay, Costa Rica, Panamá y Mozambique. Condecorada con la Cruz de la Orden del Mérito Civil de Sanidad (Ministerio de Sanidad, Servicios Sociales e Igualdad). Hija adoptiva de la Ciudad de Las Palmas y de la isla de Gran Canaria.

\section{Cristina Ibarrola}

Jefa del Servicio de Efectividad y Seguridad Asistencial.

Servicio Navarro de Salud- Osasunbidea.

Licenciada en Medicina y Cirugía. Especialista en Medicina Familiar y Comunitaria. Master Universitario en Gestión y Planificación Sanitaria para Directivos de la Salud por la Universidad Europea de Madrid. Programa de Alta Dirección en Instituciones Sanitarias IESE. Diploma Postgrado en Evaluación de Tecnologías Sanitarias por la Universidad Pompeu Fabra. Experto en Investigación en Servicios de Salud y Enfermedades Crónicas por la Universidad de Alcalá. Ha sido Directora General de Salud del Gobierno de Navarra, Directora de Atención Primaria y Directora Gerente del Servicio Navarro de Salud-Osasunbidea.

\section{Santiago Alfonso}

Director. Acción Psoriasis.

Actualmente es vicepresidente del Foro Español de Pacientes. También es vicepresidente de UNIMID (asociación de personas con enfermedades crónicas inflamatorias inmunomediadas), y miembro del Comité de Ética de la Investigación de Medicamentos del Hospital Universitario "Parc Taulil". Desde 2007 dirige la asociación Acción Psoriasis.

\section{Maite San Saturnino}

Presidenta. Cardioalianza.

Es presidenta de la Asociación Corazón sin Fronteras, presidenta de la Asociación de CroniSport (club deportivo para enfermos crónicos), y vocal de la Junta Directiva de la Plataforma de Organizaciones de Pacientes. 
Con el patrocinio de:

U NOVARTIS 